\title{
Um Método de Tractografia Global \\ Utilizando Imagens de Ressonância Magnética Ponderadas por Difusão
}

Rafael Reggiani Manzo

\author{
DisSERTAÇÃO APRESENTADA \\ $\mathrm{AO}$ \\ Instituto DE MATEMÁticA E EstatísticA \\ DA \\ Universidade DE SÃo Paulo \\ PARA \\ OBTENÇÃO DO TÍTULO \\ $\mathrm{DE}$ \\ Mestre em CiÊnCIAS
}

Programa: Mestrado em Ciência da Computação

Orientador: Prof. Dr. Marcel Parolin Jackowski 


\section{Um Método de Tractografia Global Utilizando Imagens de Ressonância Magnética Ponderadas por Difusão}

Esta versão da dissertação contém as correções e alterações sugeridas pela Comissão Julgadora durante a defesa da versão original do trabalho, realizada em 13/03/2017. Uma cópia da versão original está disponível no

Instituto de Matemática e Estatística da Universidade de São Paulo.

Comissão Julgadora:

- Prof. Dr. Marcel Parolin Jackowski (orientador) - IME-USP

- Prof. Dr. João Ricardo Sato - CCMC-UFABC

- Prof. Dr. Marcelo Finger - IME-USP 


\section{Resumo}

MANZO, R. R. Um Método de Tractografia Global Usando Imagens de Ressonância Magnética Ponderadas por Difusão. 2017. Dissertação (Mestrado) - Instituto de Matemática e Estatística, Universidade de São Paulo, São Paulo, 2017.

As imagens de ressonância magnética ponderadas por difusão retratam a difusividade de moléculas de água presentes em tecidos biológicos. Em estruturas biológicas altamente organizadas e compactas como fibras nervosas e musculares, a difusividade é maior na direção paralela às fibras do que perpendicularmente às mesmas. Essa propriedade permite a reconstrução digital das trajetórias das fibras, técnica denominada tractografia, representando uma das poucas formas não invasivas de investigação da conectividade anatômica e organização estrutural do cérebro e do coração. A metodologia de tractografia mais difundida faz uso da integração numérica da direção principal de difusividade para reconstruir essas trajetórias. Porém, esta técnica apresenta problemas como o erro intrínseco a métodos de integração numérica e o erro associado a regiões de incerteza nos dados de difusividade. Uma metodologia considerada mais robusta consiste da modelagem da tractografia como a simulação de um sistema de partículas. No entanto, tal metodologia possui diversos parâmetros que precisam ser otimizados para cada caso e apresenta alta complexidade computacional. Esta dissertação apresenta uma metodologia de tractografia global baseada em sistema de partículas, mas com custo computacional reduzido pois evita passos desnecessários da otimização para reconstrução das trajetórias. Avaliamos sua acurácia em conjuntos de dados com graus de complexidade crescentes utilizando imagens sintéticas de difusão construídas digitalmente e em imagens reais de difusão do miocárdio humano. Nesses testes foram observadas reduções no consumo de tempo e maior acurácia para metodologia global apresentada com relação às descritas na literatura. Essa metodologia possui o potencial de evidenciar a organização e arquitetura de diversos tecidos do corpo humano com maior fidelidade e menor tempo de reconstrução.

Palavras-chave: imagens de ressonância magnética ponderadas por difusão, tractografia, simulação de partículas. 


\section{Abstract}

\section{MANZO, R. R. A Global Tractography Method Using Diffusion Magnetic Resonance}

Imaging. 2017. Dissertação (Mestrado) - Instituto de Matemática e Estatística, Universidade de São Paulo, São Paulo, 2017.

The diffusion magnetic resonance imaging portray the diffusivity of water molecules present on biological tissues. High organized and compact biological structures like neuronal fibres and muscles present higher diffusivity parallel to the fibres than perpendicular to those. This property allows the digital reconstruction of fibres trajectories, technique named tractography, being one of the few non invasive ways of investigation of the anatomical connectivity and structural organization of the brain and heart. The most common tractography methodology uses numerical integration following the main diffusion direction in order to reconstruct trajectories. Yet, this technique is prone to intrinsic error to numeric integration and the error associated to uncertainty regions on diffusion data. A methodology considered more robust to such problems consists on modelling tractography as a particle system simulation. However, such methodology has several parameters that require fine tuning for each case and has a high computational complexity. This dissertation presents a global tractography methodology based on particle system but at lower computational cost because of the avoidance of unnecessary optimization steps on trajectory reconstruction. We evaluate its accuracy on synthetic diffusion datasets of increasing complexity and on real human cardiac diffusion images. Theses tests evidence reduced time consumption and increased accuracy for the presented methodology compared to the ones described in the literature. This methodology has the potential to reveal the organization and architecture of several tissues from the human body with higher fidelity and lower reconstruction time.

Keywords: diffusion magnetic resonance images, tractography, particle simulation. 


\section{Sumário}

1 Preâmbulo 1

2 Introdução $\quad 3$

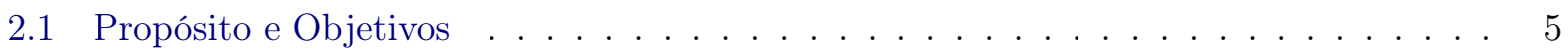

3 Materiais e Métodos $\quad 7$

3.1 Revisão Bibliográfica . . . . . . . . . . . . . . . . . . . . . . 7

3.2 Principais Referências . . . . . . . . . . . . . . . . . . 8

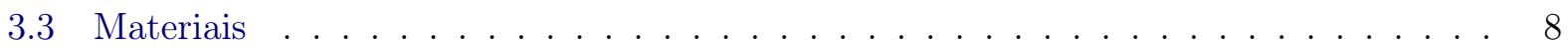

3.3.1 Construção dos Dados Sintéticos . . . . . . . . . . . . . . . . 8

3.3 .2 Dados Cardíacos . . . . . . . . . . . . . . . . . . . 11

3.3.3 Recursos Computacionais . . . . . . . . . . . . . . . . . . . . 12

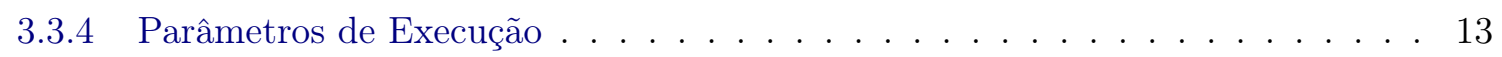

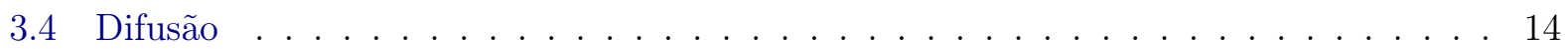

3.5 Ressonância Magnética Ponderada por Difusão . . . . . . . . . . . . . . . . . . 14

3.5.1 Codificação da Difusão por Ressonância Magnética . . . . . . . . . . . . . . . . 14

3.5 .2 Aplicação . . . . . . . . . . . . . . . . . . . . . 15

3.6 Tensor de Difusão . . . . . . . . . . . . . . . . . . . . . . . . . . . . . 16

3.6 .1 Difusividade Média . . . . . . . . . . . . . . . . . 16

3.6 .2 Anisotropia Fracionária . . . . . . . . . . . . . . . . . . 16

3.6 .3 Visualização . . . . . . . . . . . . . . . . . . . . . . . . . . . . . . . . . . . 17

3.7 Efeito de Volume Parcial no Tensor de Difusão . . . . . . . . . . . . . . . . . . . . 18

3.8 Transformada de Funk-Radon em dMRI . . . . . . . . . . . . . . . . . . . . . 19

3.9 Tractografia . . . . . . . . . . . . . . . . . . . . . . 20

3.9 .1 Propagação de Linha . . . . . . . . . . . . . . . . . . . . . . 21

3.9 .2 Global . . . . . . . . . . . . . . . . . . . . . . 21

3.9 .3 Probabilística . . . . . . . . . . . . . . . . . . . 22

3.9 .4 Conceitos Base . . . . . . . . . . . . . . . . . . . . 23

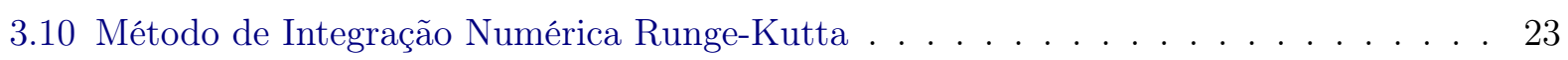

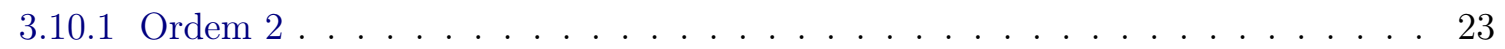

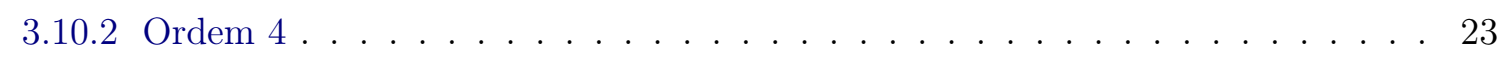

3.11 Métodos de Monte Carlo Utilizando Cadeias de Markov . . . . . . . . . . . . . . . 23

3.11 .1 Cadeias de Markov . . . . . . . . . . . . . . . . . . . 24

3.11 .2 Amostragem de Metropolis . . . . . . . . . . . . . . . . . . 24

3.11 .3 Arrefecimento Simulado . . . . . . . . . . . . . . . . . . 25 
3.11.4 Amostragem de Gibbs . . . . . . . . . . . . . . . . . . . . 25

3.12 Tractografia Global por Simulação de Partículas . . . . . . . . . . . . . . . . . . 25

3.13 Jarros de Spin . . . . . . . . . . . . . . . . . . . . . 26

3.14 Processo de Polimerização e Física Estatística . . . . . . . . . . . . . . . . 27

3.14 .1 Descrição Teórica . . . . . . . . . . . . . . . . . . . . . . 27

3.14 .2 Algoritmo Básico . . . . . . . . . . . . . . . . . . . . 31

3.15 Método de Tractografia Global por Simulação de Partículas em Grade com Autocorreção . . . . . . . . . . . . . . . . . . . . . 34

3.15 .1 Algoritmo Geral . . . . . . . . . . . . . . . . . . . 35

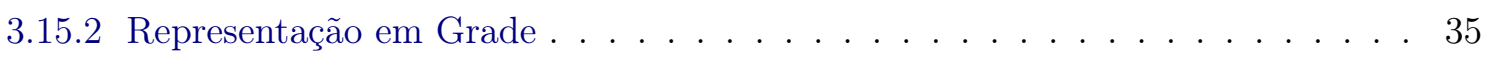

3.15 .3 Inicialização das Partículas . . . . . . . . . . . . . . . . 36

3.15 .4 Conexões e Movimentações . . . . . . . . . . . . . . . . . . . . . . . . . . . . . . . 36

3.15 .5 Histórico de Conexões . . . . . . . . . . . . . . . . . . . . . . . . . 37

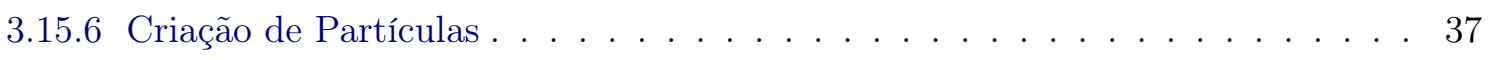

3.15 .7 Formatação de Saída . . . . . . . . . . . . . . . . . . . . . 37

3.16 Análise de Consumo de Recursos . . . . . . . . . . . . . . . . . . . 38

3.16 .1 Método de Integração Numérica Runge-Kutta . . . . . . . . . . . . . . . 38

3.16 .2 Método Global por Polimerização . . . . . . . . . . . . . . . . . . . . 39

3.16 .3 Método SAGA . . . . . . . . . . . . . . . . . . . . . . . 41

3.17 Implementação . . . . . . . . . . . . . . . . . . . . . . . 4 42

3.17.1 Parâmetros de Entrada e Constantes Adotadas . . . . . . . . . . . . . . . . . 42

3.17 .2 Tecnologias . . . . . . . . . . . . . . . . . . . . . 43

3.17 .3 Qualidade do Código . . . . . . . . . . . . . . . . . . 43

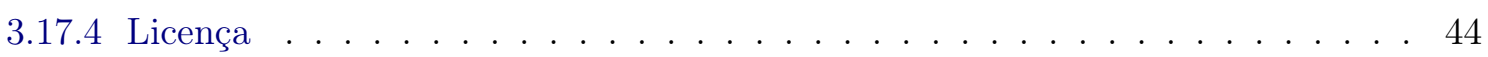

3.18 Validação . . . . . . . . . . . . . . . . . . . . . . . . 44

4 Resultados $\quad 47$

4.1 Dados Sintéticos . . . . . . . . . . . . . . . . . . . . . . . . . . . . . . . . . . . . .

4.2 Dados Cardíacos . . . . . . . . . . . . . . . . . . 52

5 Discussão $\quad \mathbf{5 5}$

5.1 Dados Sintéticos . . . . . . . . . . . . . . . . . . . 55

5.2 Dados Cardíacos . . . . . . . . . . . . . . . . . . . . 55

6 Conclusões $\quad 57$

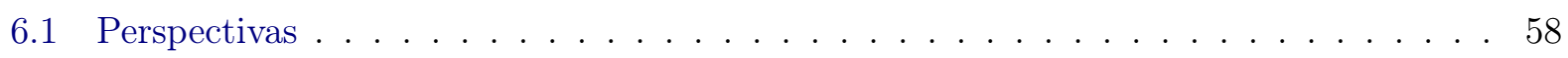

$\begin{array}{ll}\text { Referências Bibliográficas } & 61\end{array}$ 


\section{Capítulo 1}

\section{Preâmbulo}

Informações sobre a arquitetura dos tecidos humanos são vitais para a compreensão da conectividade de fibras nervosas e musculares. A neurociência, em particular, busca esclarecer detalhes desconhecidos sobre o funcionamento do cérebro humano utilizando informações da conectividade entre a substância branca e regiões de substância cinzenta cerebrais [CJ93]. Além de auxiliar na compreensão do funcionamento normal do cérebro, esse tipo de informação é importante para o estudo de várias doenças, incluindo o mal de Alzheimer [FSS $\left.{ }^{+} 97\right]$ e a Esclerose Múltipla, além de ser útil no planejamento cirúrgico.

Os primeiros estudos sobre a conectividade cerebral foram realizados por meio da injeção de contraste em cérebros de animais sobre os quais imagens estruturais de ressonância magnética eram coletadas. Porém, esse tipo de técnica não é considerada ética para aplicação em humanos e a propagação de contraste no cérebro após a morte acontece apenas até um raio de $5 \mathrm{~mm}\left[\mathrm{KAB}^{+} 00\right]$. Como alternativa não invasiva para o uso de voluntários humanos em pesquisa, foi mostrado que há correlação entre a organização estrutural de feixes de fibras axonais que compõem a substância branca cerebral e o processo de difusão das moléculas de água presentes nos tecidos. Com isso foi possível reconstruir parte da anatomia utilizando imagens de ressonância magnética ponderadas por difusão [BML94], técnica essa denominada tractografia, tema desta dissertação.

Outra aplicação de igual importância para as técnicas de ressonância magnética ponderada por difusão e tractografia é o estudo do coração humano. O bom funcionamento desse órgão depende da saúde de suas células que se interconectam formando fibras que são responsáveis pelas contrações e relaxamentos sincronizados do coração. Porém, quando afetadas por patologias como infarto $\left[\mathrm{MHD}^{+} 11\right]$, uma das consequências é a degeneração do tecido miocárdico e finalmente a interrupção dessas ligações $\left[\mathrm{GMM}^{+} 01\right]$, observáveis pela uso da tractografia $\left[\mathrm{MJS}^{+} 15\right]$. 


\section{Capítulo 2}

\section{Introdução}

Imagens de ressonância magnética ponderadas por difusão (dMRI) fornecem a informação sobre a preferencialidade na direção das moléculas de água durante o processo de difusão. No caso de tecidos altamente organizados, como tecidos fibrosos e musculares, a maior difusividade se dá na direção paralela às fibras, propriedade essa denominada anisotropia (Fig. 2.1b).

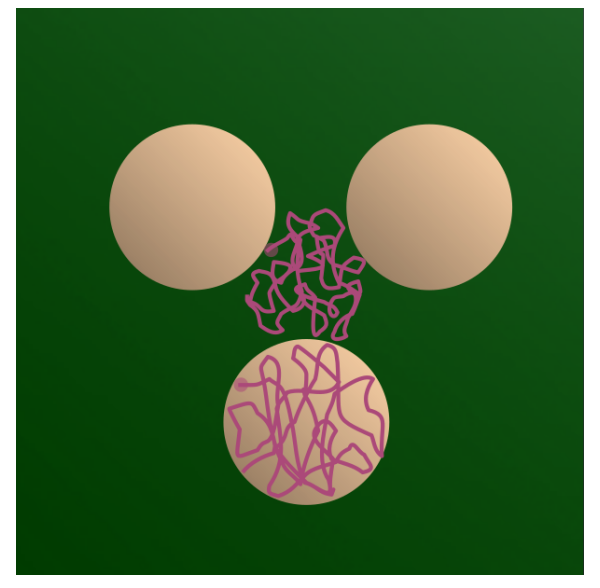

(a)

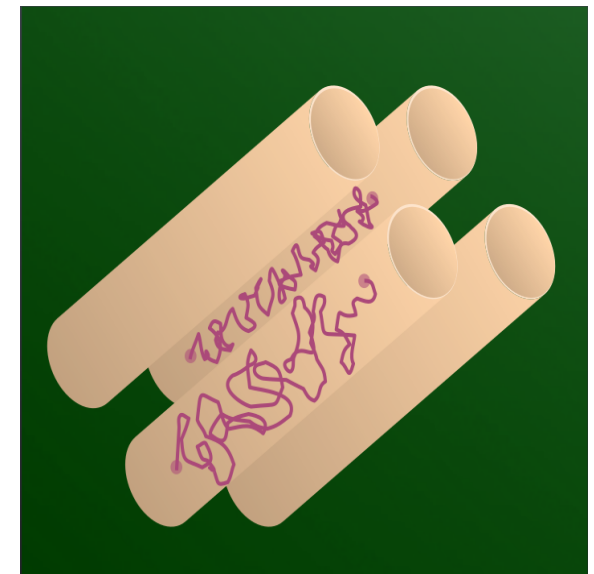

(b)

Figura 2.1: Exemplos do trajeto das moléculas de água durante os diferentes processos de difusão. (a) Na ausência de organização, a difusão é dita isotrópica, e a probabilidade da difusão é igual em todas as direções. (b) Na presença de estruturas altamente organizadas, a difusão é dita anisotrópica, pois possui uma direção predominante de difusividade.

Consequentemente, através da informação sobre o processo de difusão, é possível reconstruir a arquitetura e organização de tecidos biológicos. Uma forma de modelar esse processo é através do tensor de difusão[BML94], uma representação tensorial que codifica as três direções principais de difusividade e suas respectivas magnitudes. Porém, tais imagens estão sujeitas a diversos artefatos decorrentes do processo de aquisição que tornam a reconstrução da organização e arquitetura dos tecidos biológicos uma tarefa que é alvo de muitos estudos científicos. Esta reconstrução digital baseada em dMRI é denominada tractografia.

A técnica de tractografia mais difundida consiste de seguir as direções principais dos tensores de difusão empregando métodos de integração numérica (seção 3.10), com resultados exemplificados pela Fig. 2.2. Esses tensores assumem que o processo de difusão segue uma distribuição Gaussiana. As vantagens na aplicação desse técnica são a relativa simplicidade, resultados de natureza determinística e rapidez de computação. Seu uso permitiu estudos inéditos da conectividade anatômica do cérebro $\left[\mathrm{JKQ}^{+} 05\right]$ e sobre a organização das fibras do miocárdio [MJS $\left.{ }^{+} 15\right]$. Entretanto, mesmo sendo uma técnica com pontos positivos, essa ainda não é robusta o bastante para superar regiões de incerteza nos dados, como por exemplo em regiões contendo cruzamento de fibras. Isso se deve ao fato de nestas regiões, em uma resolução de aquisição de imagem viável, a difusão não segue a 
distribuição Gaussiana assumida pela modelagem tensorial do processo de difusão. Assim, seu uso na prática clínica ainda é limitado.

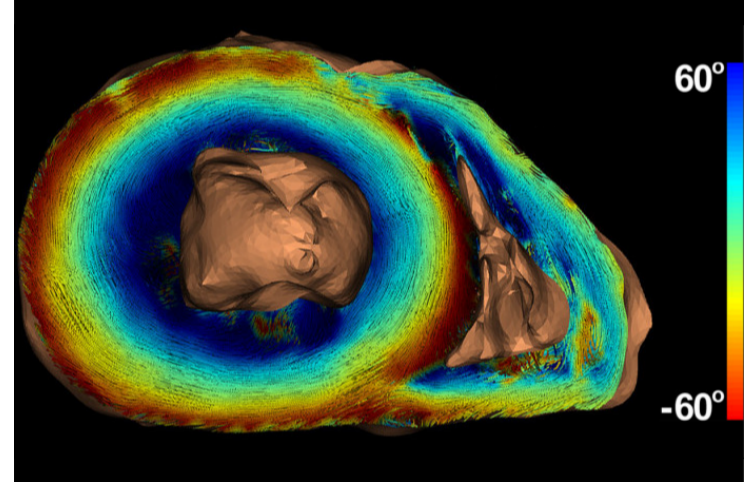

(a)

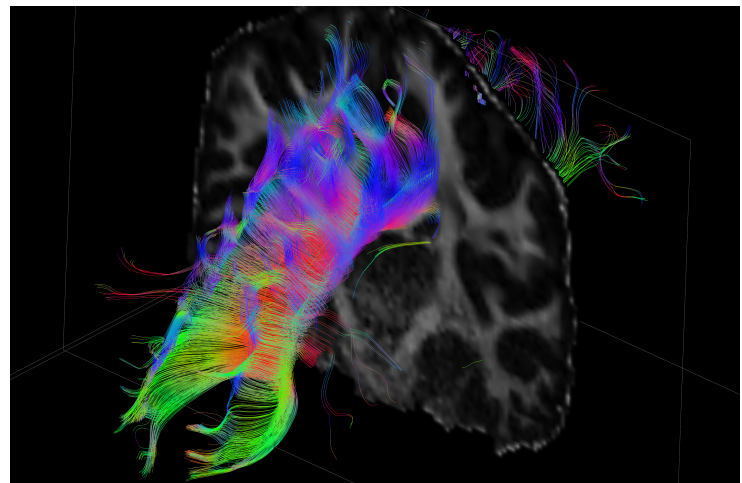

(b)

Figura 2.2: Resultados da tractografia por propagação de linha pela direção principal do tensor de difusão. Em (a) fatia do coração humano cujas fibras são coloridas de acordo com o ângulo helicoidal (extraída de [MHC $\left.\left.{ }^{+} 12\right]\right)$. Em (b) corpus callosum do cérebro humano visualizado em ângulo com coloração de acordo com a direcionalidade.

Como aumentar a resolução é inviável na prática clínica devido aos aumentos do ruído de aquisição e do tempo necessário para adquirir a imagem, outros modelos foram propostos para substituir o tensor de difusão. Esses consistem de métodos probabilísticos onde, ao invés do tensor, a cada voxel (unidade básica de uma imagem tridimensional) é associada uma distribuição de probabilidades sobre as direções de difusão. Assim, os picos de maior probabilidade podem ser tomados como as direções principais para o traçado conseguindo assim expressar melhor os já mencionados cruzamentos.

Da mesma forma, como evolução à integração numérica, que é classificada como uma metodologia local, foram propostos métodos globais de reconstrução que buscam utilizar todos os voxels da imagem a cada passo e adicionam suposições anatômicas de forma que a metodologia se torne capaz de reconstruir regiões de incerteza. Porém ambas as melhorias de modelagem e método acarretam em maior consumo de tempo que acaba inviabilizando seu uso na rotina clínica. É importante esclarecer que esses não resolvem completamente os problemas de incerteza na reconstrução, mas são uma ferramenta adicional para ser utilizada em conjunto com as demais. Na literatura, os métodos globais demonstram serem capazes de reconstruir estruturas conhecidas da anatomia por meio de outros métodos, como dissecação após a morte, mas que outras metodologias de tractografia mais utilizadas não eram capazes de realizar. Para tornar os métodos globais viáveis para utilização na rotina clínica e pesquisa neurocientífica permitindo que seu potencial seja explorado, e assim expandir o uso da tractografia, são necessários métodos que mantenham tal robustez porém ao custo computacional reduzido.

$\mathrm{O}$ método proposto por $\left[\mathrm{RMA}^{+} 11\right]$ realiza a reconstrução global através da modelagem do problema da tractografia como a simulação de um sistema de partículas que é otimizado utilizando Metropolis-Hastings (um método de Monte Carlo baseado em cadeias de Markov). Tal metodologia foi capaz de superar diversas regiões de incerteza em comparação com mais outros nove métodos $\left[\mathrm{FDG}^{+} 11\right]$. Porém, com custo computacional ainda muito alto, tomando de 12 a 24 horas para reconstrução da arquitetura do cérebro humano, esse método ainda não é utilizado na prática clínica apesar de possibilitar a reconstrução de regiões onde a tractografia utilizando o modelo tensorial e integração numérica são ineficientes. Em comparação à integração numérica usando o tensor de difusão, os métodos globais são de natureza probabilística fazendo da estabilidade entre execuções outro problema a ser considerado. Outro método global de simulação de partículas é o proposto por $\left[\mathrm{MPC}^{+} 02\right]$ que é explorado junto do primeiro em detalhes no capítulo 3 que também descreve o novo método fruto dessa dissertação. 


\section{$2.1 \quad$ Propósito e Objetivos}

Dadas as aplicações possíveis para tractografia, esse trabalho explora as limitações de cada método de tractografia a fim de melhor compreendê-las e embasar o desenvolvimento de alternativas que procuram manter as propriedades dos métodos globais com relação às regiões de incerteza ao mesmo tempo que o consumo de recursos computacionais sejam reduzidos. Ao analisar os principais métodos descritos na literatura, é notável que poucos fornecem as implementações para os métodos e os que as fornecem possuem espaço para otimização dos recursos computacionais necessários. Com isso, é esperado que sejam possíveis estudos mais profundos que empreguem métodos de tractografia global e permitam outros sobre as regiões de incerteza.

Os principais objetivos deste trabalho são:

- Elaboração de uma metodologia de tractografia global com redução do tempo computacional;

- Avaliação do algoritmo da metodologia em dados sintéticos simples que avaliam sua acurácia;

- Aplicação em dados do miocárdio. 


\section{Capítulo 3}

\section{Materiais e Métodos}

\subsection{Revisão Bibliográfica}

A tractografia é uma área com desafios ainda abertos que motivam pesquisas desde o processo de aquisição das imagens de RM até a modelagem final de uma reconstrução das fibras. Isso leva a uma quantidade grande de trabalhos sendo desenvolvidos dentre os quais alguns dos principais e mais relevantes para o contexto dessa dissertação são destacados.

Muitos dos métodos expostos na tabela 3.1 foram avaliados no concurso Fiber Cup [FDG $\left.{ }^{+} 11\right]$ e outros foram selecionados de acordo com sua relevância em buscas sobre o tema e por conferências reconhecidas pela excelência dos trabalhos apresentados nas áreas de computação gráfica (MICCAI) e ressonância magnética (ISMRM - International Society for Magnetic Resonance in Medicine). Essas foram classificadas de acordo com os três critérios destacados anteriormente durante a introdução: modelagem da difusão; localidade; e natureza.

\begin{tabular}{|c|c|c|c|}
\hline Referência & Modelo de difusão & Localidade & Natureza \\
\hline$\left[\mathrm{SKF}^{+} 14\right]$ & $\mathrm{DT}^{1}$ & Global $^{2}$ & Probabilístico \\
\hline [RZA13] & $\mathrm{NODDI}^{3}$ & Local & Probabilístico \\
\hline [SCBP13] & DT \& QBall & Local & Probabilístico \\
\hline$\left[\mathrm{BBJ}^{+} 07\right]$ & Multi-fibre Fit & Local & Probabilístico \\
\hline$\left[\mathrm{CSR}^{+} 05\right]$ & DT \& QBall & Local & Probabilístico \\
\hline$\left[\mathrm{JKQ}^{+} 05\right]$ & $\mathrm{DT}$ & Global & Determinístico \\
\hline [PA03] & $\mathrm{ODF}^{4}$ & Local & Probabilístico \\
\hline [Goh09] & ODF & Local & Determinístico \\
\hline [GSG09] & $\mathrm{DT}$ & Local & Determinístico \\
\hline [JLTS09] & ODF & Local & Determinístico \\
\hline [MSR09] & $\mathrm{DT}^{5}$ & Local & Determinístico \\
\hline [RMRG09] & $\mathrm{DT}^{6}$ & Local & Determinístico \\
\hline [RMK09a] & Mixture of Gaussian & Global & Probabilístico \\
\hline [Sak09] & PAS-MRI & Local & Determinístico \\
\hline [TLB09] & DT & Local & Determinístico \\
\hline [YAK09] & ODF & Global & Determinístico \\
\hline [FPM09] & DT & Global & Probabilístico \\
\hline [KMK08] & DT & Global & Probabilístico \\
\hline [Tuc04] & ODF & Local & Probabilístico \\
\hline [PR11] & ODF & Local & Probabilístico \\
\hline [DDPLT15] & ODF & Global & Determinístico \\
\hline [SRA10] & ODF & Global & Determinístico \& Probabilístico \\
\hline
\end{tabular}

Tabela 3.1: Comparativo entre diversos algoritmos de tractografia existentes 
Após a classificação destas 22 técnicas, é possível notar que boa parte do esforço da comunidade está em modelos diferentes para se representar a difusão e que grande parte são técnicas locais com iguais distribuições entre abordagens determinísticas e probabilísticas.

Por outro lado, no já citado concurso Fiber Cup a comparação entre seus dez concorrentes levou a conclusões de que o único algoritmo global submetido [RMA $\left.{ }^{+} 11\right]$ foi o que teve melhor precisão para regiões de incerteza. Ao passo que os métodos por tensor de difusão erram ao reconstruir tais regiões, mas são melhores para regiões com uma única direção e mais robustos aos ruídos inerentes à ressonância magnética.

\subsection{Principais Referências}

Sobre os princípios de difusão, MR, tensor de difusão e tractografia a referência mais geral e completa é o livro de Johansen-Berg [JBB09]. Sobre o método de tractografia global por simulação de partículas utilizando o conceito de jarros de spin é [FPM09]. Já para o método utilizando os conceitos de polimerização a principal publicação é [RMA $\left.{ }^{+} 11\right]$, porém a mais rica em detalhes é a de [RMK09a].

\subsection{Materiais}

Para avaliar os métodos de tractografia, como parte desse trabalho foram elaboradas baterias de testes com diferentes tipos de dados que reproduzem diferentes níveis de complexidade e refletem desafios a serem ultrapassados. Para possibilitar a comparação entre resultados, todos esses testes foram repetidos para os algoritmos escolhidos no mesmo equipamento. Da mesma forma, parâmetros compartilhados entre os métodos de simulação de partículas foram mantidos inalterados. Todas essas variáveis são detalhadas a seguir.

\subsubsection{Construção dos Dados Sintéticos}

Esta primeira bateria de testes utiliza dados gerados por scripts $^{7}$ que reproduzem isoladamente os seguintes casos abordados na seção 3.7 :

- Reta inclinada em 45 graus com relação ao eixo Y (Fig. 3.1);

- Cruzamento de duas retas inclinadas em 45 graus, formando um cruzamento de 90 graus na intersecção (Fig. 3.2);

- Cruzamento de uma reta inclinada em 45 graus com outra sem inclinação, formando um cruzamento de 45 graus na intersecção (Fig. 3.3);

- Alta curvatura (Fig. 3.4);

Os dados utilizados para testes foram construídos por scripts em linguagem Python de forma que a variação da direcionalidade ocorra em duas dimensões ( $\mathrm{X}$ e $\mathrm{Z}$ ) e tal variação seja replicada em três fatias na outra dimensão (Y). Dessa forma, é possível seguir uma curva bidimensional, $f(x)$, para a qual a primeira derivada, $f^{\prime}(x)$, seja bem definida. Assim, para formar as coordenadas $(x, z)$ da curva, $x$ é variado continuamente com $z=f(x)$. Outras geometrias complexas são obtidas

\footnotetext{
${ }^{1}$ Diffusion Tensor - Tensor de Difusão

${ }^{2}$ Conectividade entre regiões de interesse.

${ }^{3}$ Detalhado por [ZSWKA12].

${ }^{4}$ ODF é abreviatura de Orientation Distribution Function (Função da Distribuição de probabilidades de Orientação) que pode ser aproximada pela FRT ou mensurada com a aquisição pela técnica de DSI.

${ }^{5}$ Tensor de difusão duplo.

${ }^{6}$ Em áreas complexas, combina dois tensores.

${ }^{7}$ https://gitlab.com/rafamanzo/data_gen
} 
iterando de forma similar, mas utilizando a forma paramétrica. Para superar esses desafios foram usadas técnicas que aliam esquemas de aquisição mais rápidos com a sincronização ao ritmo cardíaco do paciente.

Para a construção do tensor é utilizado o valor de $f^{\prime}(x)$ na construção do autovetor principal $v_{0}=\left(x_{0}, y_{0}, z_{0}\right)$. O segundo autovetor é construído de forma a ser perpendicular ao primeiro e em função desse: $v_{1}=\left(-z_{0}, y_{0}, x_{0}\right)$. O terceiro autovetor é fixado para ser perpendicular aos demais por $v_{2}=(0,1,0)$. Em seguida, os autovalores são definidos respectivamente com $\lambda_{0}=0.8, \lambda_{1}=0.1$ e $\lambda_{2}=0.1$ de forma que a anisotropia resultante seja alta. Com esses dados é possível reconstruir o tensor pela expressão:

$$
T=(V \times \lambda) \times V^{-1}
$$

Finalmente a ODF para uma dada direção $u$ (para estes testes foram escolhidas 724 direções não colineares) é dada em função do tensor $D T$ pela equação de [ALS09]:

$$
O D F(u)=\frac{1}{4 \pi|T|^{\frac{1}{2}}\left(u^{t} D T^{-1} u\right)^{\frac{3}{2}}}
$$

Quanto às dimensões espaciais, o objetivo foi de gerar dados minimais que representem cada caso problemático, mas que permitam processamento instantâneo e possam ser empregados em testes automatizados durante o processo de desenvolvimento. Portanto, todos os conjuntos possuem apenas três fatias com dados sobre direcionalidade definidos e o maior destes com dimensões para os eixos $\mathrm{X}$ e $\mathrm{Z}$ de $40 \times 40$.

As figuras a seguir ilustram os conjuntos de dados construídos com esta metodologia:

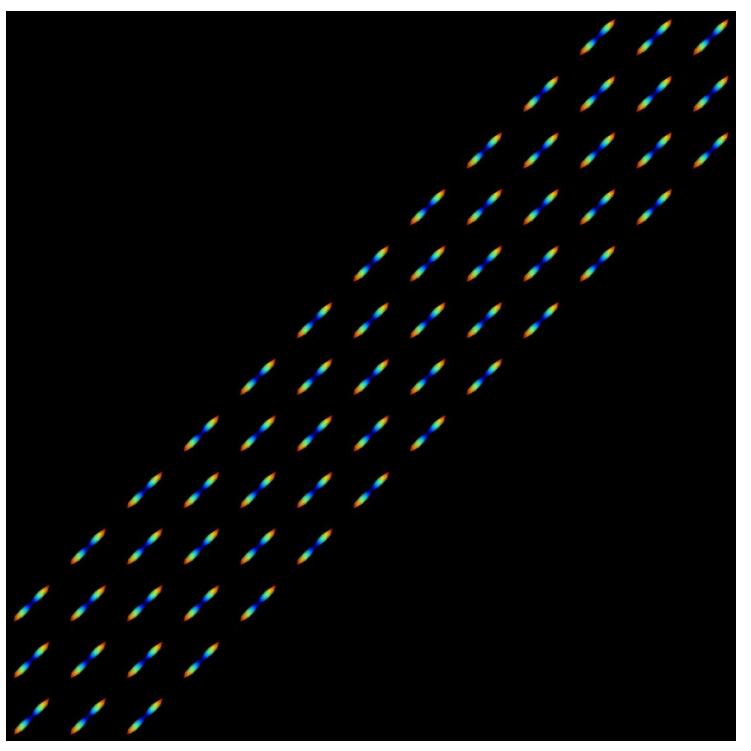

(a)

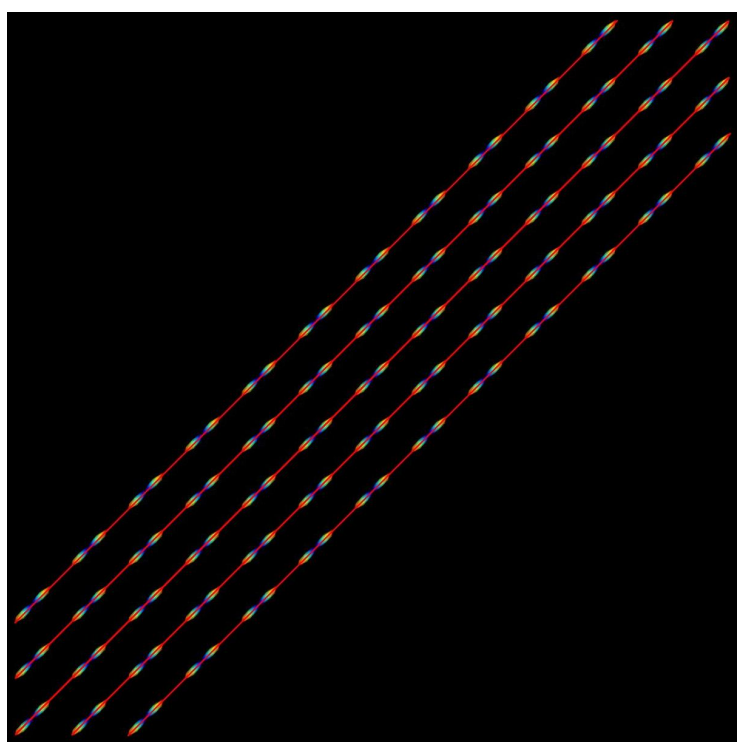

(b)

Figura 3.1: Visões do corte coronal da representação gráfica das ODFs (a) geradas e da estrutura de fibras reconstruídas esperada (b) para uma reta inclinada em 45 graus. Para ambas imagens as funções esféricas que representam as ODFs foram coloridas utilizando o mapa de cores jet de forma a destacar os picos na direcionalidade. 


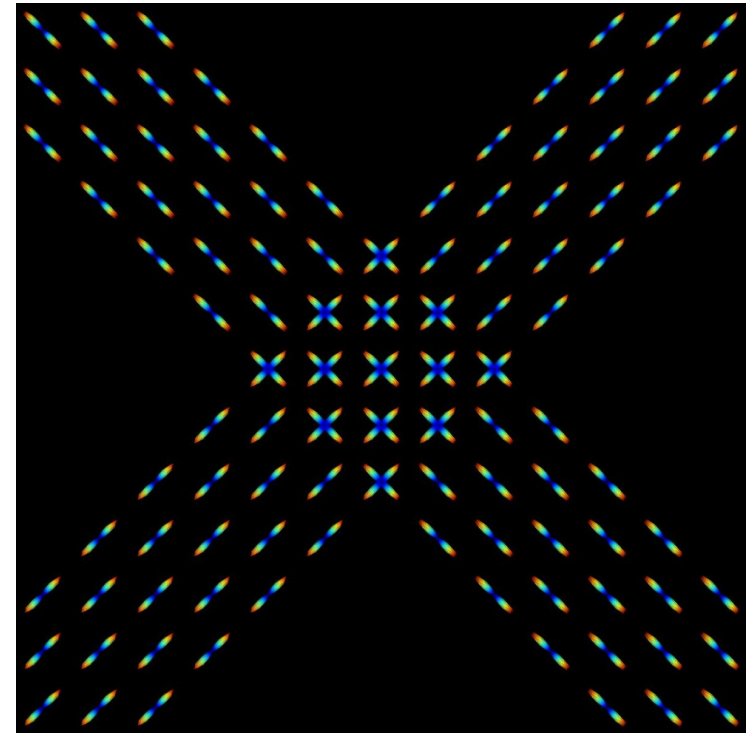

(a)

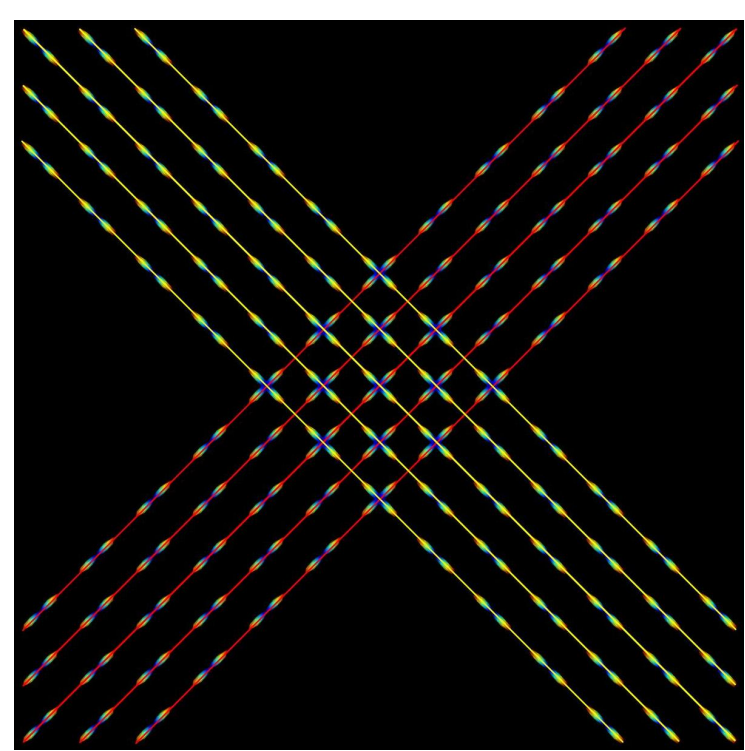

(b)

Figura 3.2: Visões do corte coronal da representação gráfica das ODFs (a) geradas e da estrutura de fibras reconstruídas esperada (b) para um cruzamento formando 90 graus. Para ambas imagens as funções esféricas que representam as ODFs foram coloridas utilizando o mapa de cores jet de forma a destacar os picos na direcionalidade.

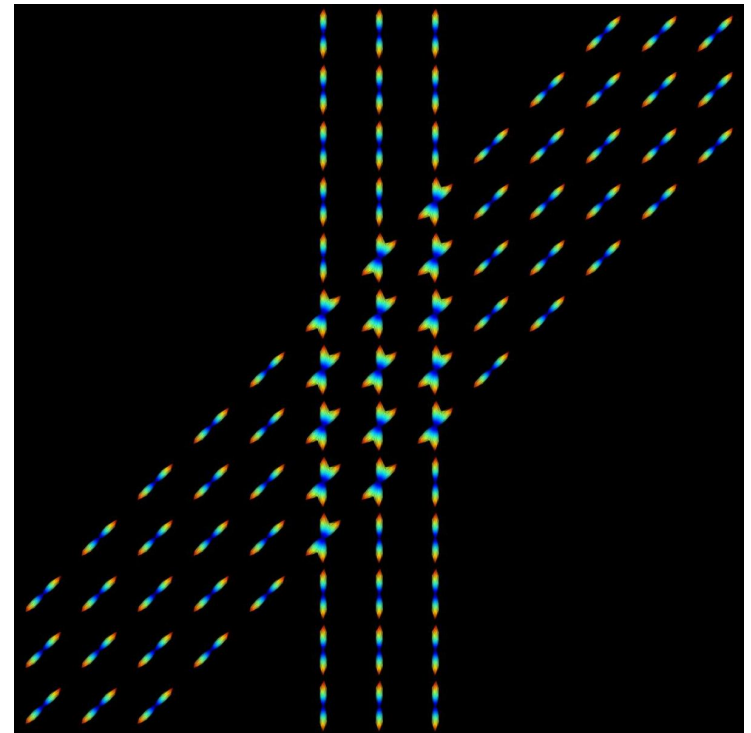

(a)

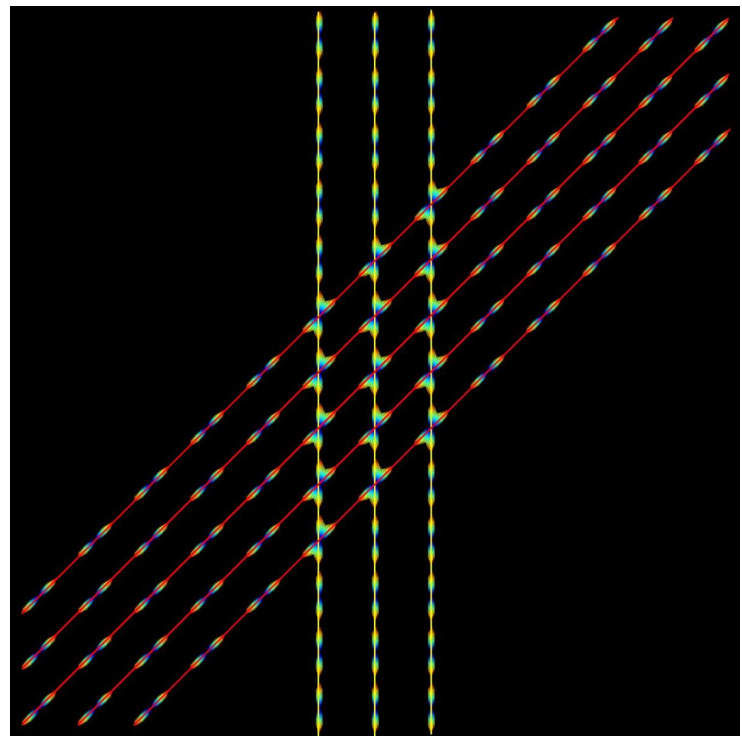

(b)

Figura 3.3: Visões do corte coronal da representação gráfica das ODFs (a) geradas e da estrutura de fibras reconstruídas esperada (b) para um cruzamento formando 45 graus. Para ambas imagens as funções esféricas que representam as ODFs foram coloridas utilizando o mapa de cores jet de forma a destacar os picos na direcionalidade. 


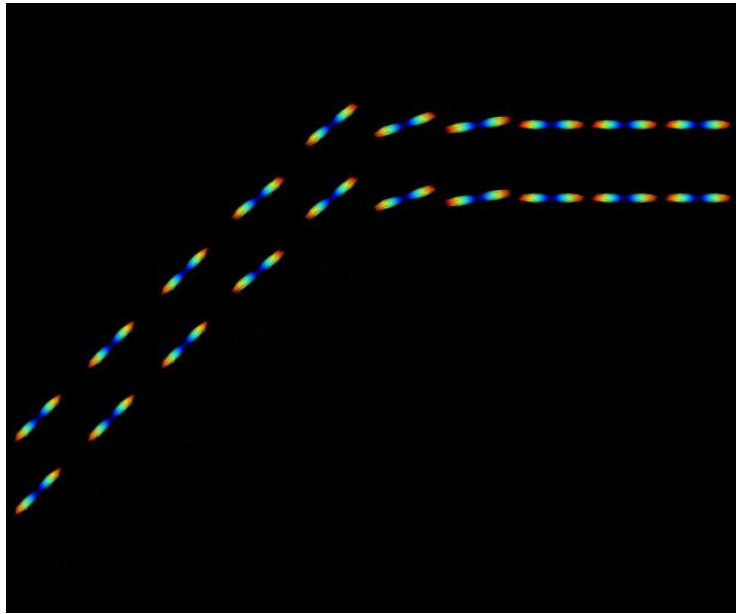

(a)

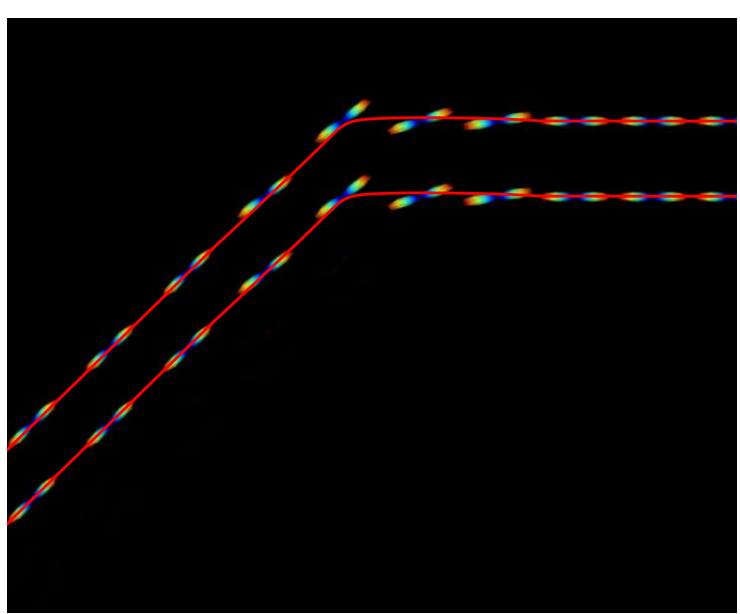

(b)

Figura 3.4: Visões do corte coronal da representação gráfica das ODFs (a) geradas e da estrutura de fibras reconstruídas esperada (b) para uma curvatura acentuada. Para ambas imagens as funções esféricas que representam as ODFs foram coloridas utilizando o mapa de cores jet de forma a destacar os picos na direcionalidade.

\subsubsection{Dados Cardíacos}

A aplicação de dMRI ao coração in vivo é uma técnica que se desenvolveu recentemente com a evolução da tecnologia dos escâneres que permitem a amostragem dessa musculatura mesmo sendo um músculo em constante movimento. Como descrito em [MJS $\left.{ }^{+} 15\right]$, esse tipo de aquisição impõe desafios adicionais com respeito a: deformações e deslocamentos não rígidos; redução do tempo de difusão; e não homogeneidade dos campos magnéticos que fazem parte do processo de aquisição (seção 3.5.1).

Com respeito à tractografia, ele não apresenta regiões de incerteza como as detalhadas na seção 3.7. Sua dificuldade para a tractografia reside na anatomia que forma um contínuo de fibras sem inicio ou fim como ilustrado na figura 3.5.

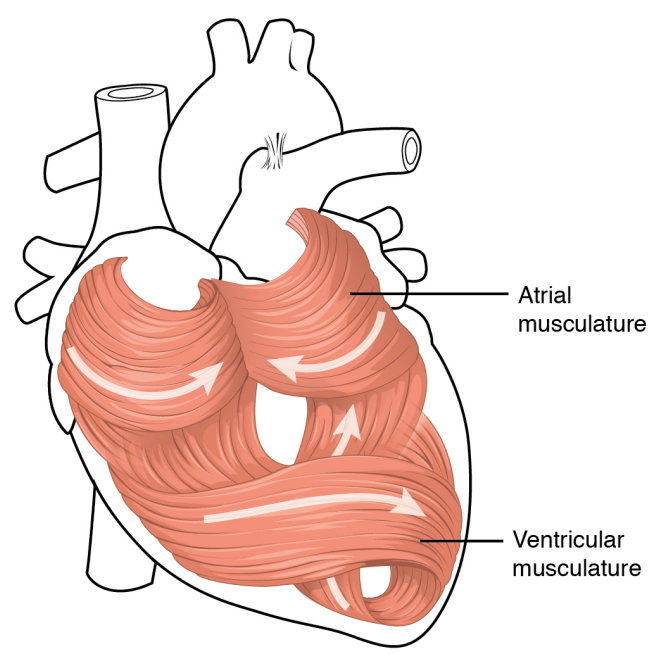

Figura 3.5: Esquema da musculatura cardiaca [OCAP06].

O conjunto de dados utilizado é de alta qualidade (pouco ruído e alta resolução) e foi usado em outro estudo anterior $\left[\mathrm{MHC}^{+} 12\right]$. Esse estudo detalha seus parâmetros e processo de aquisição em sua seção de materiais.

Sem acesso a técnicas de validação histológica, a avaliação dos resultados neste tipo de dados é puramente visual. Assim, foi feita uma fatia com 20 voxels de tamanho nas três dimensões no 
ventrículo esquerdo, conforme ilustrado na Fig. 3.6.

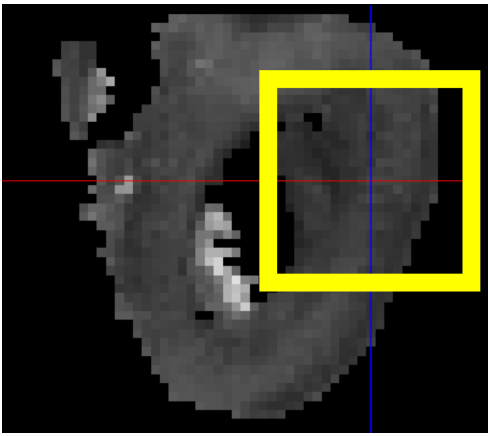

(a)

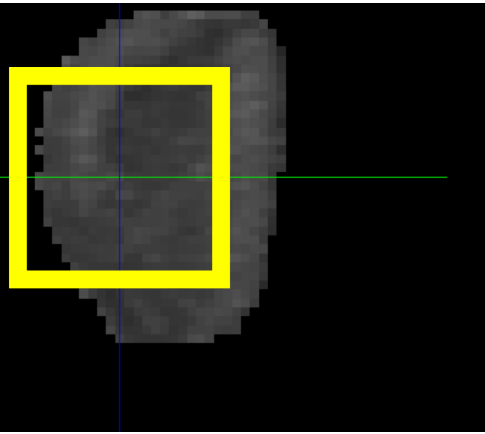

(b)

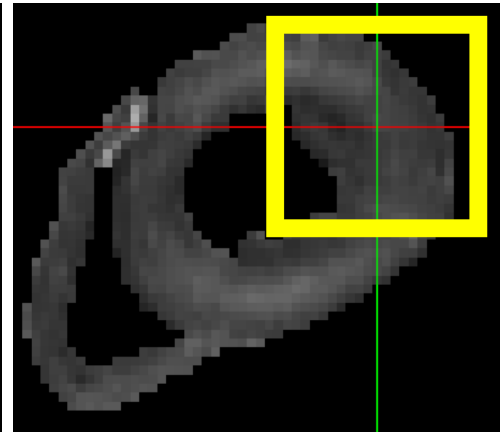

(c)

Figura 3.6: Visão em três fatias, coronal (a), sagital (b) e axial (c), da imagem do coração colorida em tons de cinza de acordo com valor de FA. A região de interesse para os testes é destacada pelas caixas amarelas.

O modelo de difusão adotado foi o tensor. Por ser um contínuo de fibras e não conter cruzamentos ou altas curvaturas, esse modelo é suficiente para fornecer uma representação do perfil de difusão que não prejudica a qualidade da tractografia para esta parte da anatomia.

Em estudos sobre o coração, são adotadas coordenadas sobre suas quatro paredes, conforme a imagem abaixo da visão volumétricas dos dados:

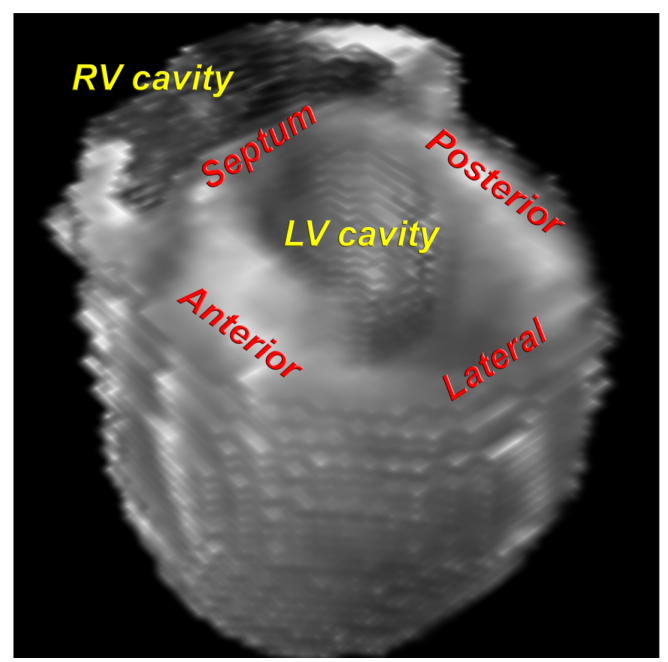

Figura 3.7: Coordenadas anatômicas para o coração. Em amarelo são indicadas as cavidades de ambos os ventrículos e, em vermelho, as paredes do ventrículo esquerdo.

\subsubsection{Recursos Computacionais}

Todos os testes detalhados a seguir foram realizados em um Dell PowerEdge T620 equipado com processador Intel Xeon E5-2630. Este equipamento tem seus recursos virtualizados utilizando o hypervisor KVM. Os experimentos detalhados nesse capítulo foram realizados em uma máquina virtual desse servidor com as seguintes especificações:

- 10 núcleos de processamento dedicados;

- 8GB de memória RAM;

- sistema operacional GNU Linux Ubuntu 16.10. 


\subsubsection{Parâmetros de Execução}

\section{Propagação de Linha}

Para produzir resultados visualmente comparáveis com os outros dois métodos globais, os pontos iniciais do processo de propagação de linha foram selecionados aleatoriamente com probabilidade 0.3 dentro de sua máscara. Foi utilizado o método de Runge-Kutta de ordem 4 disponível no software BioImage Suite [PJR $\left.{ }^{+} 05\right]$, tamanho de passo $h=0.25$ com os seguintes critérios de parada: ângulo máximo de 45 graus; e torção máxima de 140.

\section{Método de Polimerização}

Em 3.14.1 foi detalhado o método, os parâmetros envolvidos e seus significados. Para os testes realizados foram reproduzidos os parâmetros encontrados em [RMK09a] e os faltantes foram obtidos pelo estudo do código da ferramenta DITFibertools [KHI]. Esses parâmetros, de acordo com o também definido na subseção 3.17.1, são:

- $c=1$;

- $w=0.2$

- $\sigma=0.4$;

- $l=0.4$

- $L=0.4$;

- $\lambda_{\text {int }}=0.935$;

- $\lambda_{\text {ext }}=0.065$;

- $T_{\text {start }}=0.1$

- $T_{\text {end }}=0.001$;

- Limiar de alta curvatura, $\alpha=\cos \left(\frac{\pi}{6}\right)$.

Além desses, é definida a quantidade de iterações de acordo com cada conjunto de dados. Essas quantidades são detalhadas na tabela de resultados para cada teste dos resultados (4). Finalmente os resultados apresentados não foram obtidos com a ferramenta implementada pelo autor principal. Nessa ferramenta os resultados se mostraram inconsistentes, de difíceis visualização e comparação com os demais métodos. Por isso, esse trabalho optou por uma implementação própria disponibilizada junto com o método proposto (3.17).

\section{Método SAGA}

A maior parte dos parâmetros do método são oriundos do método de polimerização utilizado para realizar os movimentos e conexões entre partículas. Esses foram mantidos idênticos para preservar a comparação entre os métodos. Além desses, o método modificado adiciona um parâmetro de entrada com respeito ao grau de interpolação da grade (3.15.2) para o qual foi utilizado o valor 0 nos testes realizados. 


\subsection{Difusão}

Difusão é um processo de transporte de massa que resulta na mistura das partículas sem movimentar grandes quantidades de massa. Sendo regido pela Primeira Lei de Fick:

$$
J=-D \nabla c
$$

Onde $D$ é o coeficiente de difusão e $\nabla c$ é o gradiente da função que descreve a concentração das partículas no espaço. Da equação 3.3, temos que as partículas tendem a se deslocar de regiões de maior concentração para as de menor concentração de forma análoga ao que ocorre com o calor na termodinâmica.

Por outro lado, Brown através da observação de partículas de pólen suspensas em água e outros experimentos, notou que as partículas se movem aleatoriamente sem causa aparente, introduzindo o chamado movimento Browniano [Bro28].

Einstein posteriormente introduziu um modelo probabilístico para descrever o movimento de um grupo de partículas durante o processo de difusão [Ein05]. Assim colocando em acordo as observações de Brown com a Primeira Lei de Fick. Esta distribuição do deslocamento das partículas descreve sua quantidade que deve atravessar certo espaço unidimensional num determinado intervalo de tempo:

$$
<x^{2}>=2 D \Delta
$$

Onde $\left\langle x^{2}\right\rangle$ denota a média do quadrado do deslocamento, $D$ o coeficiente de difusão e $\Delta$ o intervalo de tempo.

\subsection{Ressonância Magnética Ponderada por Difusão}

Imagens de ressonância magnética (MRI) em essência medem propriedades magnéticas das moléculas que compõem os tecidos, com base na ressonância magnética (MR) nuclear. Esse fenômeno ocorre nos elétrons e no núcleo dos átomos que apresentam um dipolo magnético. Esse dipolo, chamado de spin [Sue09], possui momentos magnético e angular.

Apesar de diversos elementos apresentarem spin, o hidrogênio é o alvo da maior parte dos estudos. Portanto, como o corpo de um humano adulto médio é formado $65 \%$ por água [Hal10], empregar MRI é útil no estudo da maior parte dos tecidos do corpo humano. Assim, ela constitui uma importante forma de estudo não invasivo do corpo humano devido ao seu poder de sensibilizar a maior parte de suas moléculas sem oferecer os riscos à saúde da radiação ionizante que é aplicada na tomografia computadorizada, que emprega raios $\mathrm{X}$.

\subsubsection{Codificação da Difusão por Ressonância Magnética}

O processo para obtenção de imagens de ressonância magnética ponderadas por difusão se baseia no manejo adequado do escâner. Ele permite a configuração de intervalos de tempo para ativação e desativação dos campos magnéticos gradientes e das radiofrequências emitidas bem como suas intensidades. Essa versatilidade permite desde as funcionalidades mais básicas como definição da resolução, qualidade e seleção de fatias até a sensibilização de diferentes moléculas e estimativa de seu perfil de difusão. 


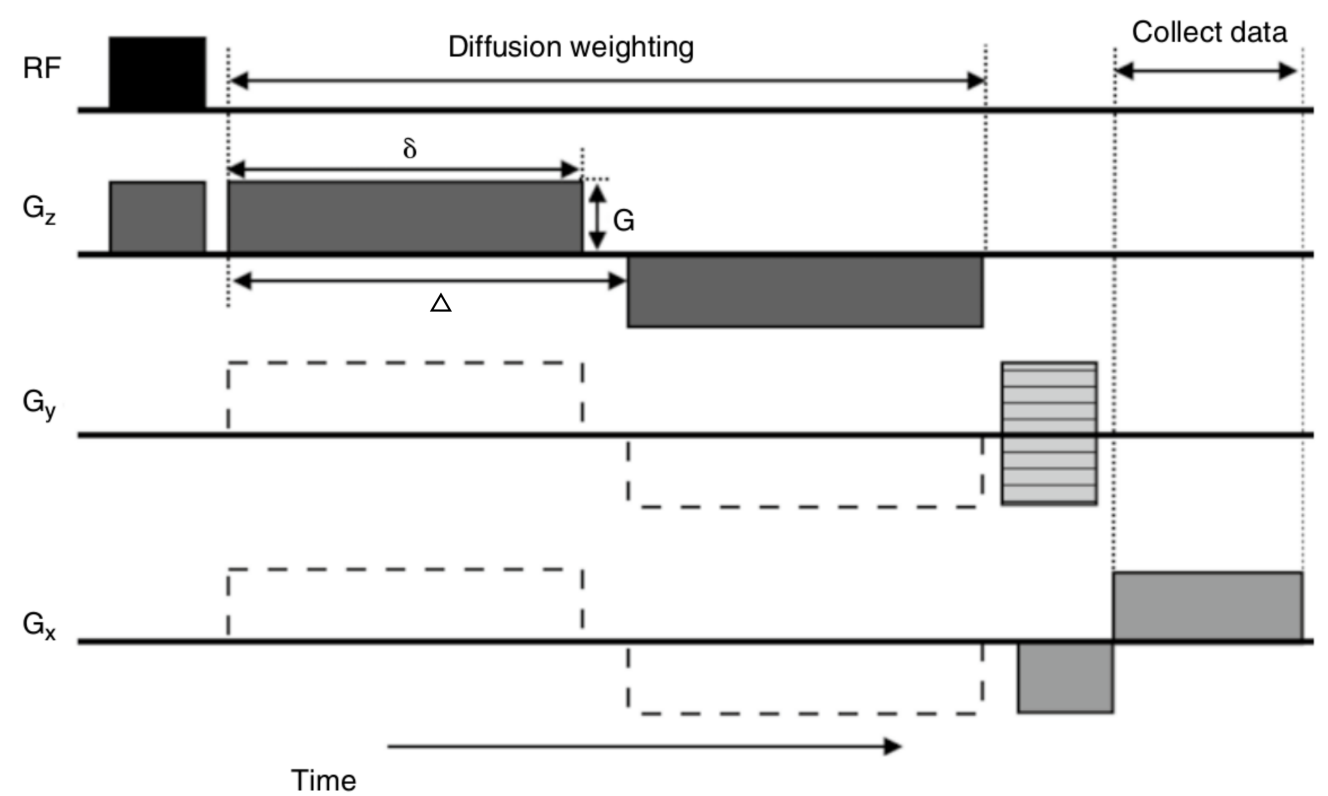

Figura 3.8: Aplicação de gradiente bipolar para ponderação por difusão apenas no eixo $z . G_{x}, G_{y}, G_{z}$ denotam os gradientes nos três eixos do espaço, $R F$ a radiofrequência, $G$ a intensidade do campo gradiente, $\delta$ a duração do gradiente e $\Delta$ o tempo até o gradiente oposto ao primeiro. As linhas pontilhadas denotam como seria a aplicação para os demais eixos. Extraída de [JBB09].

A figura 3.8 exemplifica o esquema de uma sequência simples para aplicar ponderação por difusão em apenas um eixo utilizando um gradiente bipolar. Os spins são excitados por radiofrequência e em seguida é aplicado o primeiro campo magnético gradiente. Esse campo adiciona uma fase positiva aos spins com intensidades diferentes de acordo com a sua localização espacial. Em seguida o segundo campo gradiente, oposto ao primeiro, é aplicado adicionando fase negativa aos spins. Assim, moléculas que não se movimentaram durante esse processo terão as fases dos spins anuladas pelos campos gradientes enquanto que os que apresentaram movimento estarão defasados em razão das diferenças de intensidade entre os dois campos magnéticos.

Sobre as imagens obtidas existem propriedades a respeito de sua qualidade que são importantes: sua resolução, ou seja a distância física entre as fatias; e a razão de sinal para ruído (Signal to Noise Ratio - SNR). A primeira diz respeito à quantidade de detalhes sendo amostrada para a qual quanto maior a magnitude (menor distância entre fatias) melhor a imagem. A segunda diz respeito à qual fração da amostra diz respeito à amostragem de interesse sobre ruído de fundo. Dessa forma, valores altos para essa relação são desejáveis.

A resolução e a SNR estão relacionadas de forma que altas resoluções costumam reduzir o valor de SNR comprometendo a qualidade da imagem. Isso faz necessário ponderar a melhor relação entre ambas. Além do efeito negativo sobre SNR, resoluções altas aumentam o tempo de aquisição necessário podendo impedir que determinados estudos sejam viáveis em sujeitos vivos ou mesmo que experimentos mais longos sejam realizados sem que as propriedades da água mudem durante esse tempo.

\subsubsection{Aplicação}

A versatilidade, por meio de modificações na sua sequência de pulso, é um dos pontos mais fortes em MRI, permitindo maior peso no contraste de diferentes tecidos ou características físicas destes de acordo com o interesse do estudo sendo executado. Uma destas formas de aquisição de imagens é a chamada ponderação por difusão (em inglês DWI - Diffusion Weighted Imaging). Nesta sequência de aquisição, além dos campos magnéticos gradientes na direção dos três eixos do espaço, são feitas aquisições com outros campos gradientes em direções oblíquas entre si de forma a capturar o perfil de difusão das moléculas em cada voxel. Essa quantidade de direções de difusividade amostradas 
é um parâmetro de qualidade adicional onde números maiores produzem resultados melhores. Por outro lado, eles não são aumentados indiscriminadamente pois é preciso ponderar mais uma vez com relação ao tempo de aquisição que aumenta.

O interesse em mensurar o perfil de difusão em cada ponto de um volume parte do fato que a geometria de barreiras físicas afetam diretamente a difusão das moléculas. Na ausência de barreiras físicas organizadas as moléculas tendem a se deslocar com probabilidade igual em todas as direções, configurando a chamada isotropia. Por outro lado, na presença de barreiras físicas organizadas permeáveis ou semipermeáveis, a difusão passa a ter maior probabilidade de ocorrer nas direções livres de barreira. Esse último comportamento é denominado anisotropia.

Dessa forma, pelo perfil de difusão é possível estudar in vivo, de forma não invasiva e sem os riscos da radiação ionizante as características de diversos tecidos do corpo humano que apresentam uma organização em fibras. Isso é possível por meio de técnicas de reconstrução digital chamadas de tractografia. Os tecidos mais estudados por tais métodos são a substância branca cerebral composta principalmente de axônios [ABA02, AP08, $\left.\mathrm{JKQ}^{+} 05, \mathrm{OYS}^{+} 07\right]$ e os músculos em geral, mas com importante destaque para o músculo cardíaco $\left[\mathrm{MHD}^{+} 11, \mathrm{MHC}^{+} 12, \mathrm{MJS}^{+} 15\right]$.

\subsection{Tensor de Difusão}

Uma vez adquiridos os dados sobre o perfil de difusão para todo um volume, ainda é preciso representar estas informações em algum modelo que expresse suas características quanto a direcionalidade e intensidade da difusão aferida. Nesse sentido, um dos primeiros modelos propostos e mais utilizado é o tensor de difusão (DT) como definido em [JBB09]:

$$
D T=\left(\begin{array}{lll}
D_{x x} & D_{x y} & D_{x z} \\
D_{x y} & D_{y y} & D_{y z} \\
D_{x z} & D_{y z} & D_{z z}
\end{array}\right)
$$

Esta matriz pode ser compreendida como a matriz de covariância da distribuição de probabilidade da difusividade em três dimensões num dado intervalo de tempo. Dessa forma, os elementos da diagonal principal representam a difusão em cada eixo e os demais elementos da matriz a correlação entre estes eixos. Assim como a equação de transporte de massa supõe que a difusão segue uma distribuição Gaussiana [Ein05], este modelo também herda esta suposição que é sua maior desvantagem e mais a frente serão detalhadas as razões na seção 3.7.

Indo além, a matriz 3.5 sempre aceita uma decomposição em autovalores e autovetores positivos $\left[\mathrm{BMA}^{+}\right.$05]. Desta forma, seus autovetores são interpretados como as três direções principais de difusão e os autovalores associados a eles como a intensidade em cada uma destas direções. Assim, quando todos esses autovalores possuem valores muito próximos, classifica-se como um caso de isotropia e, analogamente quando um dos autovalores tem valor muito maior que os outros dois, a anisotropia.

\subsubsection{Difusividade Média}

A difusividade média (do inglês $M D$ - Mean Diffusivity) quantifica a intensidade média da difusão independente da direção e é dada pela soma do três auto valores do tensor ou também pelo seu traço dividido por três. Este índice é relevante para determinação de patologias cerebrais como isquemia aguda $\left[\mathrm{LBC}^{+} 97\right]$.

\subsubsection{Anisotropia Fracionária}

A anisotropia fracionária (do inglês FA - Fractional Anisotropy) é outro índice muito utilizado derivado dos autovalores $\lambda_{1}, \lambda_{2}$ e $\lambda_{3}$ do tensor:

$$
F A=\sqrt{\frac{1}{2}} \sqrt{\frac{\left(\lambda_{1}-\lambda_{2}\right)^{2}+\left(\lambda_{2}-\lambda_{3}\right)^{2}+\left(\lambda_{3}-\lambda_{1}\right)^{2}}{\left(\lambda_{1}+\lambda_{2}+\lambda_{3}\right)}}
$$


Os valores da equação 3.6 são reais que variam entre zero, quando não existe direção preferencial alguma (meio isotrópico), e 1, quando toda a difusão se dá em uma única direção (meio anisotrópico).

\subsubsection{Visualização}

Uma vez que o tensor esteja calculado, esta matriz não é facilmente interpretável por seres humanos. Então, para auxiliar na interpretação dos dados, além dos índices acima descritos, glifos são utilizados. O mais comum entre eles é o elipsoide (como visualizado na figura 3.9), apesar de que superquádricas e toros sejam comprovadamente $\left[\mathrm{MHD}^{+} 11\right]$ mais expressivos para este fim.

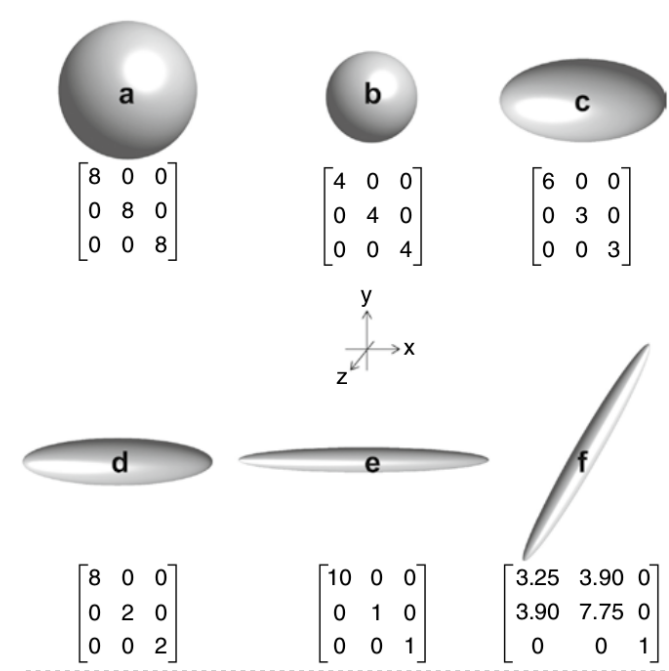

Figura 3.9: Representação dos tensores como elipses. Tal visualização permite ter dimensão de direções e magnitudes no tensor. Em $\boldsymbol{a}$ e $\boldsymbol{b}$ temos exemplos de isotropia em diferentes magnitudes. Em $\boldsymbol{c}, \boldsymbol{d}$ e $\boldsymbol{e}$ observamos anisotropia na direção do eixo $x$. Em $\boldsymbol{f}$ a anisotropia se dá em um ângulo oblíquo nos eixos $x$ e y. Figura reproduzida de [JBB09].

Em seguida, outra forma de trazer mais informação à quem precisa interpretar tais dados é por meio de cores que em geral são utilizadas para trazer informações sobre índices baseados no tensor como a difusividade média e a anisotropia fracionária. Na figura 3.10 é dado um exemplo dessa coloração pelo índice FA aplicado à elipses. 


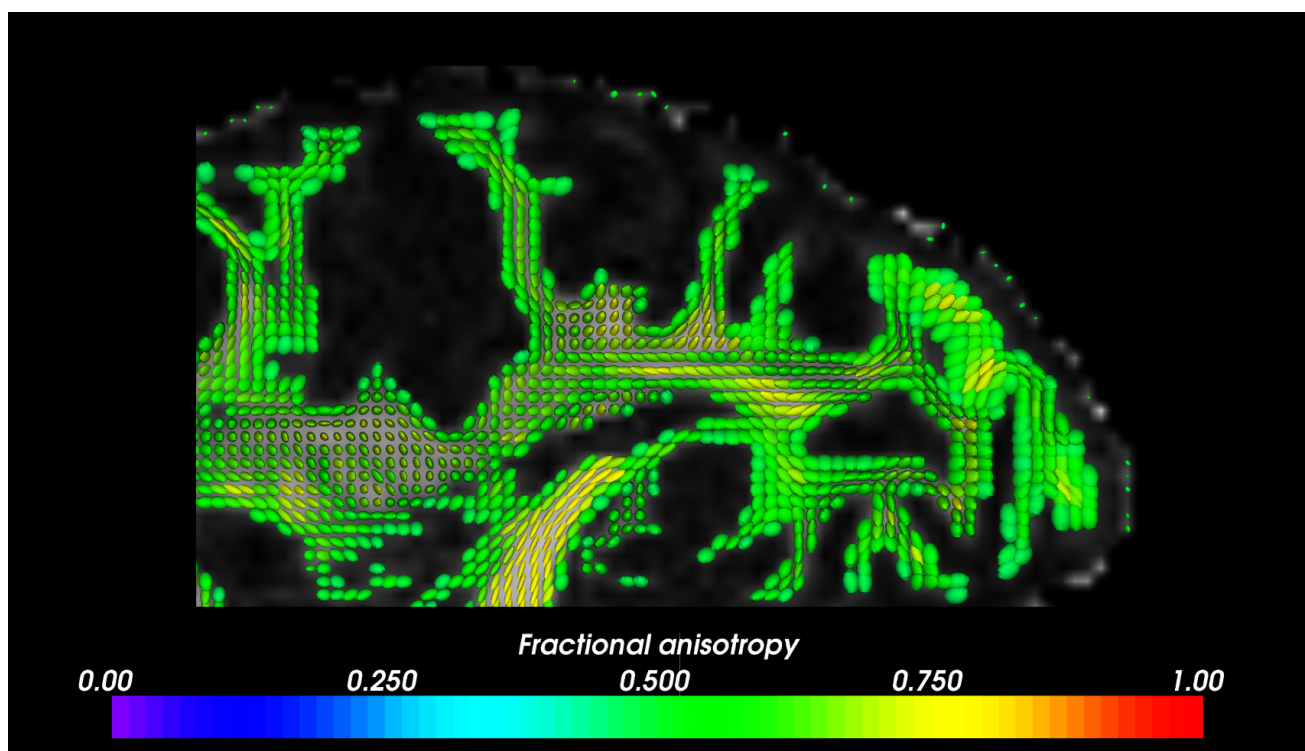

Figura 3.10: Exemplo de representação do tensor em elipsoides para uma seção de um corte axial do cérebro humano. Codificação de cores de acordo com o índice de FA.

\subsection{Efeito de Volume Parcial no Tensor de Difusão}

Como já foi mencionado, a maior desvantagem deste modelo de tensor de difusão está na sua suposição de que a difusão sempre segue uma distribuição Gaussiana [AHL ${ }^{+}$01]. Isso pois a resolução de aquisição das imagens não é suficiente para captar diversos casos onde partes de mais de uma fibra estão representadas em um único voxel [WLW00]:

- Cruzamento de fibras (crossing) 3.11a;

- Separação (ou junção) de fibras (splitting) 3.11b;

- Alta curvatura (bending) 3.11c;

- Se tocando pontualmente (kissing) 3.11d;

- E a formação de formas helicoidais que se interlaçam (fanning).

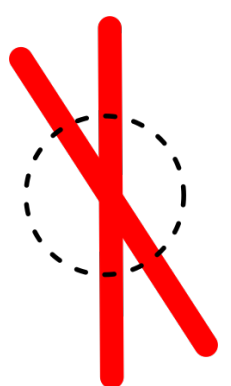

(a)

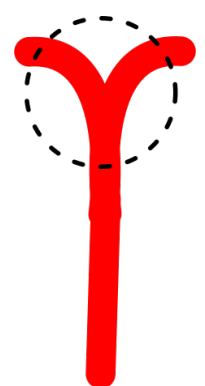

(b)

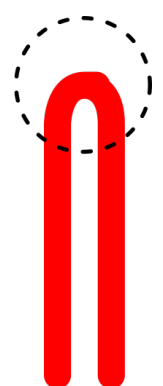

(c)

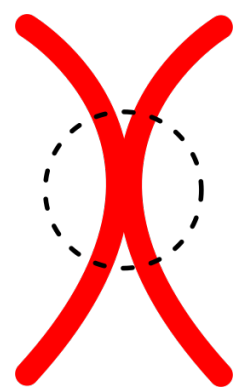

(d)

Figura 3.11: Exemplos simplificados de configurações de fibras que produzem o efeito de volume parcial (circulado em preto). A configuração de fanning é difícil de representar visualmente, pois ocorre em três dimensões. (a) Cruzamento de fibras. (b) Separação (ou junção) de fibras. (c) Fibra com alta curvatura. (d) Fibras se tocando pontualmente.

Tais configurações geométricas são passíveis de serem encontradas em estruturas de tecidos biológicos, mas não são as únicas. Como a anatomia é desconhecida nessas regiões de incerteza, por 
isso são estudas, podem existir outras formas que ainda não são descritas na literatura, mas que gerem incerteza nos dados.

Aumentar a resolução da imagem a ponto de ser possível amostrar essas regiões não é viável tanto em termos do valor de SNR que cai quanto pelo tempo de aquisição que aumenta. Isso motiva a proposição de alternativas e melhorias ao tensor de difusão na literatura. Parte dos esforços para melhorar este modelo buscaram associar dois tensores ou mais a um mesmo voxel, assim tentando minimizar os efeitos. Outra parte dos esforços se concentram em substituir o tensor por distribuições de probabilidade sobre a direcionalidade da difusão em cada voxel e o grau de certeza sobre a medição feita.

Isso pode ser alcançado por um método de aquisição mais recente denominado Diffusion Spectrum Imaging (DSI) que eleva a quantidade de direções de gradientes necessários da casa das dezenas para a casa das centenas e portanto ainda não é possível na prática em um tempo aceitável [JBB09]. Resultados parecidos podem ser alcançados pela aproximação da distribuição de probabilidade de direcionalidade por meio de deconvolução esférica, técnica chamada de QBall [Tuc04], utilizando esquemas de aquisição mais fáceis de serem alcançados em tempo aceitável [CSR $\left.{ }^{+} 05, \mathrm{PPR}^{+} 05\right]$.

\subsection{Transformada de Funk-Radon em dMRI}

A já citada técnica $Q B a l l$ [Tuc04] aproxima a distribuição de probabilidades de orientação, $\psi$, de cada voxel partindo da suposição que o sinal dMRI é a convolução desta distribuição. Com direções suficientes, é possível reconstruir a distribuição por meio de processos de deconvolução esférica sobre o sinal, como a transformada de Funk-Radon (FRT).

Antes de detalhar o processo, é preciso definir:

- $Q$ : matriz $3 \times m$ das direções de aquisição;

- $U$ : matriz $3 \times n$ das direções de reconstrução ${ }^{8}$.

O processo inicia obtendo o equador de cada direção de reconstrução $u_{i}$ construindo um círculo com $k$ pontos igualmente espaçados no plano $x y$ representado na matriz $k \times 3$ (nos testes de [Tuc04] foi utilizado $k=48$ ):

$$
C=\left(\begin{array}{ccc}
\cos \theta_{1} & \operatorname{sen} \theta_{1} & 0 \\
\cos \theta_{2} & \operatorname{sen} \theta_{2} & 0 \\
\vdots & \vdots & \vdots \\
\cos \theta_{k} & \operatorname{sen} \theta_{k} & 0
\end{array}\right)
$$

Onde $\theta$ é o vetor $\frac{2 \pi}{k}\left[\begin{array}{llll}1 & 2 & \ldots & k\end{array}\right]$.

Para cada direção, este círculo é rotacionado para a direção normal a $u_{i}$ com a seguinte matriz de rotação, onde $z$ é o vetor da base canônica e $I_{3}$ a matriz identidade $3 \times 3$ :

$$
R_{z}\left(u_{i}\right)=\frac{\left(z+u_{i}\right)\left(z+u_{i}\right)^{t}}{\left(z^{t} u_{i}+1\right)}+I_{3}=\frac{1}{\left(u_{i, 3}+1\right)}\left(\begin{array}{ccc}
u_{i, 1}^{2} & u_{i, 1} u_{i, 2} & u_{i, 1}\left(u_{i, 3}+1\right) \\
u_{i, 1} u_{i, 2} & u_{i, 2}^{2} & u_{i, 2}\left(u_{i, 3}+1\right) \\
u_{i, 1}\left(u_{i, 3}+1\right) & u_{i, 2}\left(u_{i, 3}+1\right) & \left(u_{i, 3}+1\right)^{2}
\end{array}\right)+I_{3}
$$

Finalmente, os pontos equatoriais para $u_{i}$ são dados por $R_{z}\left(u_{i}\right) C$. Que então é concatenado em uma única matriz $S=\left[\begin{array}{llll}R_{z}\left(u_{1}\right) C & R_{z}\left(u_{2}\right) C & \ldots & R_{z}\left(u_{n}\right) C\end{array}\right]$.

Como os pontos das direções de aquisição não coincidem com os do equador definido, é preciso interpolá-los utilizando uma medida de distância na esfera $d\left(n_{1}, n_{2}\right)=\cos ^{-1}\left|n_{1}^{t} n_{2}\right|$ e uma função básica (Gaussiana esférica) $\phi(\alpha)=e^{\frac{-\alpha^{2}}{\sigma^{2}}}$ onde $\alpha=d\left(n_{1}, n_{2}\right)$.

\footnotetext{
${ }^{8}$ As direções de reconstrução devem ser oblíquas entre si e amostrar o mais uniformemente a esfera. A forma utilizada pelo artigo é produzir um dodecaedro e tesselá-lo cinco vezes, assim obtendo 812 direções.
} 
Finalmente a transformação $A$ sobre o sinal $e$ com resultado $\psi$ são obtidos seguindo os seguintes passos e definições:

1. $H=\phi\left(\cos ^{-1}\left|Q^{t} U\right|\right)$;

2. $H^{+}=\left(H^{t} H\right)^{-1} H^{t}$;

3. $G=\phi\left(\cos ^{-1}\left|S^{t} U\right|\right)$;

4. $A=\left(I_{n} \otimes 1_{k}^{t}\right) G H^{+} ; 9$

5. A constante de normalização $Z=1_{n}^{t} A e$;

6. $\psi=\frac{1}{Z}(A e)$.

A transformada aqui apresentada permite representar a partir dos dados de dMRI a preferencialidade do processo de difusão em qualquer direção (Fig. 3.12), diferentemente do tensor que só o pode fazer em três direções.

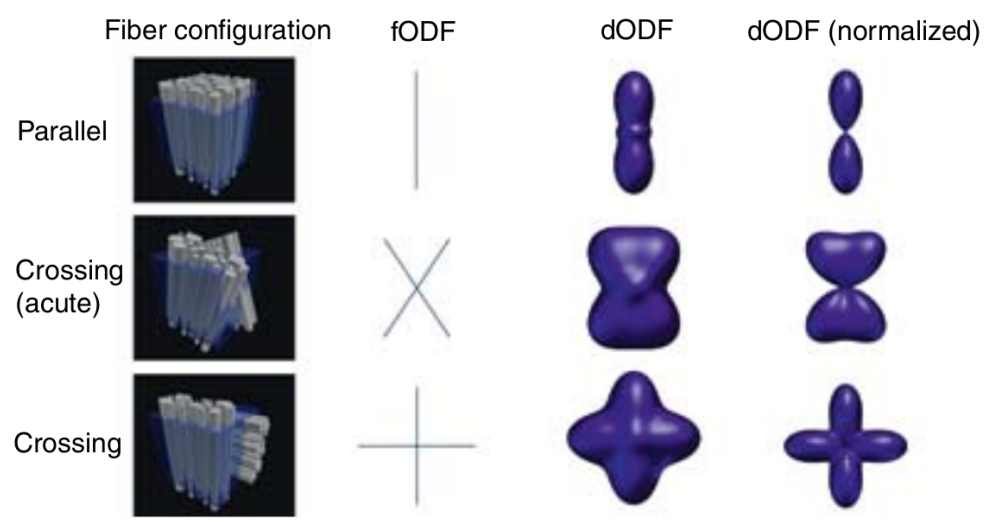

Figura 3.12: Projeção na esfera das transformações antes, Ae (terceira coluna), e após a normalização, $\psi$ (quarta coluna), para diferentes configurações de fibras. Figura reproduzida de [JBB09].

\subsection{Tractografia}

Tractografia é o nome dado ao método de reconstrução da arquitetura de tecidos a partir de dMRI. Ela é um modo de identificar e mensurar as trajetórias da anatomia de forma não invasiva e in vivo. Por outro lado, tais mensurações são indiretas de difícil interpretação e suscetíveis a erros motivando o desenvolvimento de variados métodos para realizar as reconstruções mitigando tais problemas.

Essa busca por melhores resultados motivou a variação de diversos parâmetros dentre os quais três são mais utilizados na literatura na caracterização de métodos:

- Modelo de Difusão: dada a imagem de ressonância magnética ponderada por difusão, essa pode ser modelada de diferentes formas como o tensor de difusão ou um conjunto de distribuições de probabilidades sobre a direcionalidade da difusão;

- Localidade: diz respeito a se o cálculo das trajetórias é feito considerando apenas o voxel sozinho (local) ou mais componentes do conjunto de dados (global) de forma a fornecer informação mais completa da vizinhança;

\footnotetext{
${ }^{9} G H^{+}$é uma matriz $(k n) \times m$. Para obter $A$ de forma eficiente é preciso convertê-la em $k \times n \times m$ e acumular a soma pela primeira dimensão.
} 
- Natureza: dividido entre métodos determinísticos, com expressões matemáticas exatas para a propagação como a integração voxel a voxel, e probabilísticos, que apresentam mapas da probabilidade de conectividade entre regiões e reconstroem as trajetórias com limiares determinados pelo usuário.

De acordo com esses três critérios uma revisão em maior volume dos métodos disponíveis na literatura é feita na seção 3.1. Para melhor embasar as futuras menções sobre métodos de tractografia, a seguir são detalhados três conjuntos de métodos com maior destaque na revisão mencionada: propagação de linha; métodos de otimização globais; e métodos de conectividade probabilísticos.

\subsubsection{Propagação de Linha}

A propagação de linha pela direção principal de difusão é uma das técnicas de tractografia encontrada com maior frequência na literatura. Nela a difusão pode ser representada na forma tensorial, na qual o auto vetor principal dá a direção, ou por meio de distribuições de probabilidade, como ODF, sobre as quais o pico de probabilidade dá a direção principal a ser seguida.

Se uma dada trajetória é descrita pela função $f$, esse campo vetorial com as direções principais é interpretado como a derivada $f^{\prime}$ de $f$. Então para obter $f$ basta empregar algum processo de integração como o método de Runge-Kutta (detalhado em 3.10).

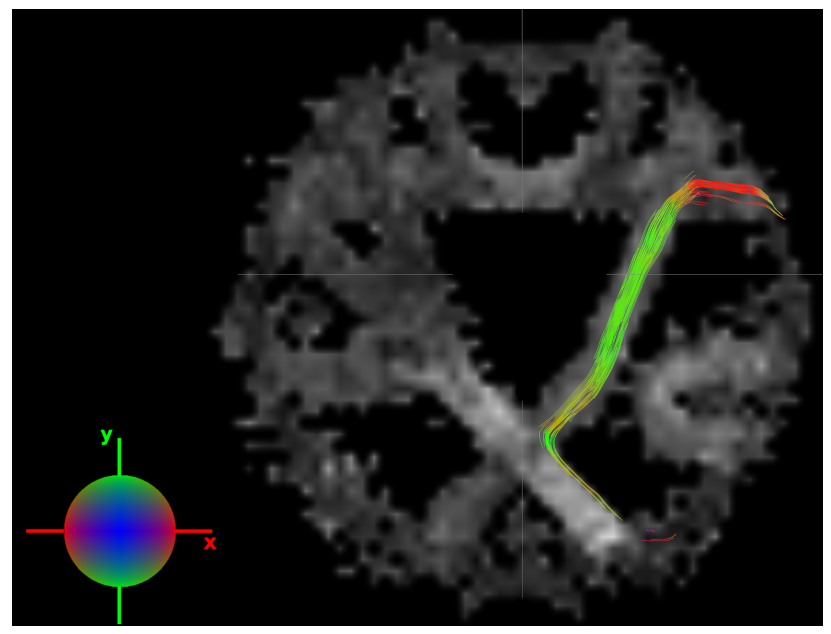

(a)

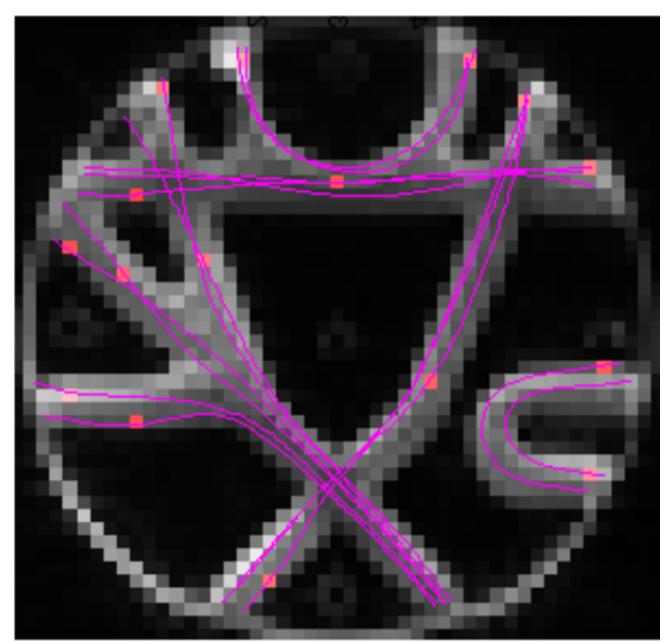

(b)

Figura 3.13: Resultados da tractografia em dados sintéticos [FDG $\left.{ }^{+} 11\right]$ para diferentes métodos. (a) Resultado da tractografia por propagação de linha $\left[P J R^{+} 05\right]$ pela direção principal do tensor de difusão a partir do centro de uma das fibras do conjunto de dados sintéticos. Com critério de parada com ângulo da fibra superior a $45^{\circ}$. Colorido de acordo com a direcionalidade. Coloração de acordo com a direcionalidade, onde a direção z está saindo da tela. (b) Resultado para simulação de partículas reproduzido de [RMK09b].

O método de integração numérica, é um processo de natureza determinística que recebe um conjunto de pontos iniciais, e critérios de parada baseados em características fisiológicas que variam desde a curvatura, torção e comprimento das fibras até valores de índices extraídos do próprio tensor de difusão como FA e MD.

Porém tal método apresenta as deficiências mencionadas na seção 3.7 e exemplificadas pela figura 3.13. Em regiões de incerteza, no caso um cruzamento de fibras, o primeiro método (Fig. 3.13a) vai reconstruir as trajetórias de forma incorreta desviando as trajetórias quando chega a cruzamentos até finalmente parar a propagação.

\subsubsection{Global}

Apesar de métodos por propagação de linha serem capazes de reconstruir todo o conjunto de dados, por exemplo definindo um ponto inicial por voxel, e considerarem uma vizinhança ao 
aplicarem interpolações a cada passo, o que é referido como tractografia global vai além dessas duas propriedades.

Os métodos de reconstrução global utilizam toda a informação fornecida pelo conjunto de dados, ao invés de uma vizinhança restrita para interpolação, e combinam essa informação com conhecimentos anatômicos, como suavidade da curvatura e ausência de terminações em certas regiões. Isso proporciona melhores resultados em regiões de incerteza, como os cruzamentos, para as quais é possível inferir pelas fibras vizinhas qual deve ser a direção a ser seguida.

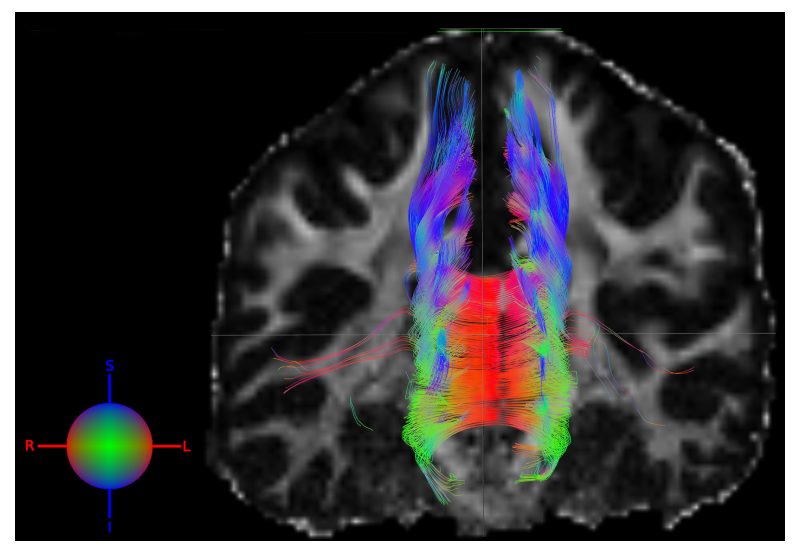

(a)

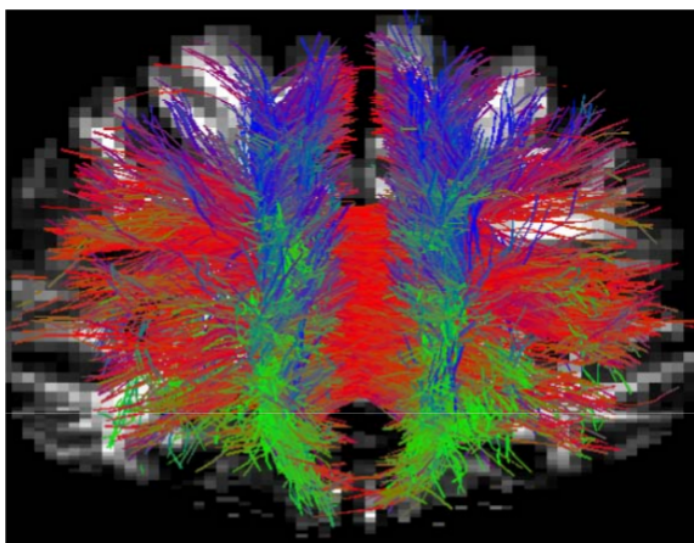

(b)

Figura 3.14: Resultados da tractografia partindo do corpus collosum do cérebro humano in vivo para diferentes métodos e em conjuntos de dados diferentes. (a) Método por integração numérica. Com critérios de parada em FA inferior a 0.2 e ângulo da fibra superior a $45^{\circ}$. Coloração de acordo com a direcionalidade, onde a os eixos superior $(S)$ e inferior (I) está na vertical, direita (R) e esquerda (L) na horizontal e a direção anterior está saindo da tela. (b) Resultado da tractografia por simulação de partículas reproduzido de $\left[R M A^{+} 11\right]$.

A simulação de partículas (3.12) é um exemplo de reconstrução das trajetórias de forma global. Sua robustez é exemplificada pelo resultado na figura 3.13b e pelo contraste demonstrado na figura 3.14 onde o método por simulação de partículas (Fig. 3.14b) reconstrói fibras com densidade muito maior $^{10}$.

Outra alternativa mais recente à simulação de partículas consiste de formular o problema como uma otimização convexa como proposto em [DDPLT] e expandido por [LSDP ${ }^{+} 14$ ] e [DDPLT15]. Tal método amostra exaustivamente fibras candidatas utilizando métodos conhecidos e robustos, como a evolução de frentes, mas que podem produzir na sua maioria falso positivos. Desse conjunto são escolhidas as fibras que melhor atendem às restrições aplicando otimização convexa.

\subsubsection{Probabilística}

Outro tipo de método são os denominados probabilísticos. Essa definição não diz respeito ao modelo de dados escolhido, mas sim ao resultado final que a princípio não é formado por fibras bem definidas. Esses métodos recebem como complemento à entrada regiões de interesse sobre as quais há o interesse de conhecer a probabilidade de se conectarem e por quais caminhos há maior probabilidade dessa conexão acontecer.

Após a execução, a saída é um novo volume para o qual cada voxel é associado a uma probabilidade de uma fibra passar por esse conectando as regiões de interesse. Com esse volume, uma reconstrução concreta de trajetórias é possível seguindo os caminhos de maior probabilidade através de, por exemplo, métodos de evolução de frentes [JKQ $\left.{ }^{+} 05\right]$. Uma das formas de visualizar esse volume e os resultados é como um mapa de calor.

\footnotetext{
${ }^{10} \mathrm{O}$ que cria o novo desafio de gerar visualizações mais informativas para reconstruções que chegam à ordem de $10^{6}$ fibras reconstruídas, como mencionado em $\left[\mathrm{GBC}^{+} 12\right]$.
} 


\subsubsection{Conceitos Base}

A seção 3.10 aborda o principal método matemático utilizado na propagação de linha. Para embasar os métodos de tractografia que serão detalhados à frente nas seções 3.13, 3.14 e 3.15, na seção 3.11 são detalhados os métodos de Monte Carlo utilizados para otimizar os diferente métodos de tractografia global por simulação de partículas.

\subsection{Método de Integração Numérica Runge-Kutta}

Seja $f^{\prime}$ o campo vetorial dado pela direção de maior difusividade de cada voxel da dMRI, $f$, sua primitiva, é a função que descreve as trajetórias a serem reconstruídas por métodos de tractografia. Como mencionado em 3.9.1, uma das formas de reconstruir $f$ aproximando-a utilizando métodos de integração numérica, como o de Runge-Kutta detalhado a seguir.

Dados um conjunto de pontos iniciais $P$, o valor de $f\left(P_{0}\right)$ para cada $P_{0} \in P$, um sistema de uma ou mais Equações Diferenciais Ordinárias (EDOs) em $f$ e um tamanho de passo $h$. Obter o valor de $f\left(P_{0}+h\right)$ é denominado Problema de Valor Inicial (PVI).

É um dos métodos para resolução de PVIs através da obtenção de uma aproximação para o valor de $f\left(P_{0}+h\right)$. Ele é uma generalização do Método de Euler através da aplicação de séries de Taylor [PTVF96]. Essa generalização nos permite a obtenção de diversas ordens do método, dentre as quais as mais comuns são 2 e 4, conhecidos como RK2 (ou, também, método do ponto médio) e $R K 4$.

Ambos os métodos possuem termos da ordem de uma potência de $h$. Estes termos são o erro associado ao método e, portanto, quanto menor o tamanho do passo, menor o erro do método.

Logo, dado um PVI conforme descrito acima com uma única equação diferencial $g=f^{\prime}$, temos os seguintes métodos definidos para apenas um ponto inicial, embora sua generalização para mais pontos consista apenas de sucessivas aplicações do mesmo método para cada ponto.

\subsubsection{Ordem 2}

Sejam $k_{1}$ e $k_{2}$ variáveis auxiliares, temos a seguinte expressão para o método de ordem 2:

$k_{1}=h \cdot g\left(P_{0}\right)$

$k_{2}=h . g\left(P_{0}+\frac{k_{1}}{2}\right)$

$f\left(P_{0}+h\right)=f\left(P_{0}\right)+k_{2}+O\left(h^{3}\right)$

\subsubsection{Ordem 4}

Sejam $k_{1}, k_{2}, k_{3}$ e $k_{4}$ variáveis auxiliares, temos a seguinte expressão para o método de ordem 4 :

$k_{1}=h . g\left(P_{0}\right)$

$k_{2}=h \cdot g\left(P_{0}+\frac{k_{1}}{2}\right)$

$k_{3}=h . g\left(P_{0}+\frac{k_{2}}{2}\right)$

$k_{4}=h . g\left(P_{0}+k_{3}\right)$

$f\left(P_{0}+h\right)=f\left(P_{0}\right)+\frac{k_{1}}{6}+\frac{k_{2}}{3}+\frac{k_{3}}{3}+\frac{k_{4}}{6}+O\left(h^{5}\right)$

\subsection{Métodos de Monte Carlo Utilizando Cadeias de Markov}

Métodos de Monte Carlo são métodos computacionais que utilizam amostragem aleatória de forma repetitiva para obter aproximações numéricas de integrais multidimensionais, simulações físicas e na otimização de modelos dos algoritmos de tractografia global por simulação de partículas.

O funcionamento desses consiste da definição de uma distribuição de probabilidades sobre a qual é definida uma cadeia de Markov ergódica cuja distribuição estacionária represente a solução do 
problema alvo. Sobre essa são tomadas amostras que, conforme sucessivas iterações são realizadas nessa cadeia, melhores são as aproximações da solução obtidas para o problema alvo.

Nas subsecções seguintes são apresentados os conceitos e métodos relevantes para a descrição da metodologia $(3.13,3.14,3.15)$ desse trabalho: Metropolis; arrefecimento simulado; e Gibbs.

\subsubsection{Cadeias de Markov}

Seja $X$ o estado de um sistema, definimos:

- seus $n$ possíveis estados são denotados $X_{0}, X_{1}, \ldots, X_{n}$;

- esse passa por $k$ mudanças de estado sucessivas através do tempo, denotadas $X_{(i, 0)}, X_{(i, 1)}, \ldots, X_{(i, k)}$ $\operatorname{com} i \in\{0,1, \ldots, n\}$;

- e regidas por distribuições de probabilidades $P\left(X_{(i, t+1)} \mid X_{(i, 0)}, \ldots, X_{(i, t)}\right) \operatorname{com} i \in\{0,1, \ldots, n\}$.

Tal processo é denominado uma Cadeia de Markov se, para cada instante $t$ a probabilidade de transicionar do estado $X_{(i, t)}$ para o estado $X_{(i, t+1)}$, não depende de nenhum outro estado anterior a $t$. Isso é formalmente denominado propriedade de Markov e expresso da seguinte forma:

$$
P\left(X_{(i, t+1)} \mid X_{(i, 0)}, \ldots, X_{(i, t)}\right)=P\left(X_{(i, t+1)} \mid X_{(i, t)}\right) \mid i \in\{0,1, \ldots, n\}
$$

Quando as probabilidades não dependem do instante $t$, a cadeia de Markov é dita homogênea e podemos denotar apenas como $P\left(X_{j} \mid X_{i}\right) \forall i, j \in\{0, \ldots, n\}$. Portanto, para descrever esse sistema são necessários seu estado inicial e as probabilidades de transição que podem ser descritas dentro da matriz $P$.

Uma distribuição de probabilidades sobre uma cadeia de Markov, $\pi$, é dita estacionária se satisfaz $\pi^{t} P=\pi^{t}$. Ou seja, uma vez atingida tal distribuição esta persiste para todos os instantes seguintes. Indo além, é definida uma cadeia de Markov ergódica aquela que para qualquer estado $X_{i, t}$ quando $t \rightarrow$ inf esta tende à distribuição estacionária $\pi$.

\subsubsection{Amostragem de Metropolis}

Primeiro definido por Metropolis em [MRR $\left.{ }^{+} 53\right]$ e depois expandido por Hastings em [Has70] e por Green em [Gre95], o algoritmo de Metropolis-Hastings-Green se provou útil para o caso onde a amostragem direta da função densidade de probabilidade é difícil por conter integrais para as quais não há solução analítica. Por meio de uma sequência de amostras aleatórias da função, é possível aproximar o histograma da distribuição e realizar o cálculo de integrais. De suas muitas aplicações constam exemplos como a simulação geofísica, renderização em computação gráfica e a tractografia por simulação de partículas $\left[\mathrm{RMA}^{+} 11\right]$.

Para simulação de sistemas, dada a função distribuição de probabilidade $P(X)$, é definida outra função densidade de probabilidades condicional (geralmente uma Gaussiana) $G\left(X_{t} \mid X_{t-1}\right)$ do estado atual ser $X_{t}$ dado que o anterior foi $X_{t-1}$. Então, o método inicia em um estado $X_{0}$ (pode ser aleatório ou definido de acordo com o problema) e é gerado um novo estado candidato $X_{1}$ com probabilidade $G\left(X_{1} \mid X_{0}\right)$. Computada a razão $R=\frac{P\left(X_{1}\right)}{P\left(X_{0}\right)} \frac{G\left(X_{0} \mid X_{1}\right)}{G\left(X_{1} \mid X_{0}\right)}$, o estado $X_{1}$ substitui $X_{0}$ nos seguintes casos:

- se $R \geq 1$;

- se $R<1$, aceita com probabilidade $R$.

Caso nenhum dos casos se concretize, $X_{1}$ é descartado e $X_{0}$ é aceito.

A probabilidade $P\left(X \mid X^{\prime}\right)$, transicionar de $X^{\prime}$ para $X$, depende da função de energia $E(X)$ (definida de acordo com cada problema) e é dada por $P(X)=e^{-\left(E(X)-E\left(X^{\prime}\right)\right)}$. 


\subsubsection{Arrefecimento Simulado}

Baseado na ideia de redução gradual da temperatura, arrefecimento simulado (simulated annealing) [Kir84], nos processos químicos de polimerização e metalúrgico para formar ligas mais resistentes, este método é uma modificação de Metropolis (3.11.2) que adiciona o conceito de temperatura ao critério de aceitação para modificações ao sistema.

Portanto, a simulação começa com temperaturas altas que dão maior probabilidade a modelos errados, permitindo que a busca percorra o espaço de soluções, mas a redução gradual dessa temperatura reduz tal probabilidade de forma que ao fim da simulação essa convirja para um máximo.

Nesse caso, a probabilidade $P\left(X \mid X^{\prime}\right)$ passa a ser definida por por $P(X)=e^{-\left(E(X)-E\left(X^{\prime}\right)\right) / T}$ para a energia $T$ do sistema. Portanto, a mesma expressão de Metropolis para $T=1$.

\subsubsection{Amostragem de Gibbs}

Outro caso especial da amostragem de Metropolis, a amostragem de Gibbs [GG84] recebeu essa nomenclatura de seus autores devido à analogia à física estatística. Nela, o processo de produção do modelo sucessor é o responsável por aproximar a amostra da distribuição de probabilidades estudada. Assim, as modificações são sempre aceitas com $R=1$. Isso é possível por meio da amostragem condicional de cada dimensão da distribuição de probabilidades.

Suponha que o objetivo seja amostrar uma distribuição $X$ com $n$ dimensões tal que $X=$ $\left(x_{0}, x_{1}, \ldots, x_{n}\right)$ cuja amostragem direta não é possível. Para produzir essa amostra é preciso maximizar a probabilidade $P(X)=P\left(x_{0}, x_{1}, \ldots, x_{n}\right)$ que, assim como amostrar $X$ diretamente, não é possível de ser calculada diretamente. Por outro lado, para cada $i \in \mathbb{N}$ tal que $i \leq n$ é possível calcular $P\left(x_{i} \mid x_{0}, x_{1}, \ldots, x_{i-1}, x_{i+1}, \ldots, x_{n}\right)$. Nesse caso, o processo de amostragem de Gibbs é aplicável de acordo com o seguinte procedimento:

- Inicialize uma amostra $X_{0}$ (uma possibilidade é tomar valores aleatórios no domínio da distribuição)

- Para obter $X_{1}$, repita $k$ vezes o processo abaixo

- Para cada $i \in \mathbb{N}$ tal que $i \leq n$, tome um $x_{i}$ aleatório

* aceite $x_{i}$ com probabilidade $P\left(x_{i} \mid x_{0}^{1}, x_{1}^{1}, \ldots, x_{i-1}^{1}, x_{i+1}^{0}, \ldots, x_{n}^{0}\right)$

* caso seja rejeitado, tome um novo $x_{i}$ aleatório e repita o teste anterior

Ao fim, $X_{1}$ é uma amostra da distribuição $X$. O parâmetro $k$ é definido de acordo com a distribuição sendo estudada e sua complexidade. Para produzir boas amostras, o valor de $k$ devendo ser grande o bastante. A fim de obter amostras mais prováveis é possível repetir esse procedimento de modo que ao fim de cada iteração $X_{0}$ assume o valor de $X_{1}$ da iteração anterior.

Na literatura esse método é aplicado para solução de problemas de inferência estatística.

\subsection{Tractografia Global por Simulação de Partículas}

Métodos globais tentam reconstruir todas as fibras simultaneamente, como parte de um único sistema, de forma que em regiões de incerteza o erro é eliminado ou suavizado por influência das demais fibras na adjacência. Uma das formas de implementar tais métodos é modelando as fibras como um conjunto de partículas que se interconectam e aplicar processos de otimização a fim de obter o modelo que melhor se adapte aos dados de entrada.

O primeiro a ganhar notoriedade por tal abordagem é o método baseado em jarros de spins (spin glass $\left.\left[\mathrm{MPC}^{+} 02\right]\right)$ que introduziu o conceito de posicionar um spin no centro de cada voxel para os quais as orientações variam. Esses estão sujeitos a duas forças complementares cujo objetivo é combinar as informações de estruturas locais (dados de RM) com conhecimento prévio da anatomia (ausência de curvas acentuadas). Tal método foi expandido em [FPM09] adicionando capacidade para movimentação e rotação dos spins e sua duplicação. Essa evolução permite convergência mais 
rápida para modelos fiéis e uma melhor qualidade por meio da densidade variável de spins como descrito na seção 3.13 .

Outra família de métodos, nessa mesma linha de segmentos que se conectam para formar estruturas complexas, são os baseados nos processos de polimerização e da física estatística denominado Gibbs-tracking [KMK08]. Tal método modela as fibras em pequenos segmentos com posição, orientação e densidade que variam continuamente. Para reconstruir todas as trajetórias do cérebro humano esse método consumiu um mês devido à sua alta complexidade computacional em relação ao tempo e falta de escalabilidade.

Estendendo o Gibbs-tracking, Reisert [RMK09a, RMK09b, RMA $\left.{ }^{+} 11\right]$ melhora tais métodos para um dia de processamento. Tal ganho advém da mesclagem da abordagem global com a local que é utilizada para aproximar as soluções ótimas locais no sistema. Esse método é descrito em detalhes na seção 3.14.

Retomando os objetivos desse trabalho (2.1) e após estudar a fundo os principais métodos de tractografia por simulação de partículas detalhados nas duas próximas seções (3.13 e 3.14), esses métodos como definidos abaixo apresentam espaço para redução de desperdícios de computação. A seção 3.15 se dedica a detalhar a nova metodologia de redução dos custos computacionais na qual foram tomados os melhores elementos da metodologia por jarros de spin, da metodologia de polimerização e criadas outras soluções inéditas para compor um algoritmo baseado em etapas de simulação.

\subsection{Jarros de Spin}

Nesse método, $N$ pequenos segmentos de fibra com posição $p \in \mathbb{R}^{3}$ e tangente $t \in \mathbb{S}_{2}$, denominados spins, são criados dentro de um domínio $X$ denominado como jarro. Esse domínio na prática é a máscara que representa a região de interesse, como a substância branca cerebral. O posicionamento de cada spin pode seguir três estratégias diferentes com crescentes graus de liberdade e complexidade:

- agulha de bússola: um spin é posicionado no centro de cada voxel e apenas sua orientação e conexões com vizinhos são sujeitos à otimização;

- spin quicando (bouncing spin): adiciona a liberdade das posições de cada spin variar dentro do voxel;

- adaptativo: permite mais de um spin por voxel.

No trabalho mais recente [FPM09] todos os graus de liberdade descritos para a modelagem são adotados. A otimização desse modelo por este método é feita utilizando três potenciais ${ }^{11}$ :

- difusão: atua como um campo magnético externo atraindo os spins para as direções principais dos dados de difusão;

- interação: pressiona o modelo a formar cadeias longas de spins interconectados e de curvatura mínima;

- generativa: impede que uma cadeia de spins termine dentro do domínio $X$.

Para isso o método faz apenas duas suposições sobre a anatomia sendo estudada: as fibras possuem baixa curvatura e não terminam em regiões de substância branca.

A otimização ocorre primeiro apenas com os potenciais de difusão e interação até o modelo atingir a estabilidade. A partir de onde apenas o potencial generativo entra em ação para preencher possíveis lacunas do modelo criando spins para cadeias que terminem dentro da região de matéria branca e mesclando cadeias compatíveis entre si.

\footnotetext{
${ }^{11}$ No método original, $\left[\mathrm{MPC}^{+} 02\right]$, apenas os dois primeiros potenciais são utilizados.
} 


\subsection{Processo de Polimerização e Física Estatística}

A comparação com a física estatística (e seu nome em homenagem ao físico Josiah Willard Gibbs) advém da modelagem adotada para os potenciais de energia que servem como função objetivo para este método de tractografia. Assim como na termodinâmica, essas funções de energia (3.11 e 3.14) traduzem para a tractografia global princípios como minimização da energia quando o sistema atinge o equilíbrio e homogeneidade de partículas próximas.

Por sua vez, a comparação com o processo de polimerização vem do método de otimização escolhido para minimizar a energia descrita anteriormente. Esse método, o arrefecimento simulado (3.11.3), se baseia em iniciar com uma temperatura alta, proporcionando alta variabilidade no sistema, que é reduzida gradualmente até a otimização parar. Isso faz com que o sistema tenha oportunidade de explorar configurações diferentes (altas temperaturas) durante o processo e conforme se aproxima do fim convergir para um modelo refinado (baixas temperaturas).

O método completo é detalhado a seguir com uma descrição teórica do que é encontrado nos artigos publicados, aprofundando passagens e pormenores não mencionados nas publicações, mas que durante o desenvolvimento desse trabalho e dos testes foram possíveis de descobrir. Em seguida, é analisada a implementação computacional disponibilizada que reflete o publicado [RMK09a, RMK09b, RMA ${ }^{+}$11] e serviu como base para compreensão ainda mais profunda da teoria envolvida.

\subsubsection{Descrição Teórica}

A metodologia de otimização para este método de tractografia, baseada no Teorema de Bayes e na otimização por Metropolis-Hastings (3.11.2), possui diversos detalhes que serão descritos a seguir partindo da modelagem como um sistema de fibras e fórmulas para cálculo das funções de energias interna e externa deste sistema. Por fim, é descrito o processo de otimização que apresenta quatro proposições diferentes que são testadas a cada iteração.

\section{Modelagem}

Como se trata de uma metodologia global, o objetivo é modelar todas as trajetórias existentes nos dados. Tais trajetórias são divididas em numerosos fragmentos de fibras, aos quais nos referiremos como partículas ${ }^{12}$, das quais cada pode ter arestas para outras duas partículas. O conjunto de partículas, denotado por $Y$, e o conjunto de arestas, denotado por $\varepsilon$, formam um modelo que denotaremos por $X$.

Cada fragmento $y_{i}$ possui as seguintes características (ilustradas na Fig. 3.15):

- posição $p \in \mathbb{R}^{3}$;

- orientação $t \in \mathbb{S}_{2} ;{ }^{13}$

- comprimento $l$;

$$
\begin{aligned}
& \text { - com início em } y^{-}=p-\frac{l}{2} t \\
& \text { - e fim em } y^{+}=p+\frac{l}{2} t .
\end{aligned}
$$

\footnotetext{
${ }^{12} \mathrm{E}$ em 3.13 foram chamados de segmentos de fibra.

${ }^{13} \mathbb{S}_{2}$ denota o espaço das coordenadas esféricas
} 


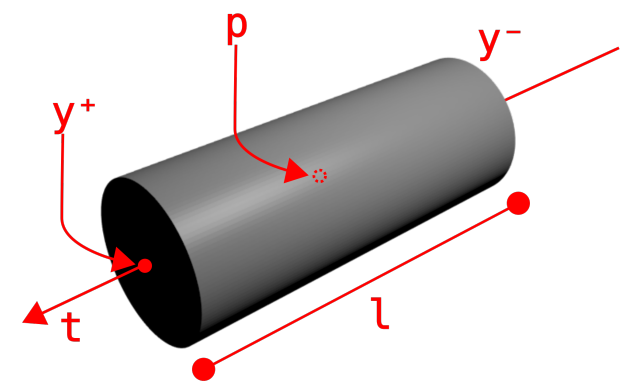

Figura 3.15: Fragmento modelado como um cilindro com origem (p), direção (t) e comprimento (l).

E cada aresta em $\varepsilon$ é um par $\left(y_{1}^{\alpha_{1}}, y_{2}^{\alpha_{2}}\right)$ onde:

- $y_{i} \in Y$;

- $\alpha_{i} \in\{+,-\}$.

Finalmente o objetivo com este modelo é maximizar a probabilidade do modelo, $X$, produzido ser fidedigno dadas as informações da dMRI, $D$, que por Bayes expressamos como:

$$
P(X \mid D)=\frac{1}{Z} e^{-E_{\text {int }}(X)-E_{\text {ext }}(X, D)}
$$

Onde $Z$ denota a função de particionamento, $E_{\text {int }}$ a energia interna e $E_{\text {ext }}$ a energia externa. A energia interna tem como objetivo pressionar o modelo a conter conexões de baixa curvatura e que não sejam muito longas ${ }^{14}$. Por sua vez a externa pressiona o modelo a conter partículas com posição e orientação fidedignos aos dados de dMRI e que essas possuam uma certa homogeneidade e espaçamento entre si.

Em [CRD $\left.{ }^{+} 14\right]$ é apresentada uma extensão para a expressão de energia que leva em consideração um atlas de trajetórias reconstruídas previamente para sujeitos independentes. Tal atlas reduziu falso positivos e forneceu informações quanto a diferenças entre os sujeitos. Por outro lado, o registro de imagens necessário é suscetível à introdução de novos artefatos à reconstrução e é mais passo para elevar o tempo necessário.

\section{Energia Interna}

A energia interna, $E_{i n t}$, é dada pela seguinte expressão:

$$
E_{\text {int }}=\lambda_{\text {int }} \sum_{\left(y_{1}^{\alpha_{1}}, y_{2}^{\alpha_{2}}\right) \in \varepsilon} U_{\text {con }}\left(y_{1}^{\alpha_{1}}, y_{2}^{\alpha_{2}}\right)
$$

Onde $\lambda_{i n t}$ é o peso dado à energia interna (um parâmetro de entrada do algoritmo) e $U_{c o n}$ representa o potencial de interação entre duas partículas com expressão dada por:

$$
U_{\text {con }}\left(y_{1}^{\alpha_{1}}, y_{2}^{\alpha_{2}}\right)=\frac{1}{l^{2}}\left(\left\|p_{1}+\alpha_{1} l t_{1}-\bar{p}\right\|^{2}+\left\|p_{2}+\alpha_{2} l t_{2}-\bar{p}\right\|^{2}\right)+L
$$

Onde finalmente $L$ representa o viés ${ }^{15}$ e $\bar{p}=\frac{p_{1}+p_{2}}{2}$.

\footnotetext{
${ }^{14}$ No trabalho de [SRA10] é apresentado um outro critério que leva em conta a consistência de informações da microestrutura da fibra para isso. Esse critério tem um amparo biológico mais forte segundo o trabalho.

${ }^{15} \mathrm{O}$ viés na fórmula de energia externa trabalha como uma folga para que conexões imperfeitas sejam aceitas. Quanto maior o valor de $L$, maior o grau de imperfeição aceito.
} 


\section{Energia Externa}

Para definir a expressão de energia externa, primeiro definimos $F_{M}: \mathbb{R}^{3} \times S_{2} \rightarrow \mathbb{R}$ a função que para posições no espaço e orientações numa esfera unitária fornece o sinal previsto de acordo com o modelo $M$ contendo $N$ partículas:

$$
F_{M}(p, t)=w \sum_{i=1}^{N} e^{-c\left(t^{t} t_{i}\right)^{2}} e^{\frac{-\left|p-p_{i}\right|^{2}}{\sigma^{2}}}
$$

Onde $\sigma$ diz respeito ao desvio padrão (largura da Gaussiana) usado para ponderar a contribuição de cada partícula, $c$ é a largura da fibra e $w$ o peso dado à contribuição de todas as fibras. Essa expressão é baseada no modelo de tensor de difusão (3.6).

Assim a energia externa, onde $D$ é o sinal ponderado por difusão fornecido como entrada, é dada por:

$$
\begin{array}{r}
E_{\text {ext }}(M, D)=\lambda_{\text {ext }}\left\|F_{M}-D\right\|^{2}= \\
\lambda_{\text {ext }} \int_{\mathbb{R}^{3} \times S_{2}}\left|F_{M}(p, t)-D(p, t)\right| \partial^{3} p \partial^{2} t
\end{array}
$$

Como para minimizar esta energia apenas o valor total da diferença é necessário, e não cada um de seus termos, podemos escrever:

$$
E_{\text {ext }}=\left\|F_{M}\right\|^{2}-2\left\langle F_{M}, D\right\rangle+\|D\|^{2}
$$

Onde:

- $\| F_{M}||^{2}=C w^{2} \sum_{i=1}^{N} \sum_{j=1}^{N} I_{0}\left(c\left|t_{i}^{t} t_{j}\right|\right) e^{\frac{-\left|p_{i}-p_{j}\right|^{2}}{2 \sigma^{2}}}$

- $\left\langle F_{M}, D\right\rangle=\sum_{i=1}^{N} \int_{\mathbb{R}^{3} \times S_{2}} e^{-c\left(t^{t} t_{i}\right)^{2}} e^{\frac{-\left|p-p_{i}\right|^{2}}{\sigma^{2}}} D(p, t) \partial^{3} p \partial^{2} t=C w \sum_{i=1}^{N} D^{e f f}\left(p_{i}, t_{i}\right)$

- $D^{\text {eff }}$ é a convolução do sinal com $e^{-c\left(t^{t} t_{i}\right)^{2}} e^{\frac{-\left|p-p_{i}\right|^{2}}{\sigma^{2}}}$, que para $\sigma$ pequeno e $c$ grande é a ODF resultante da transformada Funk Radon (FRT)

Indo mais a fundo:

$$
I_{0}\left(c\left|t_{i}^{t} t_{j}\right|\right)=\int_{S_{2}} e^{-c\left(t^{t} t_{i}\right)^{2}} e^{-c\left(t^{t} t_{j}\right)^{2}} \partial t
$$

Em $\left[\mathrm{CRD}^{+} 15\right]$ a expressão para energia externa é modificada por meio de convoluções de bases de harmônicos esféricos que permitem levar em conta o efeito de volume parcial de outros tipos de tecido no sinal e diferenciar os diferentes tipos de tecido. Assim a necessidade de uma máscara inicial é dispensada e a acurácia é quantitativamente superior.

\section{Aplicação da Amostragem de Metropolis-Hastings}

Para o método foi aplicada uma derivação do algoritmo de Metropolis-Hastings (3.11.2) conhecida como cadeia de Markov Monte Carlo com saltos reversíveis (Metropolis-Hastings-Green [Gre95] ou ainda arrefecimento simulado, em inglês simulated annealing).

De forma simplificada dado um modelo atual $X$, é proposta uma modificação a este gerando um novo modelo $X^{\prime}$. Esta modificação aplicada segue para uma proposição com distribuição de 
probabilidade $P^{\text {prop }}$. Para avaliar se este novo modelo substituirá o anterior, é calculada a razão de Green, $R$, da seguinte forma:

$$
R=\left(\frac{P\left(X^{\prime} \mid D\right)}{P(X \mid D)}\right)^{\frac{1}{T}} \frac{P^{\text {prop }}\left(X^{\prime} \mid D\right)}{P^{p r o p}(X \mid D)}
$$

Onde $T$ é a temperatura que decai a cada iteração deste método.

Finalmente a modificação é aceita se $R \geq 1$. Caso contrário, ela ainda pode ser aceita mas com probabilidade $R$. Seguindo este método, após um número de iterações, a cadeia de modelos resultantes segue a distribuição desejada.

Nesta abordagem, as proposições utilizadas e que detalharemos a seguir são: criação de partícula $\left(P^{\text {birth }}\right)$; remoção de partícula $\left(P^{\text {death }}\right)$; movimentação de partícula $\left(P^{\text {shift }}\right)$; movimento ótimo de partícula $\left(P^{o p t}\right)$; e conexão de partículas $\left(P^{f i b r e}\right)$. Estas probabilidades são constantes reais definidas a priori em $[0,1]$ e cuja soma é 1.

Em um trabalho posterior $\left[\mathrm{RKD}^{+} 14\right]$ são adicionadas duas novas proposições referentes a características mesoestruturais (parâmetros de difusividades axial e radial e frações de volumes de água restritos intra-axonais e extra-axonais) de cada partícula. Como não dizem respeito à proposição de reconstrução de fibras, tais proposições não serão aprofundadas aqui.

\section{Proposições de Criação ou Remoção de Partículas}

Para criação da partícula $y$ lhe são atribuídos aleatoriamente uma posição $p$ e direção $t$ com a razão de Green sendo neste caso:

$$
R=\frac{e^{\frac{-E(X+y)}{T}}}{e^{\frac{-E(X)}{T}}} \frac{\lambda}{N+1} \frac{P^{\text {birth }}}{P^{\text {death }}}
$$

Onde:

- $E=E_{\text {int }}+E_{\text {ext }}$ é a energia total do modelo;

- $X^{\prime}=X+y$ denota o modelo $X$ acrescido da partícula $y$.

De forma análoga, para a remoção é escolhida uma partícula $y$ do conjunto $Y$ aleatoriamente para remoção. A razão de Green para este caso é:

$$
R=\frac{e^{\frac{-E(X-y)}{T}}}{e^{\frac{-E(X)}{T}}} \frac{N}{\lambda} \frac{P^{\text {death }}}{P^{\text {birth }}}
$$

Para ambas as equações, $\lambda$ é o parâmetro da distribuição de Poisson que rege quantas partículas fazem parte do modelo. Essa pode ser interpretada como o número esperado de partículas no sistema quando em estabilidade.

\section{Proposição de Movimentação de Partículas}

No movimento aleatório, que ocorre com probabilidade $P^{\text {shift }}$, são gerados aleatoriamente novas posição $p^{\prime}$ e orientação $t^{\prime}$ para uma partícula $y \in Y$ escolhida aleatoriamente. Dadas essas modificações, a razão de Green é:

$$
R=\frac{e^{\frac{-E\left(X^{\prime}\right)}{T}}}{e^{\frac{-E(X)}{T}}} \frac{P_{p^{\prime}, t^{\prime}}^{p r o p}(p, t)}{P_{p, t}^{p r o p}\left(p^{\prime}, t^{\prime}\right)}
$$

Onde $P^{\text {prop }}$ é a distribuição de probabilidades Gaussiana também utilizada para gerar $p^{\prime}$ e $t^{\prime}$.

Já para o movimento ótimo, que ocorre com probabilidade $P^{o p t}, p^{\prime}$ e $t^{\prime}$ são obtidos de forma a encontrar o ótimo para esta partícula com relação à energia interna de acordo com um de dois casos: 
1. quando apenas uma terminação da partícula é conectada outra partícula $y$

- $p^{\prime}=p_{y}+l t_{y}$

- $t^{\prime}=t_{y}$

2. quando ambas terminações possuem conexões com $y_{1}$ e $y_{2}$

- $p^{\prime}=\frac{p_{y_{1}}+\frac{l}{2} t_{y_{1}}+p_{y_{2}}+\frac{l}{2} t_{y_{2}}}{2}$

- $t^{\prime}=\frac{p_{y_{2}}-p_{y_{1}}}{\left|p_{y_{2}}-p_{y_{1}}\right|}$

Finalmente, a razão de Green para o movimento ótimo é dada por:

$$
R=\frac{e^{\frac{-E\left(X^{\prime}\right)}{T}}}{e^{\frac{-E(X)}{T}}} \frac{P^{\text {shift }} P_{p, t}^{\text {prop }}(p, t)}{P^{\text {shift }} P_{p, t}^{\text {prop }}\left(p^{\prime}, t^{\prime}\right)+P^{o p t}}
$$

\section{Proposição de Conexão de Partículas}

Para esta proposição é preciso antes definir o conceito de segmento de fibra: um conjunto ordenado de conexões $f i b=\left(E_{1}, E_{2}, \ldots\right)=\left(\left(y_{1}^{\alpha_{1}}, y_{2}^{\alpha_{2}}\right),\left(y_{2}^{\alpha_{2}}, y_{3}^{\alpha_{3}}\right), \ldots\right)$ em $\varepsilon$. E o conceito de fibra pendente: o segmento de fibra mais longo com início em uma dada partícula $y \in Y$ na direção $\alpha$.

Então, são escolhidos aleatoriamente uma partícula $y \in Y$ e uma orientação $\alpha \in\{+,-\}$. Sejam $f i b^{\text {old }}$ a fibra pendente em $y^{\alpha}$ e $X$ a configuração sem esta fibra, uma nova fibra fib ${ }^{\text {prop }}$ é amostrada com distribuição de probabilidades $P_{X}^{f i b r e}$ fazendo parte do novo modelo $X^{\prime}$. $X^{\prime}$ será aceito sobre $X$ de acordo com a seguinte expressão para a razão de Green:

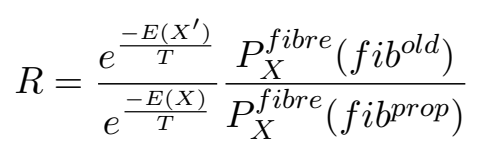

\section{Amostragem de Fibra}

O que antes foi apenas mencionado como amostragem de fibra sem maiores detalhes, na verdade é um processo de traçado que agora será aprofundado.

Dadas uma partícula $y \in Y$ e uma orientação $\alpha \in\{+,-\}$, para o primeiro passo do traçado é iniciada uma busca dentro do conjunto $S \subseteq Y$ : o conjunto de todas as partículas livres um uma esfera com centro $p+\alpha l t$ e raio $l$. Dentro deste conjunto formado, um novo sucessor é amostrado com probabilidade $P^{s u c}(s)=\frac{1}{Z} e^{\frac{-U_{c o n}\left(y_{0}^{\alpha}, S\right)}{T_{p r o p}}}$ para $s \in S$. Caso $S$ seja vazio, o procedimento para. Por último, há a probabilidade do procedimento nem ter inicio: $1 / Z$.

Onde:

- $Z=1+\sum_{s \in S} e^{\frac{-U_{c o n}\left(y_{0}^{\alpha}, S\right)}{T_{p r o p}}}$

- $P_{X}^{f i b r e}(f)=\prod_{k=0}^{n-1} p^{s u c}\left(y_{k}^{\alpha_{k}}\right)$

\subsubsection{Algoritmo Básico}

Posta esta base teórica é possível definir o algoritmo simplificado para a metodologia: 


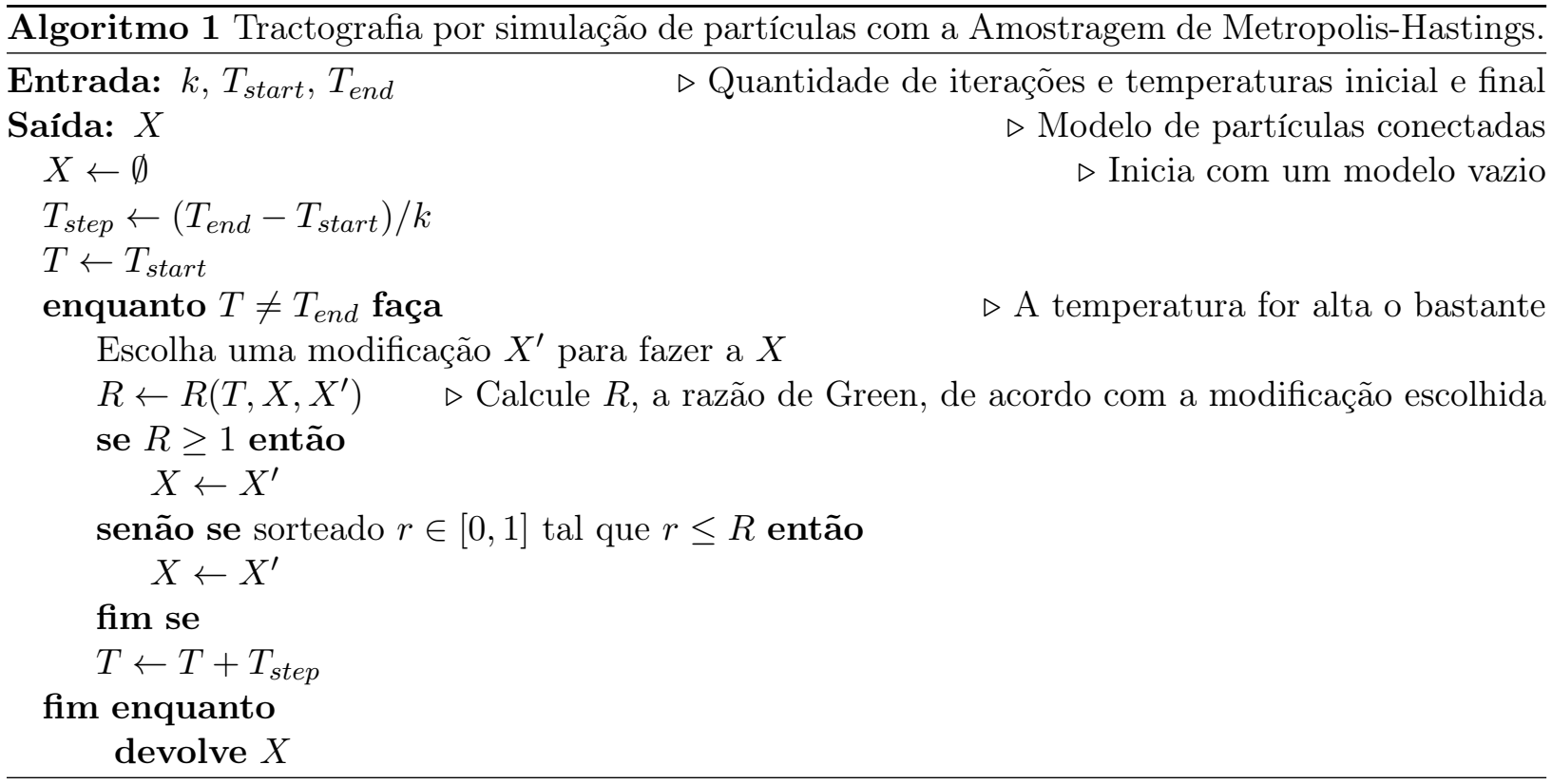

No laço principal o que é referido como temperatura é a constante $T$ da equação 3.17. Ela é inicializada por uma constante (configurável pelo usuário) e a cada passo é reduzida até um determinado valor também constante (e determinável pelo usuário).

\section{Implementação}

Como muitos artigos que possuem uma definição teórica e uma implementação utilizada em testes, o artigo de Reisert $\left[\mathrm{RMA}^{+} 11\right]$ foca no desenvolvimento teórico que foi exposto na subseção 3.14.1 em detrimento de detalhes sobre as otimizações realizadas na implementação.

Tal artigo menciona que sua reconstrução do cérebro humano contou com $3.5 \times 10^{6}$ partículas. Uma implementação em $\mathrm{C}++$, feita como parte deste trabalho, seguindo as definições encontradas no artigo leva um tempo estimado em 30 horas para avaliar apenas a energia deste modelo em um processador Intel Core 2 Duo E7400 a $2.8 \mathrm{GHz}$. Por outro lado, foram realizadas $5 \times 10^{8}$ iterações em 12 horas para chegar nesse modelo com essa quantidade de partículas de acordo com o artigo. Levando a um tempo bastante reduzido por iteração para, além de avaliação de energia, cálculo de proposições para o método de Metropolis-Hastings e interpolações.

Esses tempos incompatíveis se dão justamente pela mencionada diferença entre a descrições teórica da metodologia e as otimizações utilizadas na implementação utilizada para os testes no artigo. Felizmente a implementação é disponibilizada pelo autor na forma da ferramenta Fibertools ${ }^{16}$ que vem em código Matlab com extensões em $\mathrm{C}+{ }^{+17}$. Então por meio do estudo deste programa, a seguir, serão listadas otimizações encontradas e seus paralelos na descrição teórica para os cálculos de energia que se mostraram o gargalo de processamento nos testes.

\section{Energia Interna}

O cálculo de energia interna é implementado mais próximo da definição teórica com a única adição de impor penalidades no valor da energia, retornando valor $-\infty$, nos seguintes casos:

- baixa probabilidade de existência espacial

- criação de partícula fora dos limites da máscara fornecida

- alta curvatura

\footnotetext{
${ }^{16}$ http://www.uniklinik-freiburg.de/mr-en/research-groups/diffperf/fibertools.html acessado pela última vez em $24 / 03 / 2015$

${ }^{17}$ Outra implementação disponível do algoritmo implementado está na ferramenta MITK [NSR $\left.{ }^{+} 12\right]$
} 
- sejam $n_{0}$ e $n_{1}$ as direções de duas partículas se conectando

- e sejam $\alpha_{0}$ e $\alpha_{1}$ em $\{1,-1\}$ os sinais das respectivas conexões

- a penalidade é aplicada se $\left(t_{0} t_{1}\right)\left(\alpha_{0} \alpha_{1}\right)<-0.7$, ou seja se o ângulo formado pelas partículas for superior a aproximadamente 45 graus

- conexão muito longa

- sejam $p_{0}$ e $p_{1}$ as posições de duas partículas se conectando

- e sejam $\alpha_{0}$ e $\alpha_{1}$ em $\{1,-1\}$ os sinais das respectivas conexões

- a penalidade é aplicada caso $\left|\left(p_{0}+\alpha_{0} \frac{l}{2}\right)-\left(p_{1}+\alpha_{1} \frac{l}{2}\right)\right|>\left(\frac{l}{2}\right)^{2}$

\section{Energia Externa}

Para a energia externa a mesma penalidade para probabilidade espacial existe, mas é nesta onde se encontra a maior disparidade para a definição teórica. Sua implementação é definida para avaliar uma dada partícula $y_{i}$ iterando pelos seus vizinhos próximos, $y_{j}$, tais que $\left\|p_{i}-p_{j}\right\| \sim \sigma$.

Nessa implementação, o termo $I_{0}$ da equação 3.16 é implementado com a função Bessel modificada de ordem 0, que é mais rápida de avaliar que a integral da equação. Por outro lado, essa passagem não foi provada formalmente e essa afirmação se baseia em observações empíricas. De forma similar, os dados de dMRI alvo de deconvolução em 3.14.1, são sempre aproximados para a ODF.

\section{Computação Incremental da Variação de Energia}

Como o modelo é construído gradualmente por pequenas modificações de acordo com o processo de arrefecimento simulado, a computação dos valores de energia atual e do modelo modificado são necessárias para definir o critério de aceitação do novo modelo. Porém, a computação para o modelo completo, como descrita na subseção 3.14.1, consome muitos recursos e não é viável de ser repetida para cada iteração do método. Para isso, de acordo com a proposição aplicada, essas energias são computadas incrementalmente de forma a não desperdiçar computações anteriores. A seguir, para cada proposição, é definida a expressão para energia do modelo modificado, $E\left(X^{\prime}\right)$, de acordo com a energia do modelo atual, $E(X)$.

Para a criação de uma partícula $y$ tal que $X^{\prime}=X+y$ apenas incide a energia externa cuja variação é dada pela equação:

$$
E_{b i r t h}(X, y)=C w\left[\sum_{x \in X^{\prime}} I_{0}\left(c\left|t_{x}^{t} t_{y}\right|\right) e^{\frac{-\left|p_{x}-p_{y}\right|^{2}}{2 \sigma^{2}}}\right]-2 O D F(y)
$$

A computação no caso de remoção de uma partícula $y$ tal que $X^{\prime}=X-y$ consiste da operação inversa à de criação acrescida do desconto de eventuais conexões formadas com $y$ por outras duas partículas $^{18}, y_{0}$ e $y_{1}$ :

$$
E_{\text {death }}(X, y)=-\left[E_{\text {birth }}(X, y)+U_{\text {con }}\left(y_{0}, y\right)+U_{\text {con }}\left(y_{1}, y\right)\right]
$$

A expressão para movimentação ${ }^{19}$ de uma partícula $x \in X$, denotada por $x^{\prime} \in X^{\prime}$ após a operação, também aproveita as expressões anteriores:

$$
E_{\text {shift }}\left(X, x^{\prime}\right)=E_{\text {death }}(X, x)+E_{\text {birth }}\left(X, x^{\prime}\right)+U_{\text {con }}\left(x_{0}, x^{\prime}\right)+U_{\text {con }}\left(x_{1}, x^{\prime}\right)
$$

Por último, quando há mudança no conjunto de conexões essa é dada por um par fibras $f i b^{\text {old }} \in$ $X$ e $f i b^{p r o p} \in X^{\prime}$ para $X^{\prime}=X-f^{o l d}+f^{\text {prop }}$. Retomando a definição dada à proposição de conexão

\footnotetext{
${ }^{18}$ Se alguma das conexões não existir, o termo correspondente na soma é 0 .

${ }^{19} \mathrm{O}$ movimento ótimo é um caso particular para o qual a mesma expressão vale.
} 
feita em 3.14.1, essas fibras são compostas por uma sequência de pares de partículas $\left(x_{i}^{\alpha_{i}}, x_{j}^{\alpha_{j}}\right)$ tais que $x \in X$ e $\alpha \in\{+,-\}$. Nesse caso, a variação da energia é dada por:

$$
E_{\text {fibre }}\left(f^{\text {old }}, f^{\text {prop }}\right)=\left[\sum_{\left(x_{i}^{\alpha_{i}}, x_{j}^{\alpha_{j}}\right) \in f^{\text {prop }}} U_{\text {con }}\left(x_{i}^{\alpha_{i}}, x_{j}^{\alpha_{j}}\right)\right]-\left[\sum_{\left(x_{i}^{\alpha_{i}}, x_{j}^{\alpha_{j}}\right) \in f^{\text {old }}} U_{\text {con }}\left(x_{i}^{\alpha_{i}}, x_{j}^{\alpha_{j}}\right)\right]
$$

Finalmente a expressão geral para computar a energia do modelo modificado de acordo com a proposição é: $E\left(X^{\prime}\right)=E(X)+E_{\text {prop }}\left(X, X^{\prime}\right)$. Onde $E_{\text {prop }}$ se refere a uma das expressões detalhadas anteriormente.

\subsection{Método de Tractografia Global por Simulação de Partículas em Grade com Autocorreção}

O novo método a ser detalhado é denominado tractografia global por Simulação de pArtículas em Grade com Autocorreção (referenciado pelo acrônimo SAGA durante este trabalho). Ele é dividido em etapas de simulação que são listadas a seguir e detalhadas nas subseções seguintes:

1. representação do modelo em forma de grade;

2. inicialização da grade com partículas que representem a maior parte da direcionalidade dos dados;

3. criação de conexões na grade e movimentação restrita de partículas;

4. armazenamento do histórico de conexões;

5. correção dos modelo de acordo com histórico;

6. checagem por fibras com terminação inválida no modelo;

7. adição de novas partículas ao modelo;

8. representação dos resultados em termos de curvas suaves.

Essa separação tem como objetivo evitar que computação seja desperdiçada refazendo passos para os quais já foi encontrada uma solução. Da mesma forma, partes do problema que possuem um espaço de busca muito grande são formuladas de forma a limitá-lo ou encontrar uma solução de forma determinística quando possível.

Isso se opõe aos outros dois métodos de simulação de partículas para os quais o processo de otimização a cada iteração escolhe uma modificação, que pode alterar qualquer parâmetro, para aplicar ao sistema. Devido a essa característica, mesmo que o sistema alcance um estado com orientações e posições de partículas que representam os dados de dMRI fielmente, ainda é consumida computação para tentar modificá-los e tais modificações sejam rejeitadas. 


\subsubsection{Algoritmo Geral}

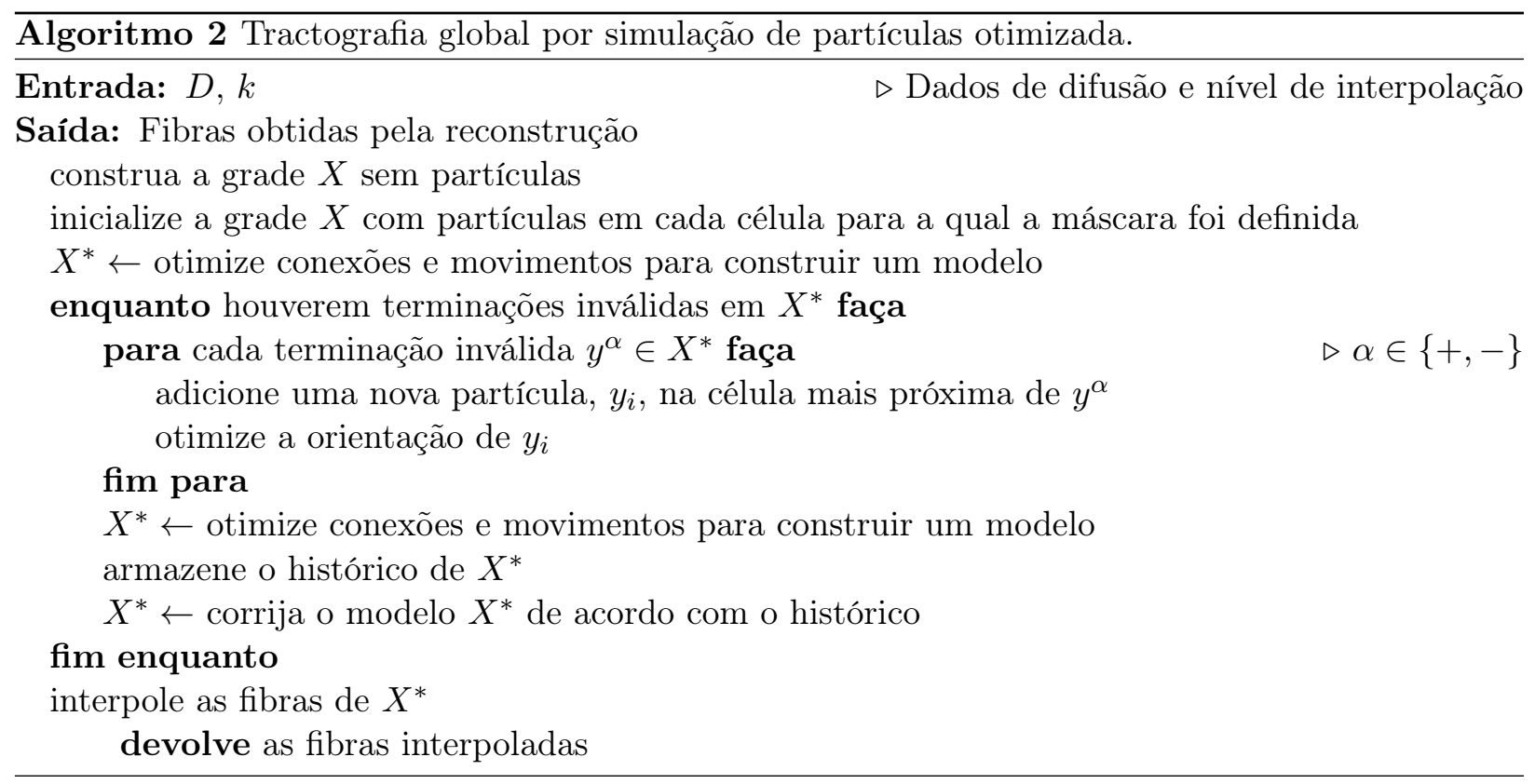

Merece destaque o critério de parada do algoritmo que é representado por "enquanto houverem terminações inválidas em $X^{*}$ ". Esse se baseia na suposição de que fibras não são terminadas dentro da máscara fornecida, como já foi feito no processo por jarros de spin (3.13).

\subsubsection{Representação em Grade}

A imagem tridimensional pode ser compreendida como uma grade, compostas de muitas células para as quais é dado o nome de voxel. Nesse algoritmo, inicialmente cada partícula está no centro de uma célula, como ocorre no modelo de jarros de spin (3.13).

Essa forma de representação possui duas características importantes para o algoritmo: restringir o espaço de busca para as posições de cada partícula; e permitir o controle sobre a densidade da reconstrução alcançada através de subdivisões das células. Assim, como um parâmetro é recebido o nível de subdivisão da grade para o qual 0 é uma grade com uma célula por voxel, 1 são quatro células por voxel (representado pela figura 3.16), 2 são dezesseis células por voxel e assim sucessivamente.

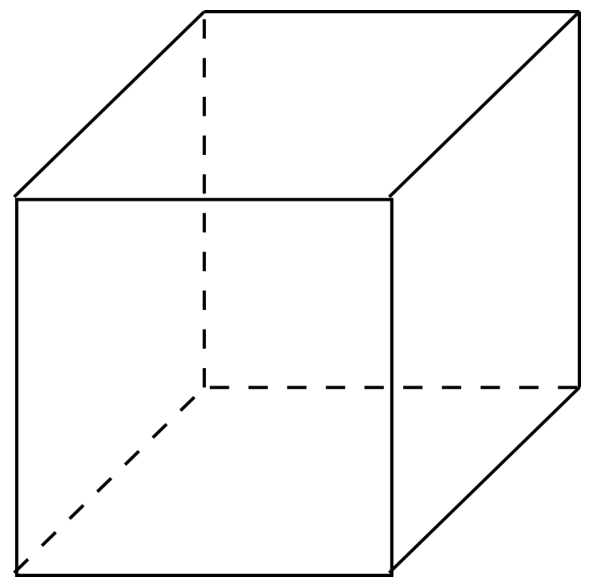

(a)

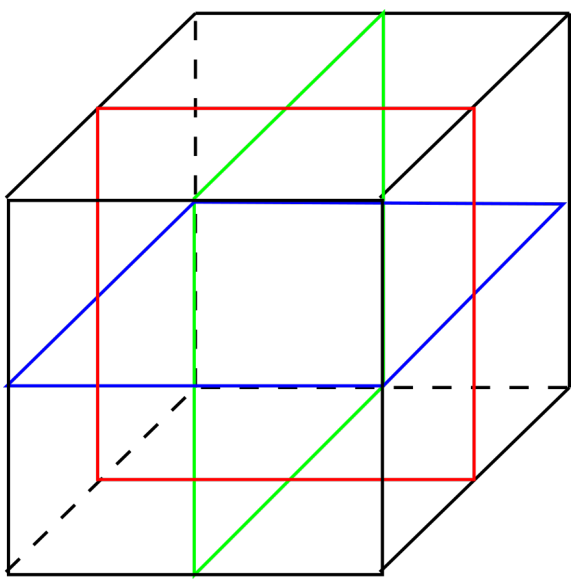

(b)

Figura 3.16: Em (a) é representado um único voxel com nível 0 de subdivisão, que em seguida é subdivido para o nível $1 \mathrm{em}$ (b) onde os planos de subdivisão são representados pelas cores vermelho (eixo $x$ ), verde (eixo z) e azul (eixo y) resultando em 4 novas células na grade. 


\subsubsection{Inicialização das Partículas}

Uma vez construída a grade, são inicializadas as partículas do sistema com posições nos centros das células. Suas orientações são então escolhidas de forma ótima de acordo com as respectivas ODFs. Quando a grade é subdividida as células não definidas na imagem original são aproximadas pela interpolação trilinear.

Esse processo é baseado no fato de que a ODF, como descrita em 3.8, é uma função densidade de probabilidade cuja área total é 1 . Assim é possível definir um limiar $\alpha \in[0,1]$ com respeito ao quanto da direcionalidade de cada célula o sistema deve representar. Esse é utilizado em conjunto com a ODF para construir as orientações de cada partícula seguindo o algoritmo:

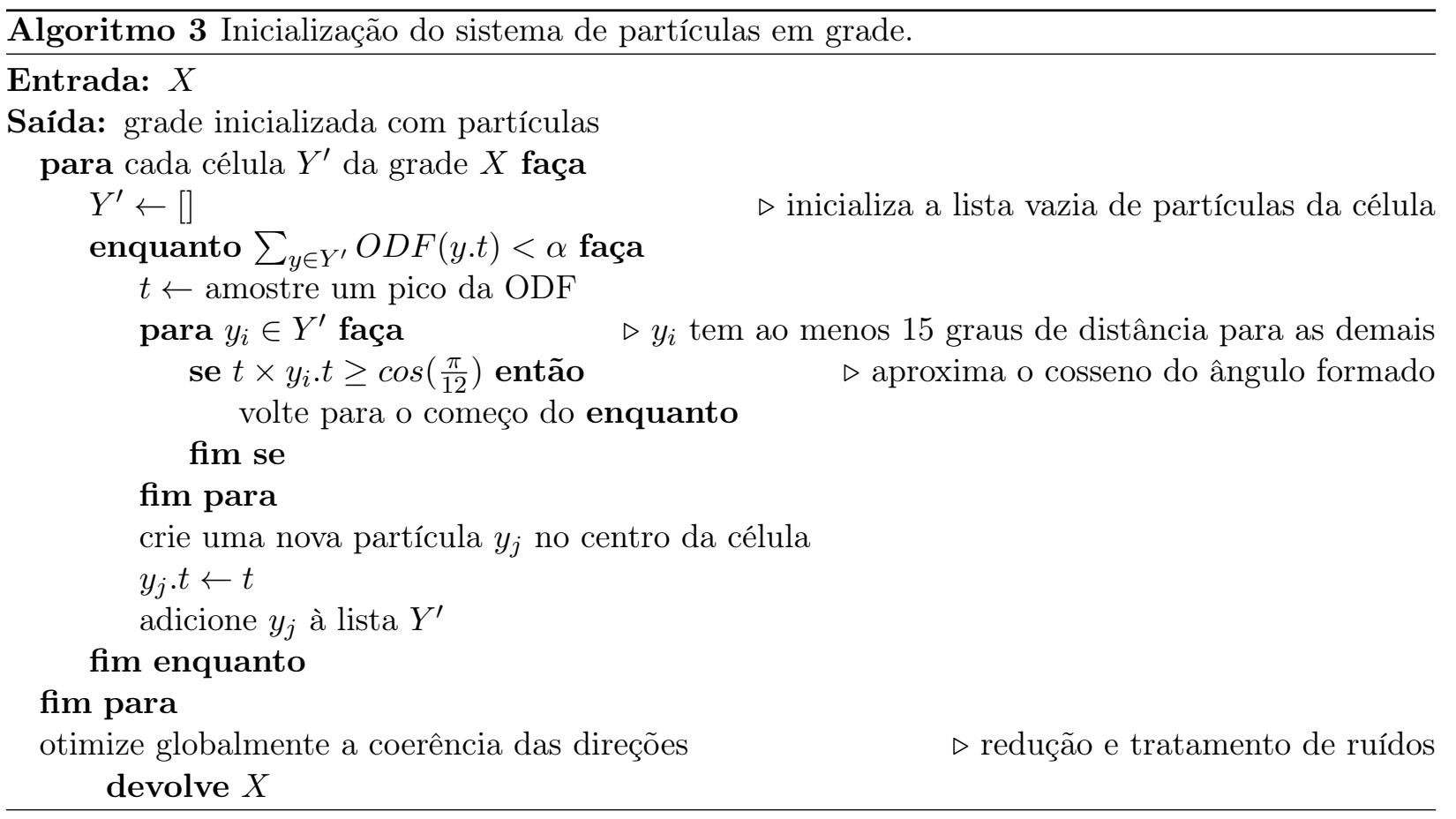

Na prática, como a ODF é obtida através da FRT, essa é uma lista finita de amostras que pode ser ordenada e as orientações de maior probabilidade são obtidas. Assim o passo "amostre um pico da ODF" pode ser computado eficientemente. Isso é suficiente no caso ideal da ausência de ruído. Contudo, para lidar com esse problema real, são utilizadas a otimização global e a energia externa como definidos pelo processo de polimerização (3.14). Aplicando esse processo em um sistema já inicializado da forma descrita poupa tempo de computação.

\subsubsection{Conexões e Movimentações}

Nesse algoritmo o termo "otimize conexões e movimentos para construir um modelo" diz repeito ao algoritmo de amostragem de fibras do processo de polimerização (3.14.1). Esse foi mantido inalterado no que diz respeito às conexões, mas a movimentação sofreu uma modificação menor a fim de reduzir o espaço de busca. Tal modificação consistiu de preservar as orientações e realizar a geração aleatória de posições apenas dentro da mesma célula e restrita de acordo com a orientação da partícula, $y$ : 


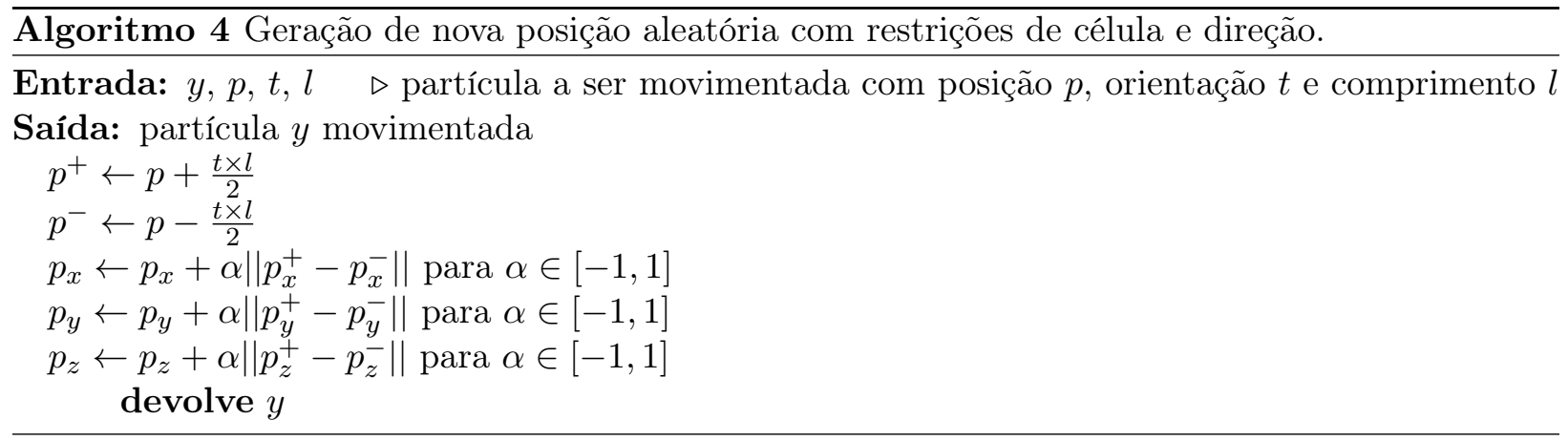

A aceitação desse movimento segue o mesmo critério, pela razão de Green, do método de polimerização.

\subsubsection{Histórico de Conexões}

A natureza do método de conexões por arrefecimento simulado adotada do método de polimerização, ao mesmo tempo que permite uma busca ampla no espaço de soluções, também gera instabilidade sobre as reconstruções. Isso é mitigado no método de polimerização pelo alto número de partículas que cada simulação possui. Como a representação em grade reduz a quantidade de partículas da simulação para apenas o mínimo necessário, esse problema de instabilidade se intensificou.

Como forma de mitigá-lo, foi adotada uma estrutura que identifica unicamente cada partícula e armazena suas conexões de forma que, ao fim de cada simulação, seu resultado pode ser corrigido de acordo com o histórico. Sua forma de funcionamento consiste de buscar por terminações inválidas e através do histórico buscar a conexão mais frequente que tal terminação realizou nas simulações anteriores. Se tal conexão for possível (não foi feita com uma terceira partícula), essa é criada como correção sobre o modelo resultante.

\subsubsection{Criação de Partículas}

Apesar da inicialização da grade (3.15.3) buscar realizar uma amostragem completa das direções necessárias para cada voxel, essa ainda pode apresentar falhas que requerem correções. No método de polimerização, isso é feito por meio de movimentações abruptas e criação de novas partículas em posições aleatórias da região de interesse.

Em contraposição, nesse algoritmo são buscadas as terminações inválidas para as quais uma nova partícula é adicionada de acordo com um dos dois casos a seguir:

1. se existe outra partícula cuja conexão já foi realizada com uma terceira mas essa é possível com a de terminação inválida, essa é duplicada ignorando a restrição de diferenças entre orientações das partículas de mesma célula;

2. caso contrário, são seguidos os passos como definidos de acordo com descrito no algoritmo 3 de inicialização de partículas para cada célula adicionando uma nova orientação à célula.

\subsubsection{Formatação de Saída}

O método de polimerização constrói trajetórias suaves por meio de uma proposição de movimentos ótimos como parte do processo de otimização, consumindo recursos computacionais. Em contraste o método aqui proposto remove tal proposição da otimização, construindo trajetórias descontínuas que ao fim da otimização são interpoladas com funções splines cardinais, como descritas em [PTVF96]. O efeito desse pós-processamento é exemplificado na figura 3.17. 


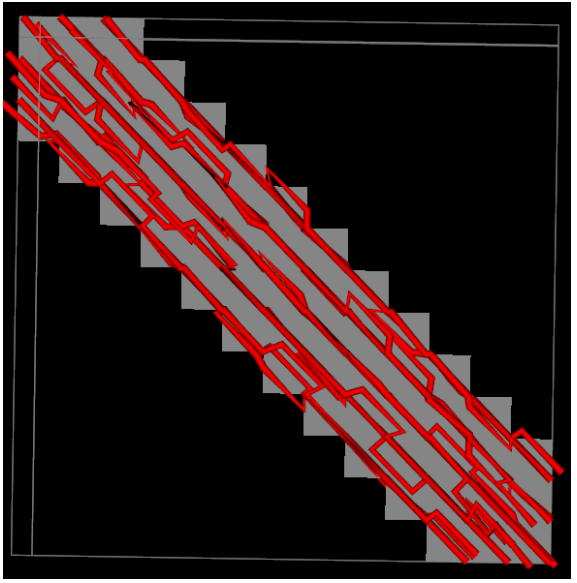

(a)

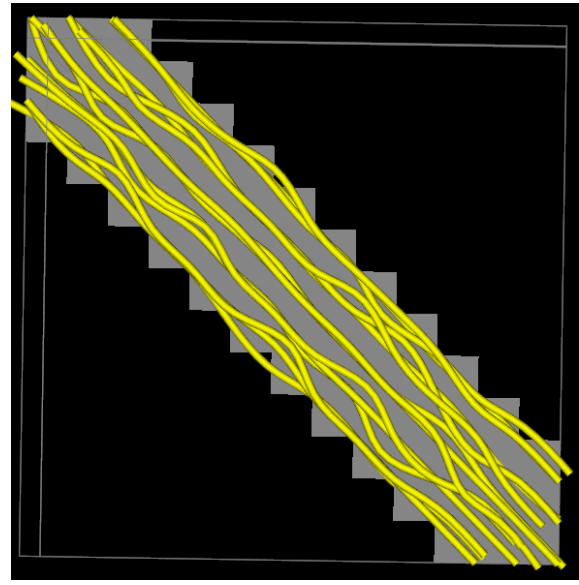

(b)

Figura 3.17: Em (a) as fibras são presentadas ainda como partículas que se interconectam para formar fibras. Essas então são interpoladas por splines cardinais produzindo as fibras exibidas em (b).

\subsection{Análise de Consumo de Recursos}

As análises feitas a seguir contam as operações matemáticas necessárias para uma iteração de três algoritmos de tractografia testados adiante (4): propagação de linha; global por polimerização; e global SAGA. Tais informações serão um parâmetro adicional a ser considerado no capítulo de discussão (5) no momento de ponderar sobre o tempo gasto e contagem de iterações resultantes dos testes realizados (4).

Essa forma de análise por contagem foi escolhida sobre uma análise de complexidade rigorosa, pois para o fim mencionado acima essa opção se mostrou mais clara sobre as diferença entre os algoritmos ao preservar constantes que seriam omitidas. Assintoticamente o método de integração numérica tem complexidade linear e os métodos globais são quadráticos. Assim as constantes são importantes ao se comparar ambos os métodos globais. Em segundo lugar, uma análise assintótica completa para os métodos globais requer que estes sejam analisados de forma probabilística, portanto, mais complexa que a simples contagem de operações por iteração feita.

Os três algoritmos apresentam diferentes critérios de parada mas que têm em comum dependência de outros critérios além dos dados dMRI para isso. Por isso, foi escolhida a solução de realizar a contagem de operações para uma única iteração. Dessa forma, em conjunto com a quantidade de iterações obtida nos testes é possível obter a comparação desejada.

\subsubsection{Método de Integração Numérica Runge-Kutta}

As operações de cada iteração do método descrito em 3.10 são dadas por ${ }^{20}$ :

\begin{tabular}{c|cccc} 
Ordem & Adições & Multiplicações & Divisões & Avaliações de $g(x)$ \\
\hline \hline 2 & 2 & 2 & 1 & 2 \\
\hline 4 & 7 & 4 & 7 & 4
\end{tabular}

Tabela 3.2: Contagem de operações para uma iteração de cada ordem do método de integração numérica Runge-Kutta.

Dadas as contagens acima, é importante esclarecer:

\footnotetext{
${ }^{20} \mathrm{Na}$ fórmula para ambas as ordens do método, há a soma de um termo $O\left(h^{k+1}\right)$ referente ao erro. Implementações não realizam tal soma e por isso a análise pode parecer que esqueceu de contar uma soma.
} 
- o custo da avaliação de $g(x)$ depende do método de interpolação escolhido, mas sua complexidade permanece constante mesmo se aplicada a interpolação trilinear;

- quanto maior $h$ menos iterações serão necessárias, porém ao custo de uma margem de erro maior.

\subsubsection{Método Global por Polimerização}

O custo do algoritmo descrito em 3.14 pode ser compreendido como a soma dos custos de produção de um modelo proposto, computar a diferença de energia e decidir se o modelo é aceito de acordo com a razão de Green. Tal soma pode ter valores diferentes de acordo com a proposição escolhida tanto com respeito ao custo de produzir uma modificação quanto ao custo de avaliar a diferença de energia que possui expressões específicas como definidas em 3.14.2.

\section{Geração de Modelo}

As contagens de operações para geração de modelo para cada proposição estão na tabela 3.3 para a qual os valores são justificados nos parágrafos posteriores.

\begin{tabular}{c|ccccc} 
Proposição & Adições & Multiplicações & Divisões & Sorteios Aleatórios & Exponenciações $^{21}$ \\
\hline \hline Criação & 0 & 0 & 0 & 5 & 0 \\
\hline Remoção & 0 & 0 & 0 & 1 & 0 \\
\hline Movimento & 0 & 0 & 0 & 5 & 0 \\
\hline Movimento Ótimo & 7 & 5 & 3 & 1 & 0 \\
\hline Conexão & $250(14|X|-1)$ & $250(15|X|-1)$ & $250(6|X|-1)$ & 2 & $|X|$
\end{tabular}

Tabela 3.3: Contagem de operações da geração de modelo de acordo com a proposição.

- Para a criação de uma nova partícula e para movimento aleatório as operações de geração do modelo novo são as mesmas: escolher uma posição aleatória na máscara; e gerar uma orientação aleatória totalizando 5 operações.

- A remoção de uma partícula $y \in X$, se usada uma estrutura de vetor para armazenar todo o conjunto, é linear no tamanho de $X$ e consome uma única geração de número aleatório.

- Para a contagem de operações necessárias na formulação de um novo modelo aplicando a proposição de movimento ótimo é assumido o pior caso onde ambas as terminações estão conectadas.

- As operações necessárias computar a norma-2 de um vetor são três multiplicações, duas somas e uma divisão. Onde o custo de computar a raiz quadrada é aproximado para o de uma divisão como forma de simplificar a notação.

- A criação de fibras se baseia no processo de amostragem definido em 3.14 .1 cujo critério de parada é probabilístico. Por outro lado, a implementação do algoritmo define um limite superior de 250 partículas conectadas por iteração que é adotado para simplificar a análise tomando o pior caso.

- Para cada conexão ser feita há o custo inicial de se escolher uma partícula e direção, dois sorteios aleatórios, para os quais a fibra que exista deve ser desfeita, consumindo $O(2[|X|-1])$ operações lógicas.

- Com a terminação livre, é possível gerar o conjunto de candidatos a sucessão, consumindo no pior caso $2|X|-1$ somas, $3|X|-1$ multiplicações e $|X|-1$ divisões.

- Cada candidato precisa ter sua probabilidade de conexão computada por uma expressão que envolve o potencial de conexão (parte da expressão de energia interna 3.14.1), $U_{c o n}$, cujo consumo é de 11 somas, 11 multiplicações e 4 divisões. 
- Isso leva ao custo no pior caso de computar as probabilidades de conexão $12|X|$ somas, $12|X|$ multiplicações, $5|X|$ divisões e $|X|$ exponenciações.

- Ao agregar todas as contagens, modificar a configuração de fibras de um modelo tem custo de pior caso de dois sorteios aleatórios, $2[|X|-1]$ operações lógicas, $250(14|X|-1)$ somas, 250(15|X|-1) multiplicações, 250(6|X|-1) divisões e $|\mathrm{X}|$ exponenciações.

\section{Computação da Variação de Energia}

Após gerado o modelo proposto, o próximo passo é analisar a complexidade de computar a diferença de energia desse novo modelo. As expressões para cada proposição foram detalhadas em 3.14 .2 e a complexidade para computar $U_{c o n}$ já foi detalhada anteriormente na análise de complexidade de geração de modelo com nova configuração de fibras. A única função complexa para a qual ainda não foi detalhada a complexidade é a Bessel modificada de ordem 0 , cujo consumo ${ }^{22}$ no pior caso é de 8 somas, 9 multiplicações, 2 divisões e uma exponenciação. Assim, a tabela de contagens nos piores casos para computação da energia de forma incremental para os modelos propostos é dada na seguinte tabela:

\begin{tabular}{c|cccc} 
Proposição & Adições & Multiplicações & Divisões & Exponenciações \\
\hline \hline Criação & $10|X|+1$ & $16|X|+3$ & $4|X|$ & $2|X|$ \\
\hline Remoção & $10|X|+14$ & $16|X|+15$ & $4|X|+4$ & $2|X|$ \\
\hline Movimento & $20|X|+15$ & $32|X|+18$ & $8|X|+4$ & $4|X|$ \\
\hline Movimento Ótimo & $20|X|+15$ & $32|X|+18$ & $8|X|+4$ & $4|X|$ \\
\hline Conexão & 2750 & 2750 & 1000 & 0
\end{tabular}

Tabela 3.4: Custo computacional da atualização do valor de energia para o modelo proposto modelo de acordo com a proposição.

\section{Computação da Razão de Green}

O último custo a ser considerado antes de obter os totais e um custo para o caso médio, é o de computar a razão de Green para cada proposição, conforme 3.14.1 é dada a tabela:

\begin{tabular}{c|cccc} 
Proposição & Adições & Multiplicações & Divisões & Exponenciações \\
\hline \hline Criação & 2 & 0 & 3 & 1 \\
\hline Remoção & 1 & 0 & 3 & 1 \\
\hline Movimento & 0 & 0 & 2 & 1 \\
\hline Movimento Ótimo & 1 & 2 & 2 & 1 \\
\hline Conexão & 0 & $|X|-1$ & 2 & 1
\end{tabular}

Tabela 3.5: Custo computacional de computação da razão de Green para o modelo proposto modelo de acordo com a proposição.

\section{Contagens Agregadas}

Finalmente os custos totais por iteração para cada proposição são:

\footnotetext{
${ }^{22}$ Seguindo a implementação disponível em [PTVF96].
} 


\begin{tabular}{c|ccccc} 
Proposição & Adições & Multiplicações & Divisões & Sorteios Aleatórios & Exponenciações \\
\hline \hline Criação & $10|X|+3$ & $16|X|+3$ & $4|X|+3$ & 5 & $2|X|+1$ \\
\hline Remoção & $10|X|+15$ & $16|X|+15$ & $4|X|+7$ & 1 & $2|X|+1$ \\
\hline Movimento & $20|X|+15$ & $32|X|+18$ & $8|X|+6$ & 5 & $4|X|+1$ \\
\hline Movimento Ótimo & $20|X|+23$ & $32|X|+25$ & $8|X|+9$ & 0 & $4|X|+1$ \\
\hline Conexão & $|X|+2750$ & $2|X|+2749$ & $|X|+1002$ & 2 & $|X|+1$
\end{tabular}

Tabela 3.6: Custo computacional de total para uma única iteração.

$\mathrm{Na}$ implementação do método de polimerização são definidos valores para as probabilidades de escolher cada proposição da seguinte forma: $P^{\text {birth }}=0.38 ; P^{\text {death }}=0.08 ; P^{\text {shift }}=0.23 ; P^{\text {opt }}=0.15$; $P^{c o n n}=0.16$. Tais valores foram definidos de forma empírica de acordo com [RMK09a]. Com isso é possível definir o custo médio esperado do algoritmo em:

\begin{tabular}{ccccc} 
Adições & Multiplicações & Divisões & Sorteios Aleatórios & Exponenciações \\
\hline \hline $12.36|X|+463.04$ & $19.84|X|+290.07$ & $5.04|X|+164.75$ & 3.45 & $2.6|X|+1$
\end{tabular}

Tabela 3.7: Custo computacional médio para uma única iteração.

\subsubsection{Método SAGA}

No algoritmo 2 a complexidade da construção da grade é regida pela quantidade de voxels válidos na máscara de interesse, $N_{\text {mask }}$, e pelo nível de subdivisões escolhido denotado por $N_{\text {subdiv }}$. Em função desses definimos a complexidade em $\Theta\left(N_{\text {mask }}\left[2^{2 N_{\text {subdiv }}}\right]\right)$ operações lógicas de instanciação das células na grade. Em seguida, para cada célula criada na grade é preciso ordenar as, $N_{d i r}$, direções a fim de para cada célula escolher as que melhor representem a direcionalidade. Isso tem custo médio $\Theta\left(N_{\text {mask }}\left[2^{2 N_{\text {subdiv }}}\right]\left[N_{\text {dir }} \log _{2} N_{\text {dir }}\right]\right)$ onde $N_{\text {dir }}$ denota a quantidade de direções para os quais a difusão foi amostrada. A soma desses dois custos resulta no custo total de pré-processamento: $\Theta\left(N_{\text {mask }}\left[2^{2 N_{\text {subdiv }}}\right]\left[\left(N_{\text {dir }} \log _{2} N_{\text {dir }}\right)+1\right]\right)$.

O laço principal consiste das seguintes operações: verificar se existem terminações inválidas no modelo, $O\left(N_{\text {part }}\right)$ operações lógicas, onde $N_{\text {part }}$ é o número de segmentos de fibra; para cada terminação inválida adicionar uma partícula nova, $O\left(N_{i n v} \times N\right)$, onde $N_{i n v}$ é o número de segmentos de fibra inválidos; otimizar as conexões para o modelo com um custo similar custo da proposição de conexão em 3.16.2, mas ao invés de ter os termos multiplicados por $|X|$ nesse caso é possível usar a constante $N_{\text {mask }}\left[2^{2 N_{\text {subdiv }}}\right]$; armazenar as conexões formadas no histórico, $O(2 N)$; aplicar correções às conexões de acordo com o histórico $O\left(N_{i n v}\right)$. Esses custos se agregam em:

\begin{tabular}{ccc} 
Adições & Multiplicações & Divisões \\
\hline \hline$N_{\text {mask }}\left[2^{2 N_{\text {subdiv }}}\right]+2750$ & $N_{\text {mask }}\left[2^{2 N_{\text {subdiv }}}\right]+2749$ & $N_{\text {mask }}\left[2^{2 N_{\text {subdiv }}}\right]+1002$
\end{tabular}

Tabela 3.8: Contagens das operações de soma, multiplicação e divisão para o método global SAGA.

\begin{tabular}{ccc} 
Sorteios Aleatórios & Exponenciações & Operações Lógicas \\
\hline \hline 2 & $N_{\text {mask }}\left[2^{2 N_{\text {subdiv }}}\right]+1$ & $N_{\text {part }}\left[N_{\text {inv }}+3\right]+N_{\text {inv }}$
\end{tabular}

Tabela 3.9: Contagens de operações de sorteio aleatório, exponenciação e lógica para o método global SAGA. 


\subsection{Implementação}

Como parte desse trabalho e forma de tornar possíveis os resultados mostrados no capítulo 4 , foram desenvolvidas implementações para os métodos de tractografia globais baseado no processo de polimerização (seção 3.14) e o SAGA (seção 3.15).

Todas as modificações e otimizações descritas na seção 3.15 são fruto do estudo prévio dos métodos de tractografia global por simulação de partículas (3.12), mas também advêm de extensa experimentação das melhores soluções tecnológicas e como as modificações se relacionam e afetam a tractografia global.

\subsubsection{Parâmetros de Entrada e Constantes Adotadas}

Tanto o método baseado no processo de polimerização quanto o método SAGA recebem como entrada os dados de dMRI e uma região de interesse para a reconstrução, também denominada máscara.

\section{Método Baseado no Processo de Polimerização}

Recebe os seguintes parâmetros:

- quantidade de iterações a serem executadas;

- quantidade esperada de partículas;

- temperatura inicial;

- e temperatura final.

\section{Método SAGA}

Por sua vez o método SAGA utiliza os seguintes parâmetros de entrada:

- nível de interpolação da grade;

- quantidade de partículas inicializadas no centro de cada célula de grade;

\section{Constantes}

No que diz respeito a constantes ambos os métodos compartilham os seguintes valores:

- $\sigma=0.4$, o raio da esfera sobre a qual as partículas são consideradas como causadoras de influência sobre suas vizinhas para os cálculos de energia;

- $W=0.2$;

- $C=1.0$, raio do cilindro modelando a partícula;

- $l=1.2$, comprimento da partícula;

- $L=0.5$, viés que dá liberdade à expressão de energia interna;

- limiar de alta curvatura $0.87 ;^{23}$

- $\lambda_{\text {ext }}=0.065$, peso da energia externa;

- $\lambda_{\text {int }}=0.935$, peso da energia interna.

\footnotetext{
${ }^{23}$ Aproximadamente $\cos \left(\frac{\pi}{6}\right)$. Assim curvaturas superiores a 30 graus são consideradas elevadas.
} 


\subsubsection{Tecnologias}

Com o objetivo de possuir desempenho comparável aos métodos de tractografia da literatura, foi construído um primeiro protótipo utilizando a linguagem de programação $C++$. Porém, as opções de bibliotecas para realizar a entrada e saída no formato NIfTI2 são limitadas nessa linguagem sem que nenhuma proporcionasse confiança ou meios de testar sua confiabilidade. Além desse problema, não foi encontrada uma biblioteca que compute a FRT forçando à uma implementação própria dessa. Isso gerou mais um ponto passível de falha, de difícil verificação e que iria requerer manutenção.

Essas restrições levaram à uma segunda implementação de protótipo utilizando a linguagem de programação Python devido à sua popularidade crescente no meio científico. Essa possui as bibliotecas necessárias ${ }^{24}$ para leitura dos dados e seu pré-processamento, como computação da FRT. Por outro lado, novamente nos testes outras duas limitações surgiram:

- o consumo de espaço em memória, quando cada modelo precisa conter uma ordem de $10^{6}$ partículas, extrapola os valores considerados aceitáveis;

- e a limitação da linguagem quanto ao paralelismo real de threads, conhecida como GIL - Global Interpreter Lock, requerendo a implementação com múltiplos processos e troca de mensagens entre esses que comprometiam o desempenho.

A solução técnica final consistiu de combinar as melhores soluções dos protótipos anteriores. Dessa forma, existe um programa principal na linguagem Python que:

- fornece uma interface por linha de comando para o programa;

- cuida da entrada dos dados de acordo com as necessidades do algoritmo;

- processa a saída do algoritmo para gerar as splines referidas na seção 3.15.7.

Esse programa interage com uma extensão da linguagem Python escrita na linguagem $\mathrm{C}++$ que acessa uma biblioteca compartilhada escrita na linguagem $C++$. A biblioteca implementa todo o método descrito na metodologia (3.15) de forma eficiente quanto aos usos da memória e do processador. Essa combinação fornece as funcionalidades necessárias para execução dos testes deste trabalho, mas mantém a implementação do método principal desacoplada e genérica o bastante para ser reaproveitada por qualquer outro programa no futuro. Essa implementação está no repositório de código fonte em https://gitlab.com/rafamanzo/gtrack_reboot.

\subsubsection{Qualidade do Código}

As várias etapas de execução e casos especiais a serem tratados para os métodos de tractografia global descritos, assim como as escolhas tecnológicas definidas, fazem dessa implementação um software mais complexo do que é esperado para um protótipo. O desenvolvimento do método consistiu de seguidos testes com objetivo de avaliar como o algoritmo é afetado por cada mudança proposta. Tal forma de trabalho, apesar de boa para formulação de um método inédito, traz mais instabilidade à correção da implementação e aumenta sua complexidade.

Nesse contexto, um controle de qualidade se fez necessário após falhas inesperadas em meio à experimentos de modificações nos métodos. Esse controle partiu da adoção de práticas de programação extrema. A primeira e mais fundamental delas é o desenvolvimento orientado a testes que levou a uma elevada cobertura com testes de unidade tanto para o programa interface quanto para a biblioteca de processamento. Essa coberturas alcançaram de $100 \%$ e $89.1 \%$ das linhas de código-fonte válido respectivamente.

Em seguida, foram escritos testes de aceitação com dados sintéticos para casos representativos sobre propriedades desejadas do algoritmo. Mais especificamente, cada teste que é apresentado

\footnotetext{
${ }^{24}$ As bibliotecas nibabel para leitura e dipy para computação da FRT ambas disponibilizadas pela comunidade NIPY (http://nipy.org - acessado pela última vez em 29/11/2016).
} 
na subseção 3.3.1 sobre resultados com dados sintéticos é um teste automatizado que pode ser executado em tempo aceitável durante o desenvolvimento. Porém, com o crescimento da bateria de testes, sua execução completa passou a tomar em média 60 minutos.

Com toda essa estrutura de verificação posta, mas com tempo de execução médio de 60 minutos, a última prática adotada foi a integração contínua. Ela possui quatro estágios: executar testes de unidade para a biblioteca de processamento; compilar a biblioteca; executar testes de unidade para o programa de interface; e executar os testes de aceitação com dados sintéticos. Todos são automatizados de forma que sempre que uma modificação na base de código esses estágio são executados e o resultado é enviado via e-mail. Dessa forma, durante o desenvolvimento não é necessário se preocupar com a execução dos testes mais demorados. Esses são executados em um servidor à $\operatorname{parte}^{25}$ que gerencia filas de execução e armazena os resultados para inspeção pelo desenvolvedor se necessário.

\subsubsection{Licença}

A adoção de software livre tem sido reconhecida pela comunidade de desenvolvedores e grandes empresas como uma forma de fornecer diversas propriedades desejáveis aos softwares:

1. facilidade para auditar quanto à qualidade do código e garantias contra defeitos, falhas de segurança e violações de privacidade;

2. liberdade completa para executar, estudar e modificar o programa conforme desejado.

No contexto do processamento de dMRI, ao longo do desenvolvimento desse trabalho a maior parte dos trabalhos estudados não fornecem as implementações utilizadas para produzir suas publicações. Outras poucas as disponibilizavam mediante autorização por escrito. E apenas duas são disponibilizadas como software livre: os da comunidade nipy ${ }^{26}$; e o software MITK [NSR ${ }^{+} 12$ ].

Dessa forma, considerando as vantagens que software livre traz e sua baixa adesão ainda dentre os métodos de tractografia, a implementação produzida por esse trabalho é liberada como software $\operatorname{livre}^{27}$ a fim de promover a colaboração e liberdade de estudo que são inerentes à ciência.

Outra vantagem na elaboração de tal implementação no formato proposto é possibilidade de definição de duas licenças separadas: uma para a biblioteca de processamento; e outra para o programa de interface. Isso permite a escolha dessas de forma que os resultados desse trabalho sejam reproduzidos sem envolver burocracia. Portanto, as licenças escolhidas foram General Public License Version 3 para o programa de interface e Lesser General Public License Version 3 para o biblioteca de processamento. Assim, a biblioteca ainda pode ser incorporada a qualquer outro software e ser modificada para este desde que continue livre.

Por outro lado, plágio acadêmico se torna uma preocupação ao passo que a implementação só será tornada pública quando este trabalho for publicado em sua versão final.

\subsection{Validação}

A validação dos métodos de tractografia nesse trabalho é constituída de imagens em diferentes planos de visualização e de métricas coletadas durante a execução de testes e após estes. As imagens são úteis para comparação visual do comportamento nas regiões de incerteza com respeito às expectativas para cada conjunto de dados. Já as métricas visam suportar a discussão sobre consumo de recursos computacionais através dos seguintes parâmetros: tempo de execução; número de iterações; quantidade de partículas; e quantidade de fibras.

O interesse sobre o tempo de execução surge da possibilidade de associá-lo às imagens obtidas e discutir sobre a troca entre tempo de execução e qualidade dos resultados. Já as demais métricas

\footnotetext{
${ }^{25}$ Até o momento da escrita desse texto foram executados mais de 2214 repetições desses.

${ }^{26}$ http://nipy.org - acessado pela última vez em $\left.29 / 11 / 2016\right)$.

${ }^{27}$ A resolução $N^{0} 7035$ da Universidade de São Paulo, de 17 de dezembro de 2014, exclui a possibilidade dessa implementação ser patenteada desde que permaneça software livre.
} 
refletem os componentes dominantes da contagem de operações realizada na análise de consumo de recursos (3.16). 


\section{Capítulo 4}

\section{Resultados}

Com a implementação detalhada na seção 3.17 foram realizados testes que empregam os materiais descritos na seção 3.3 e os critérios definidos na seção 3.18. A exibição desses se dará primeiro pelos resultados para conjuntos de dados sintéticos (seção 4.1) e posteriormente na região destacada do miocárdio humano (seção 4.2). Para todos foi realizado o primeiro teste com o método de propagação de linha como base de comparação para os dois métodos de tractografia globais de interesse. Nesse capítulo o objetivo é apresentar todos os resultados relevantes para o trabalho para no capítulo 5 discuti-los e avaliá-los para permitir que conclusões possam ser feitas no capítulo 6 . 


\subsection{Dados Sintéticos}

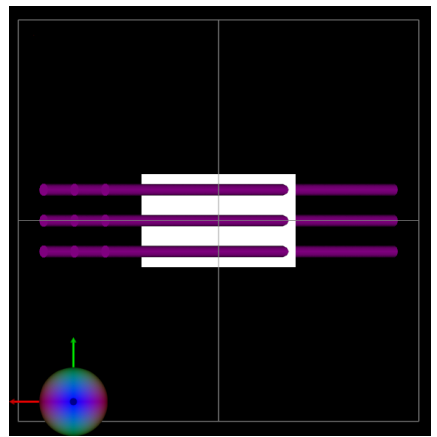

(a)

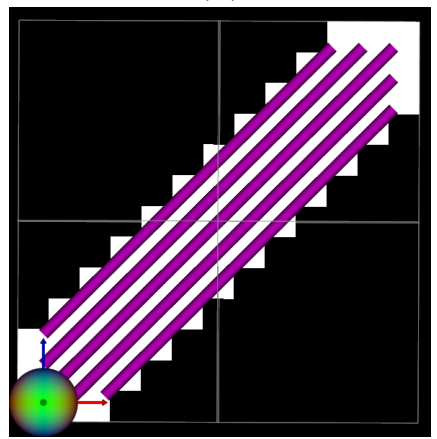

(d)

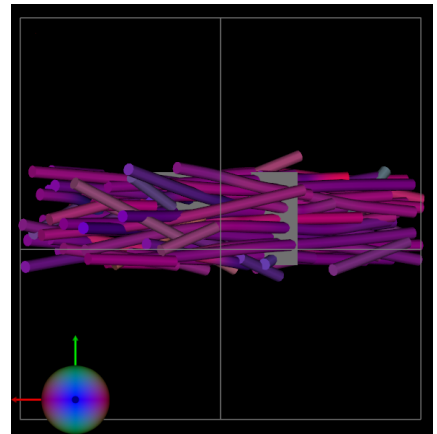

(b)

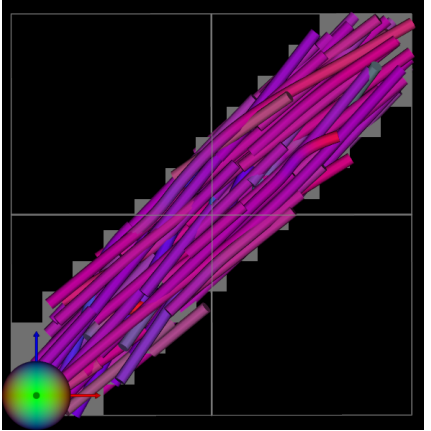

(e)

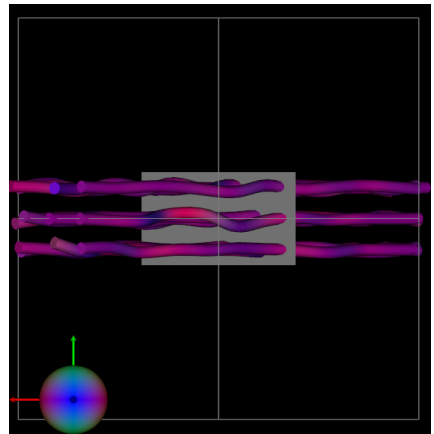

(c)

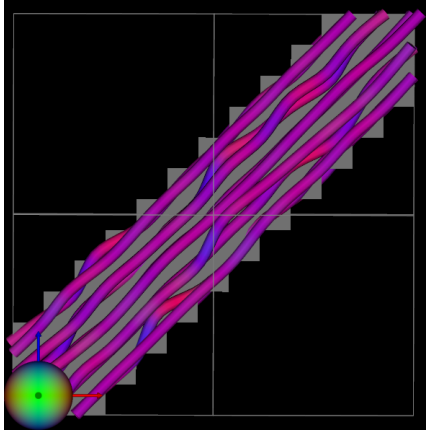

(f)

Figura 4.1: Fibras obtidas pelos métodos de tractografia nos dados sintéticos gerados a partir de uma reta inclinada em 45 graus. O processo de geração produz um volume tridimensional semelhante a um paralelepipedo. Essas fibras são exibidas nos planos xy, na primeira linha, e xz na segunda linha. Cada coluna apresenta os resultados de para cada método: (a) e (d) propagação de linha; (b) e (e) o método global de polimerização; (c) e (f) o método SAGA. As cores representam a direcionalidade de acordo com a esfera presente no canto esquerdo inferior de cada imagem. A geometria esperada é descrita na figura $3.1 b$ sobre a qual chamam a atenção: no método de propagação de linha é possível notar estabilidade da reconstrução; o método global baseado no processo de polimerização mostrou alta instabilidade; e o método global SAGA realizou a reconstrução com menor instabilidade que o método baseado em polimerização.

\begin{tabular}{ccccc} 
Método & $\begin{array}{c}\text { Tempo de } \\
\text { execução } \\
\text { (segundos) }\end{array}$ & $\begin{array}{c}\text { Quantidade } \\
\text { de partículas }\end{array}$ & $\begin{array}{c}\text { Quantidade } \\
\text { de fibras }\end{array}$ & $\begin{array}{c}\text { Quantidade } \\
\text { de iterações }\end{array}$ \\
\hline \hline Propagação de linha & 0.3435 & Não se aplica & 124 & Indisponível \\
\hline Polimerização & 720.127 & 827 & 100 & $2.1 \times 10^{5}$ \\
\hline SAGA & 49.0207 & 177 & 15 & $4.95 \times 10^{4}$
\end{tabular}

Tabela 4.1: Resultados quantitativos para testes realizados com algoritmos de tractografia no conjunto de dados sintéticos de uma reta inclinada em 45 graus. 


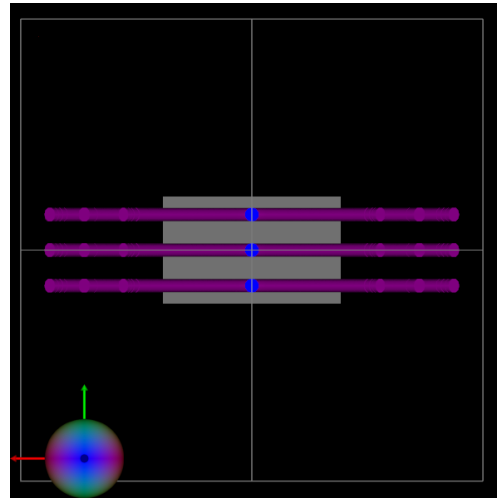

(a)

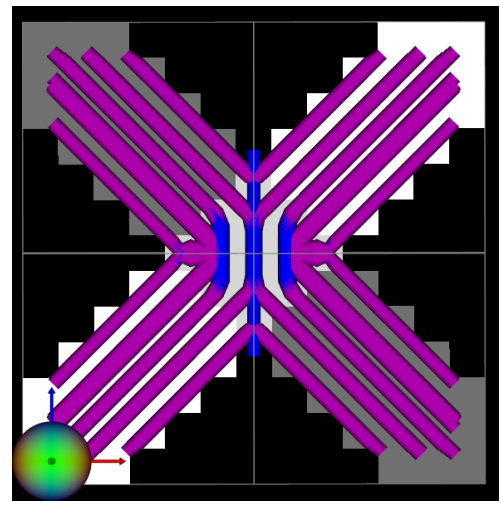

(d)

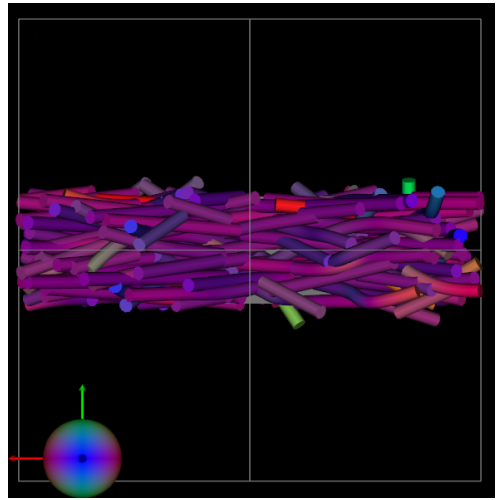

(b)

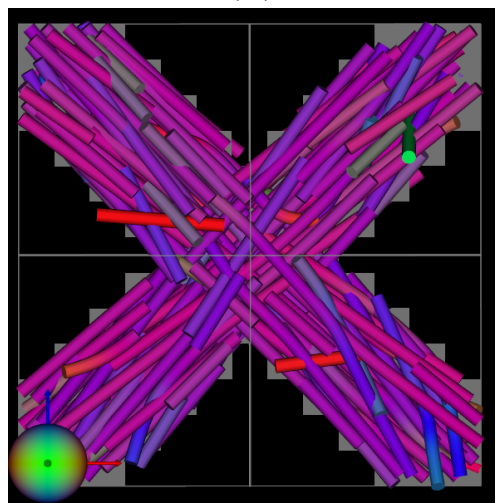

(e)

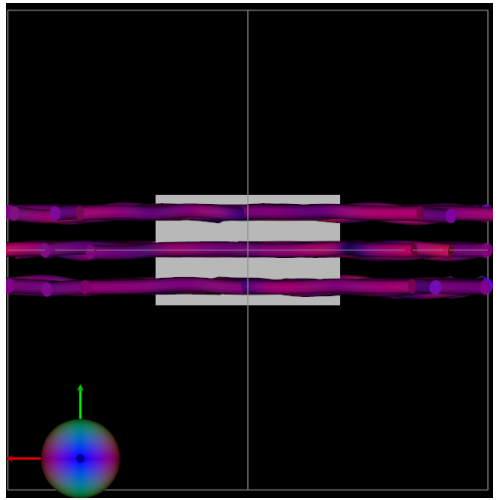

(c)

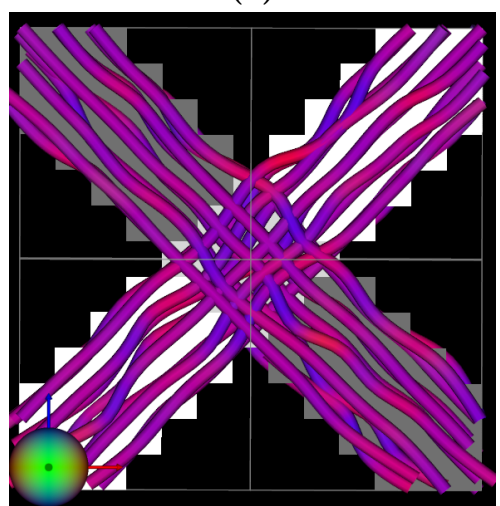

(f)

Figura 4.2: Fibras obtidas pelos métodos de tractografia nos dados sintéticos de gerados a partir de duas retas que se cruzam formando um ângulo de 90 graus. O resultado tridimensional da geração são dois volumes similares a paralelepipedos que se intersectam formando uma cruz. Essas fibras são exibidas nos planos xy, na primeira linha, e xz na segunda linha. Cada coluna apresenta os resultados para cada método testado: (a) e (d) propagação de linha; (b) e (e) o método global de polimerização; (c) e (f) o método SAGA. As cores representam a direcionalidade de acordo com a esfera presente no canto esquerdo inferior de cada imagem. A geometria esperada é descrita na figura 3.2b sobre a qual chamam a atenção: no método de propagação de linha o cruzamento não foi reconstruído, mas é possivel notar estabilidade da reconstrução; o método global baseado no processo de polimerização realizou a reconstrução do cruzamento, porém com alta instabilidade; já o método global SAGA foi capaz de reconstruir o cruzamento com menor instabilidade que o método baseado em polimerização.

\begin{tabular}{ccccc} 
Método & $\begin{array}{c}\text { Tempo de } \\
\text { execução } \\
\text { (segundos) }\end{array}$ & $\begin{array}{c}\text { Quantidade } \\
\text { de partículas }\end{array}$ & $\begin{array}{c}\text { Quantidade } \\
\text { de fibras }\end{array}$ & $\begin{array}{c}\text { Quantidade } \\
\text { de iterações }\end{array}$ \\
\hline \hline Propagação de linha & 0.7826 & Não se aplica & 255 & Indisponível \\
\hline Polimerização & 1364.16 & 1360 & 192 & $3.6 \times 10^{5}$ \\
\hline SAGA & 744.808 & 352 & 30 & $8.544 \times 10^{5}$
\end{tabular}

Tabela 4.2: Resultados quantitativos para testes realizados com algoritmos de tractografia no conjunto de dados sintéticos de um cruzamento de retas formando ângulo de 90 graus. 


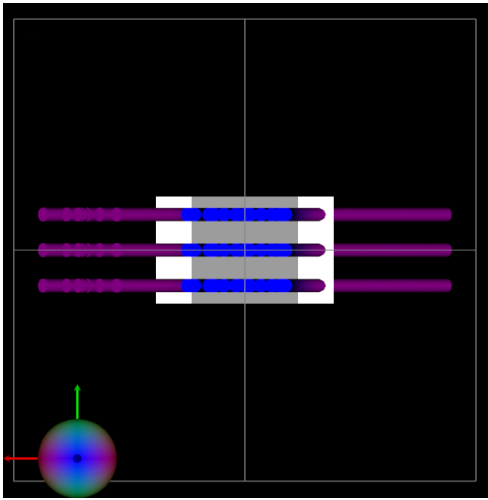

(a)

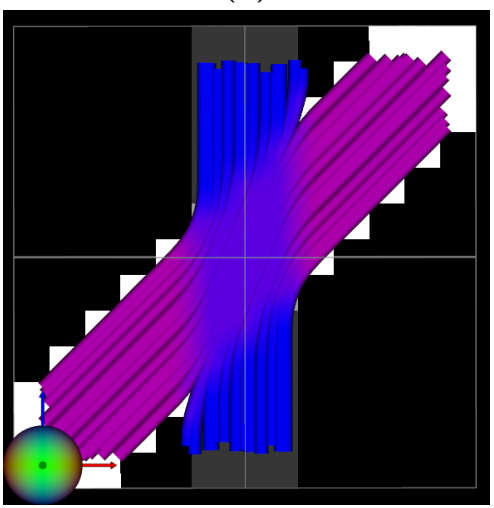

(d)

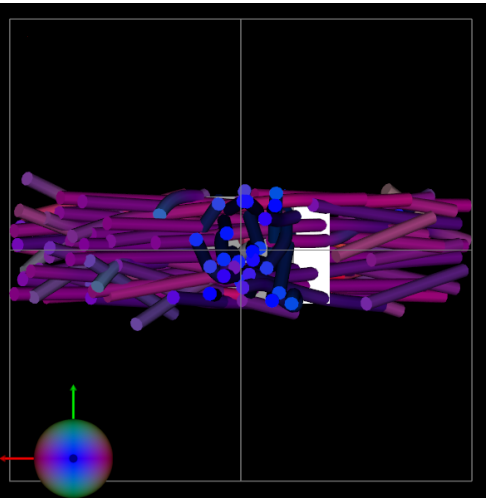

(b)

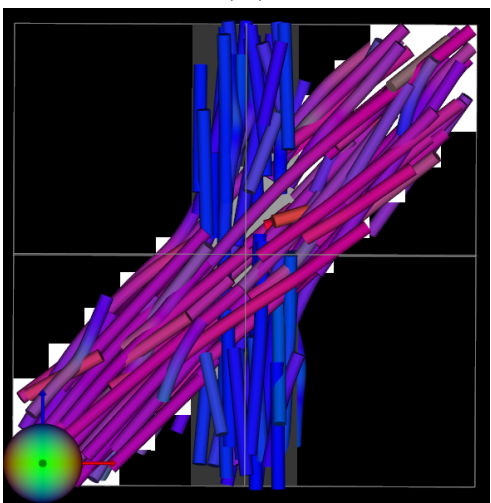

(e)

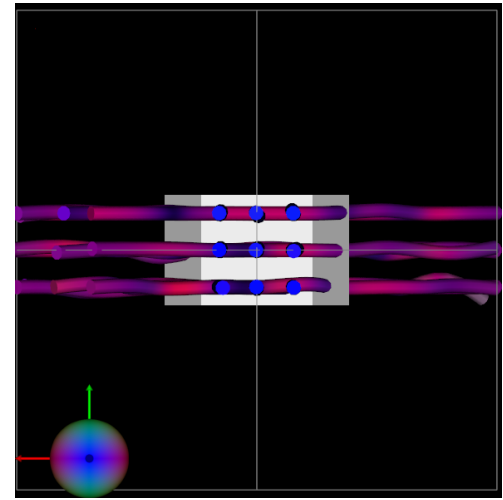

(c)

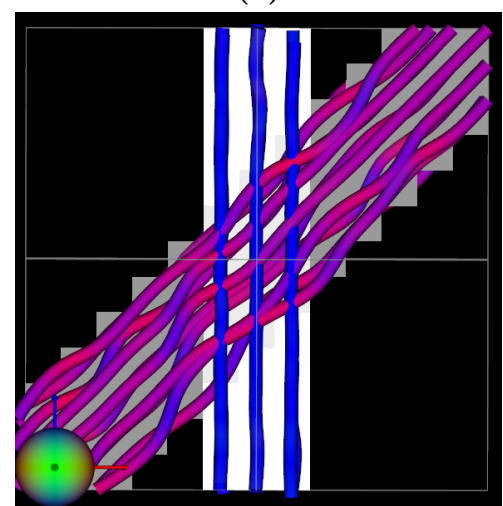

(f)

Figura 4.3: Fibras obtidas pelos métodos de tractografia nos dados sintéticos de gerados a partir de duas retas que se cruzam formando um ângulo de 45 graus. O resultado tridimensional da geração são dois volumes similares a paralelepípedos que se intersectam. Essas fibras são exibidas nos planos xy, na primeira linha, e xz na segunda linha. Cada coluna apresenta os resultados de um método: (a) e (d) propagação de linha; (b) e (e) o método global de polimerização; (c) e (f) o método SAGA. As cores representam a direcionalidade de acordo com a esfera presente no canto esquerdo inferior de cada imagem. A geometria esperada é descrita na figura $3.3 b$ sobre a qual chamam a atenção: no método de propagação de linha o cruzamento não foi reconstruído, mas é possível notar estabilidade da reconstrução; o método global baseado no processo de polimerização realizou a reconstrução do cruzamento, porém com alta instabilidade; já o método global SAGA foi capaz de reconstruir o cruzamento com menor instabilidade que o método baseado em polimerização.

\begin{tabular}{ccccc} 
Método & $\begin{array}{c}\text { Tempo de } \\
\text { execução } \\
\text { (segundos) }\end{array}$ & $\begin{array}{c}\text { Quantidade } \\
\text { de partículas }\end{array}$ & $\begin{array}{c}\text { Quantidade } \\
\text { de fibras }\end{array}$ & $\begin{array}{c}\text { Quantidade } \\
\text { de iterações }\end{array}$ \\
\hline \hline Propagação de linha & 0.7149 & Não se aplica & 255 & Indisponível \\
\hline Polimerização & 959.514 & 1054 & 152 & $2.7 \times 10^{5}$ \\
\hline SAGA & 448.235 & 294 & 24 & $6.949 \times 10^{5}$
\end{tabular}

Tabela 4.3: Resultados quantitativos para testes realizados com algoritmos de tractografia no conjunto de dados sintéticos de um cruzamento de retas formando ângulo de 45 graus. 


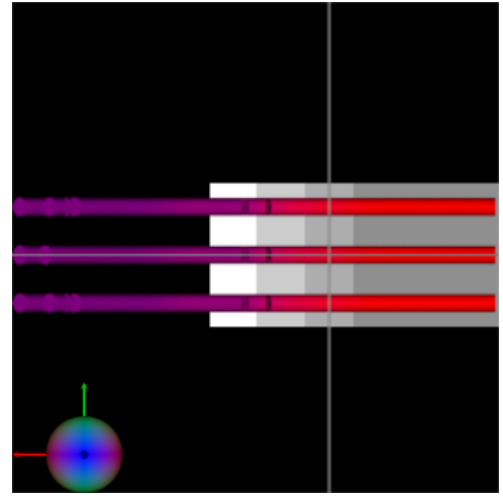

(a)

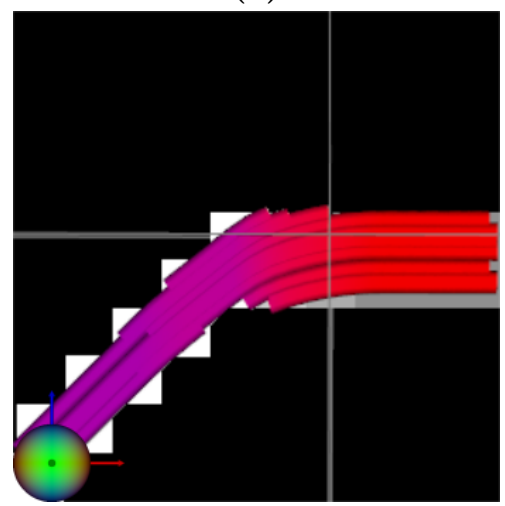

(d)

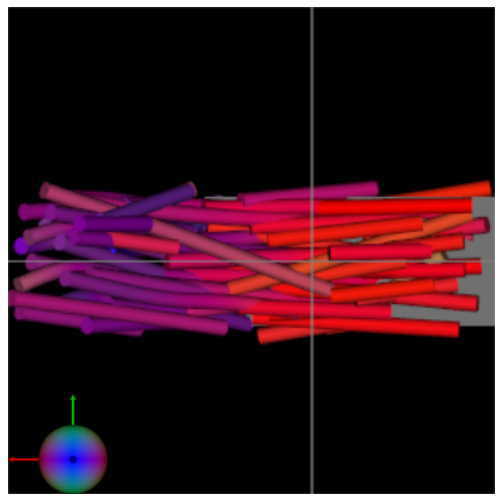

(b)

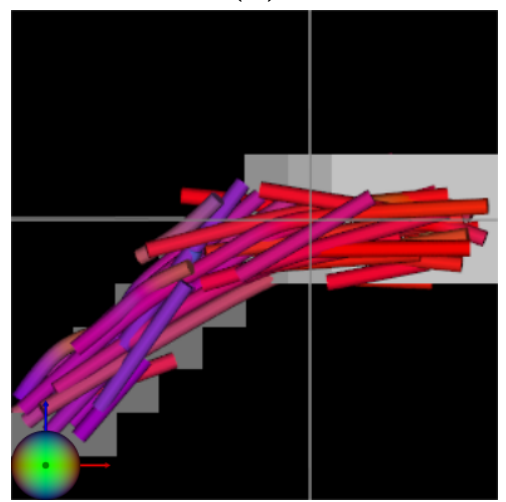

(e)

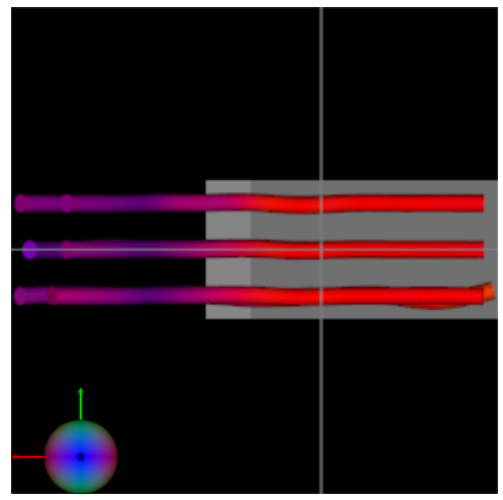

(c)

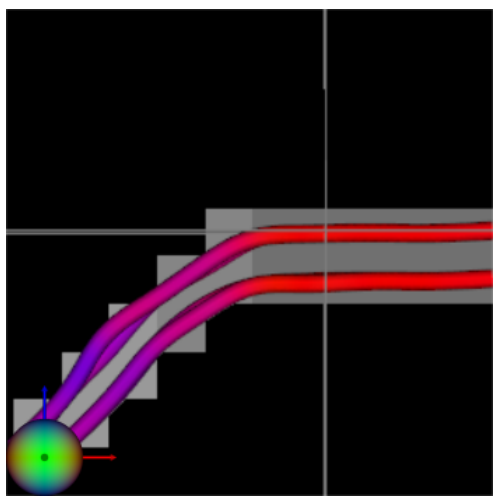

(f)

Figura 4.4: Fibras obtidas pelos métodos de tractografia nos dados sintéticos produzidos a partir de uma curva com curvatura acentuada. O resultado tridimensional dessa geração é um volume similar em forma a um cotovelo. Essas fibras são exibidas nos planos xy, na primeira linha, e xz na segunda linha. Cada coluna apresenta os resultados de um método: (a) e (d) propagação de linha; (b) e (e) o método global de polimerização; (c) e (f) o método SAGA. As cores representam a direcionalidade de acordo com a esfera presente no canto esquerdo inferior de cada imagem. A geometria esperada é descrita na figura $3.4 b$ sobre a qual chamam a atenção: no método de propagação de linha o ponto de inflexão da curva não foi reconstruído em todos os casos tendo muitas terminações prematuras, mas é possivel notar estabilidade da reconstrução; o método global baseado no processo de polimerização realizou a reconstrução da região de inflexão, porém com alta instabilidade e também muitas fibras terminando prematuramente; já o método global SAGA foi capaz de reconstruir a região de inflexão sem terminações prematuras e com menor instabilidade que o método baseado em polimerização.

\begin{tabular}{ccccc} 
Método & $\begin{array}{c}\text { Tempo de } \\
\text { execução } \\
\text { (segundos) }\end{array}$ & $\begin{array}{c}\text { Quantidade } \\
\text { de partículas }\end{array}$ & $\begin{array}{c}\text { Quantidade } \\
\text { de fibras }\end{array}$ & $\begin{array}{c}\text { Quantidade } \\
\text { de iterações }\end{array}$ \\
\hline \hline Propagação de linha & 0.2314 & Não se aplica & 84 & Indisponível \\
\hline Polimerização & 326.541 & 368 & 52 & $1.05 \times 10^{5}$ \\
\hline SAGA & 427.084 & 57 & 6 & $4.929 \times 10^{5}$
\end{tabular}

Tabela 4.4: Resultados quantitativos para testes realizados com algoritmos de tractografia no conjunto de dados sintéticos de uma curvatura acentuada. 


\subsection{Dados Cardíacos}

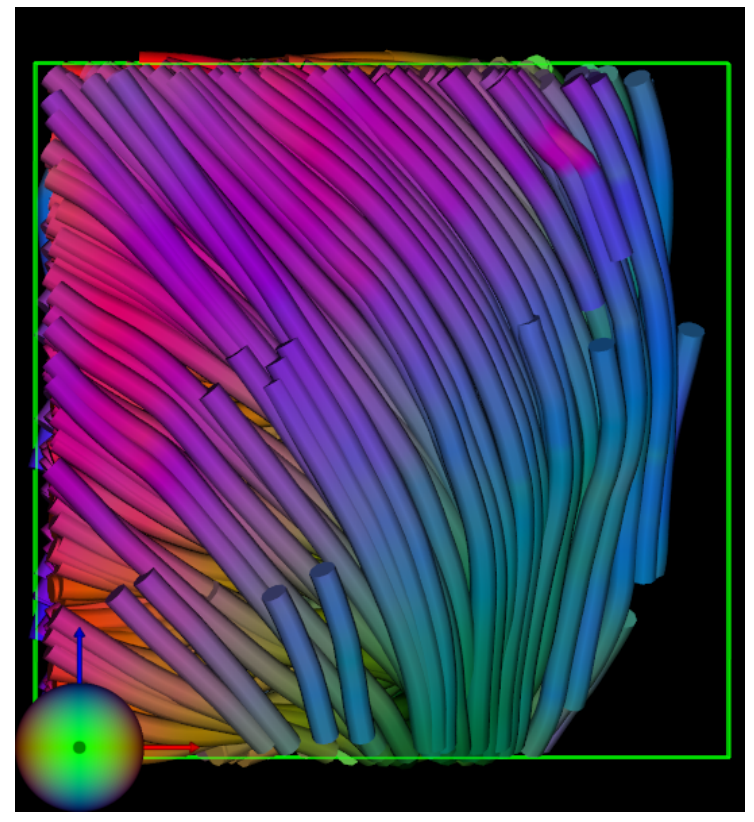

(a)

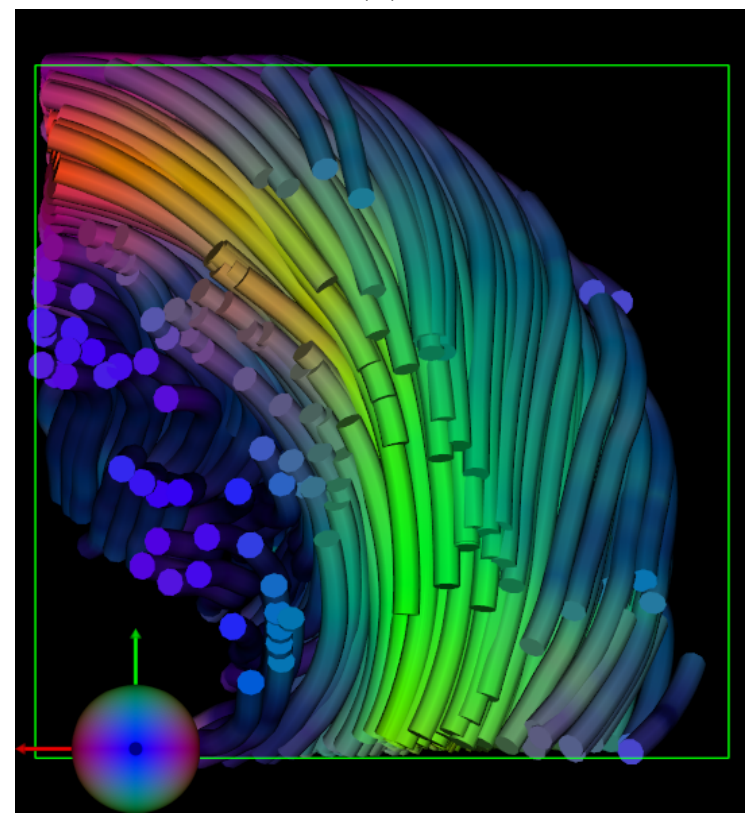

(c)

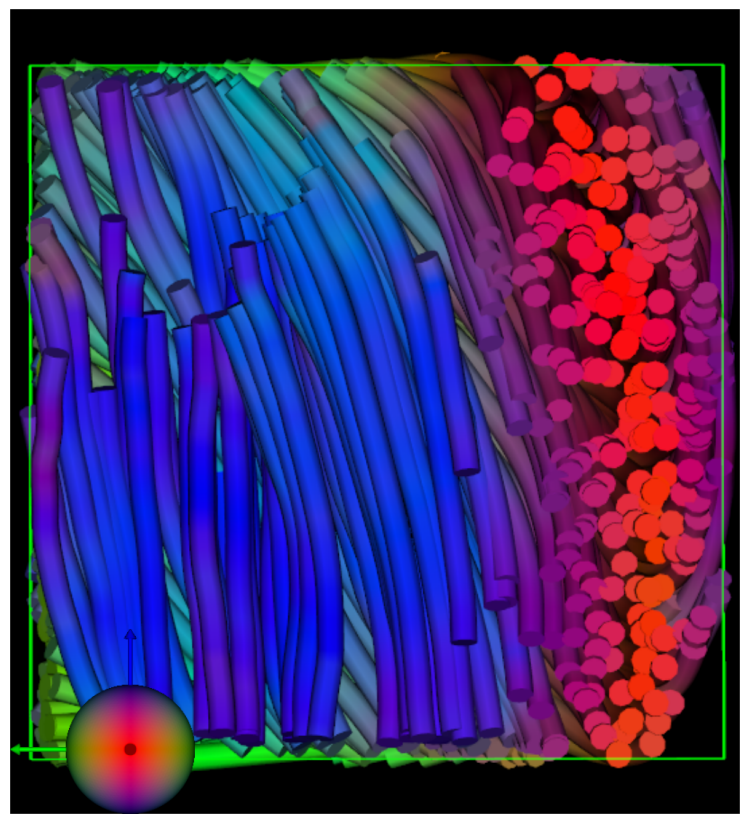

(b)

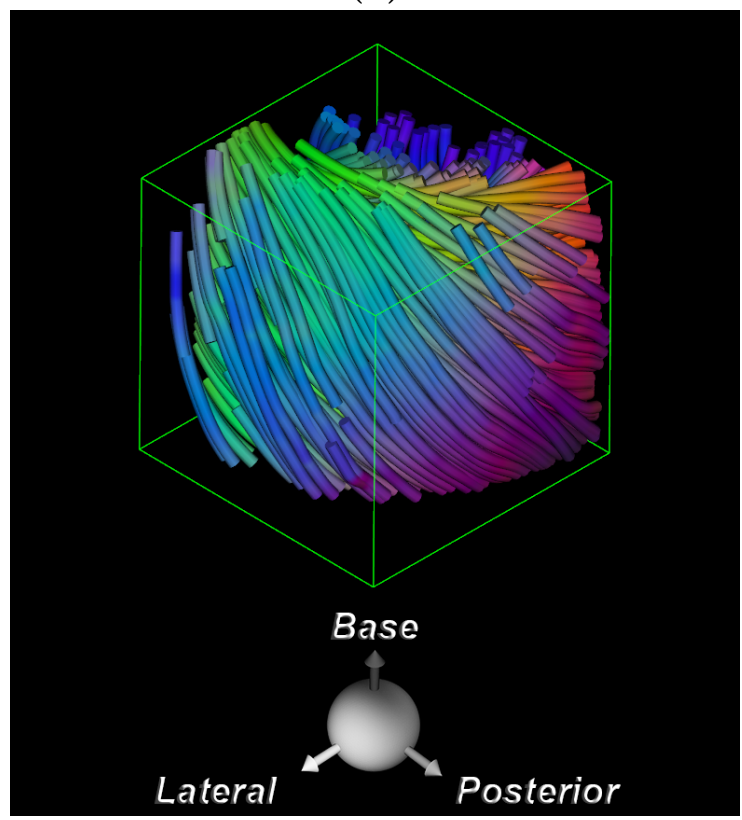

(d)

Figura 4.5: Tractografia por propagação de linha aplicada aos dados do miocárdio humano. Execução limitada à região destacada em 3.6 para a qual são exibidos quatro planos de visualização: (a) coronal; (b) sagital; (c) axial; e (d) uma perspectiva oblíqua. As cores representam a direcionalidade de acordo com a esfera presente no canto esquerdo inferior de cada imagem. Para a região destacada é esperado um contínuo de fibras sem cruzamentos. 


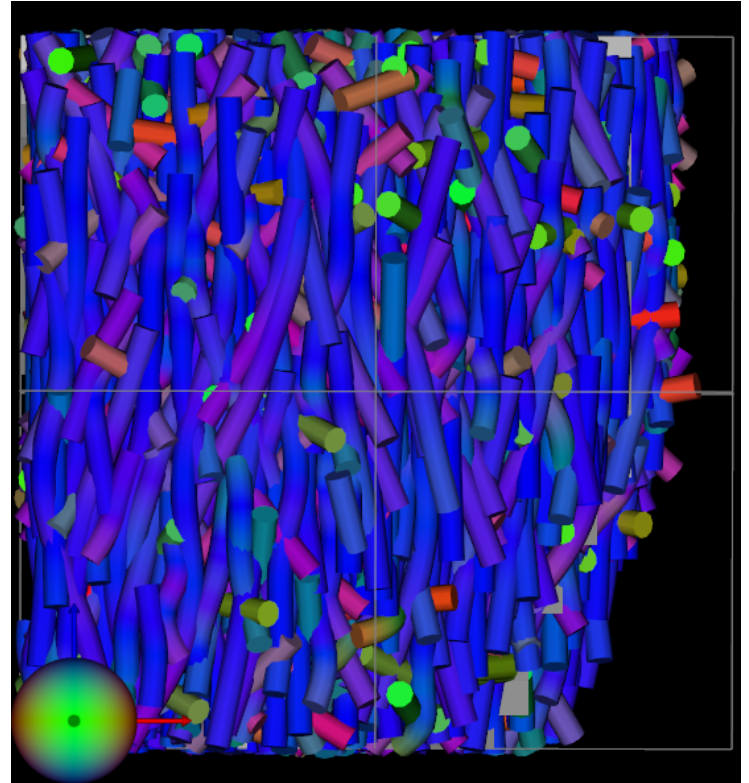

(a)

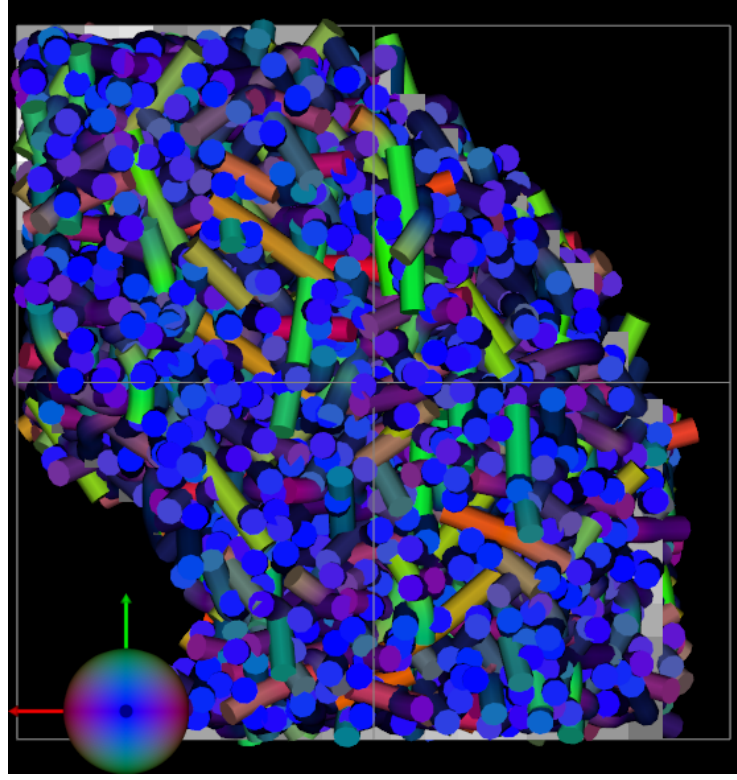

(c)

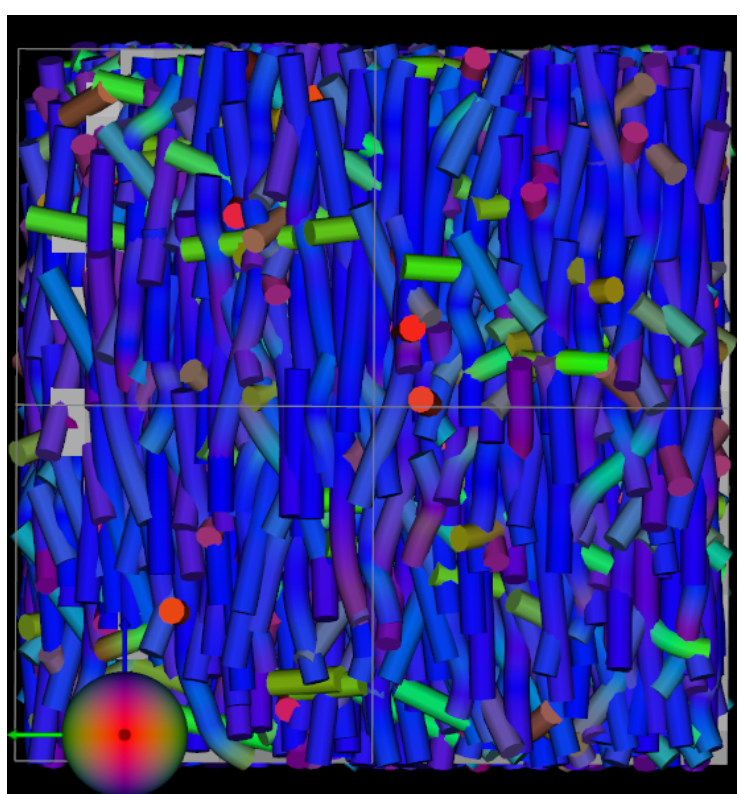

(b)

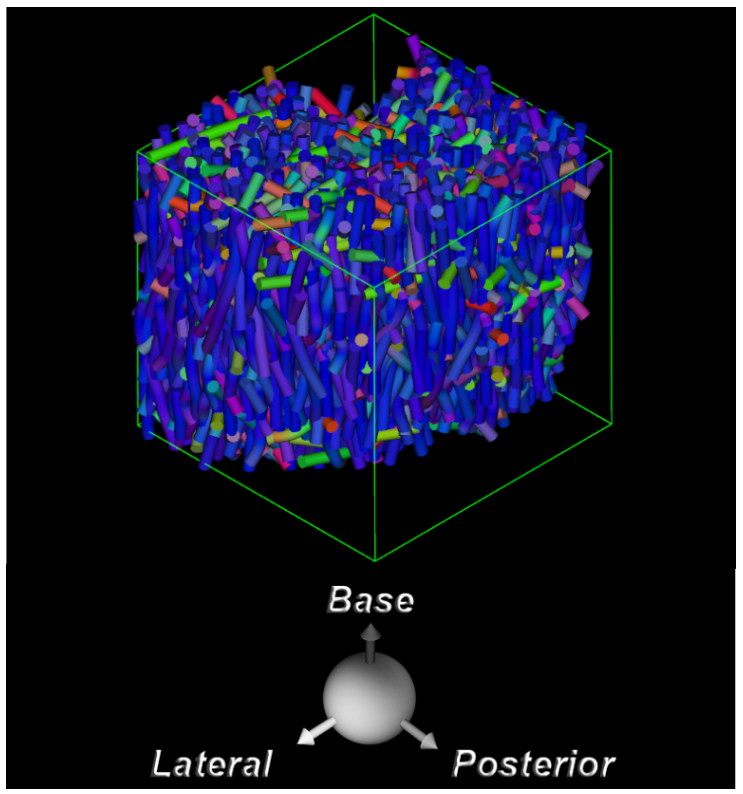

(d)

Figura 4.6: Tractografia global baseada no processo de polimerização aplicada aos dados do miocárdio humano. Execução limitada à região destacada em 3.6 para a qual são exibidos quatro planos de visualização: (a) coronal; (b) sagital; (c) axial; e (d) uma perspectiva oblíqua. As cores representam a direcionalidade de acordo com a esfera presente no canto esquerdo inferior de cada imagem. Para a região destacada é esperado um continuo de fibras sem cruzamentos. 


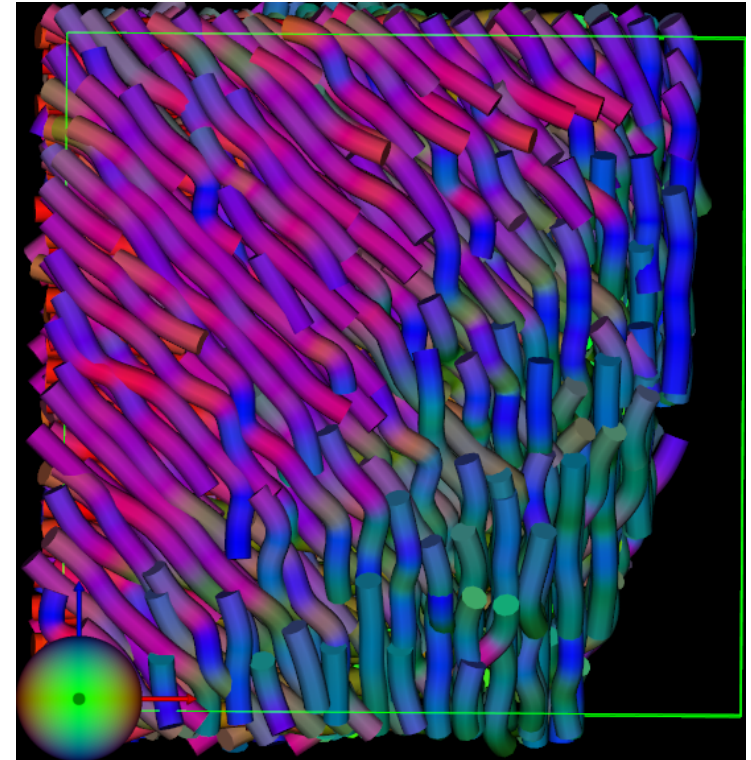

(a)

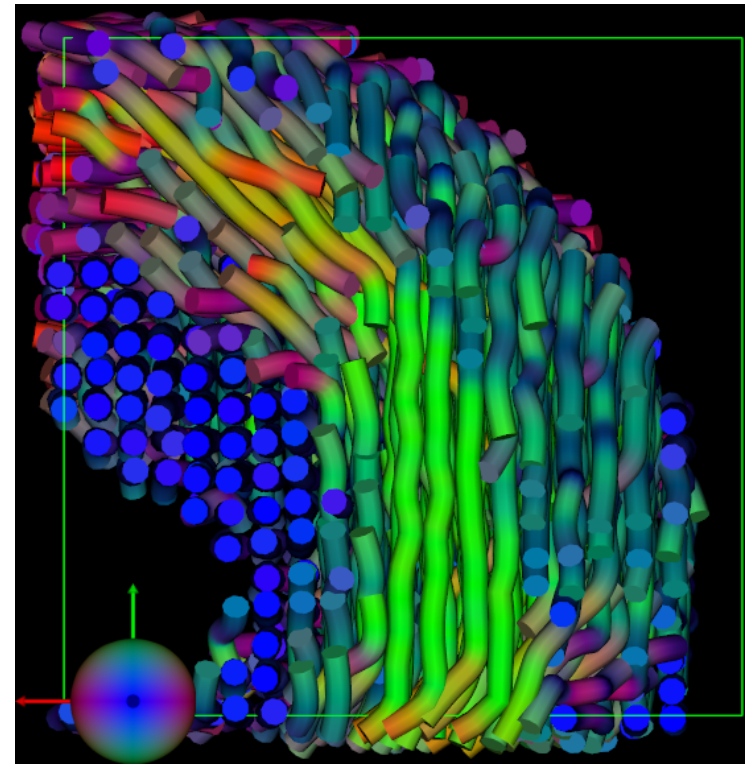

(c)

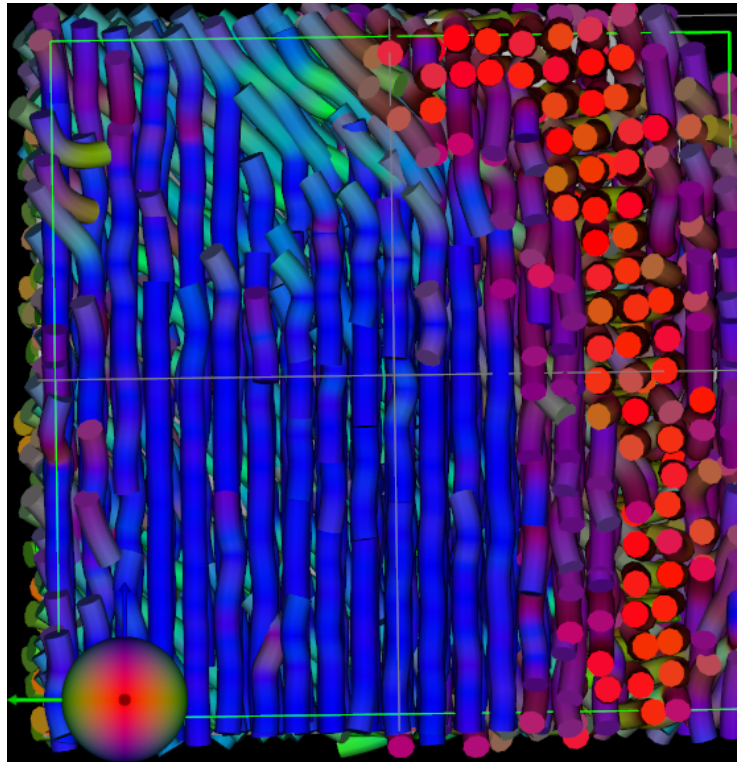

(b)

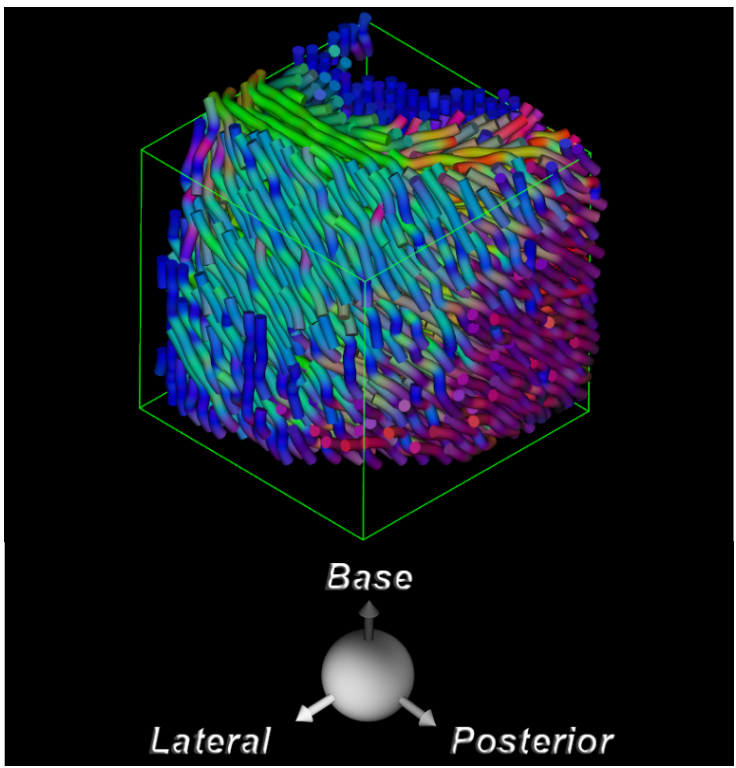

(d)

Figura 4.7: Tractografia global SAGA aplicada aos dados do miocárdio humano. Execução limitada à região destacada em 3.6 para a qual são exibidos quatro planos de visualização: (a) coronal; (b) sagital; (c) axial; $e(d)$ uma perspectiva oblíqua. As cores representam a direcionalidade de acordo com a esfera presente no canto esquerdo inferior de cada imagem. Para a região destacada é esperado um continuo de fibras sem cruzamentos.

\begin{tabular}{ccccc} 
Método & $\begin{array}{c}\text { Tempo de } \\
\text { execução } \\
\text { (segundos) }\end{array}$ & $\begin{array}{c}\text { Quantidade } \\
\text { de partículas }\end{array}$ & $\begin{array}{c}\text { Quantidade } \\
\text { de fibras }\end{array}$ & $\begin{array}{c}\text { Quantidade } \\
\text { de iterações }\end{array}$ \\
\hline \hline Propagação de linha & 2.3 & Não se aplica & 4625 & Indisponível \\
\hline Polimerização & 73887.4 & 17231 & 2394 & $4.8 \times 10^{6}$ \\
\hline SAGA & 39771.9 & 5973 & 2935 & $5.3345 \times 10^{6}$
\end{tabular}

Tabela 4.5: Resultados quantitativos para testes realizados com algoritmos de tractografia no conjunto de dados de uma parcela do coração humano. 


\section{Capítulo 5}

\section{Discussão}

Retomando os objetivos desse trabalho (seção 2.1), que são elaborar uma metodologia global com custo computacional reduzido e avaliar seu comportamento em diferentes conjuntos de dados sintéticos e do miocárdio humano, os resultados apresentados anteriormente no capítulo 4 confirmam que esses foram atingidos. Nas seções seguintes (5.1 e 5.2) são aprofundados os detalhes para cada tipo de dado testado. A única limitação que os testes demonstraram sobre o método de tractografia global SAGA é quanto ao seu tempo de execução que ainda é elevado se comparado ao método de propagação de linha. Por outro lado consome metade do tempo do método global baseado no processo de polimerização.

\subsection{Dados Sintéticos}

O primeiro conjunto de dados sintéticos testado, a reta inclinada em 45 graus, busca simular a situação mais simples que qualquer método de tractografia pode encontrar. Na figura 4.1 é possível observar que os três métodos foram capazes de reconstruir a geometria esperada, porém o método de polimerização apresentou fibras reconstruídas na região entre fatias fora do esperado. Atentando para as métricas coletadas (tabela 4.1), o baixo consumo de tempo do método de propagação de linha é confirmado e o método de tractografia SAGA apresentou resultados menores que o método de polimerização. Tal diferença entre os métodos globais é atribuída à diferença entre a quantidade de partículas necessárias no sistema.

As figuras 4.2 e 4.3 ilustram o comportamento dos métodos em regiões de cruzamento que geram incerteza nos dados. Nelas o método de propagação de linha falhou em reconstruir o cruzamento e os métodos globais obtiveram sucesso na reconstrução. Porém, o método de polimerização apresentou fibras com terminações prematuras que não conectam as extremidades do conjunto de dados. Considerando apenas os métodos bem sucedidos na reconstrução, os dados das tabelas 4.2 e 4.3 mostram que a maior organização do método SAGA se refletiu em quantidades reduzidas de partículas e fibras na simulação que, por sua vez, resultaram em um tempo de execução reduzido pela metade em comparação ao método de polimerização.

O conjunto de dados que simula alta curvatura, na figura 4.4 reforça a afirmação de que o método de polimerização é suscetível a terminar fibras prematuramente. Por outro lado, os métodos de propagação de linha e o global SAGA foram capazes de reconstruir sem problemas a geometria esperada.

\subsection{Dados Cardíacos}

Os dados cardíacos, em comparação aos sintéticos, apresentam maior complexidade para reconstrução por: terem o ruído inerente ao processo de aquisição; utilizarem o modelo de tensor de difusão que possui menos detalhes e informação que as ODFs geradas nos dados sintéticos; e possuírem dimensões maiores que impactam no tempo de execução. Com respeito à geometria das fibras, a região escolhida para os testes possui maior variação das direcionalidades entre voxels. 
Nesses dados é possível observar que a propagação de linha (figura 4.5) reconstruiu curvas suaves similares à anatomia descrita na literatura $\left[\mathrm{MHC}^{+} 12\right]$. Em contraste, o método de polimerização (figura 4.6), apesar de diversas tentativas de modificar seus parâmetros, não produziu resultados próximos ao esperado. Porém, o método SAGA demonstra na figura 4.7 que um método global por simulação de partículas é capaz de reconstruir a anatomia nessa região. Ele apresenta direcionalidades similares com as do método de propagação de linha, mas as curvas produzidas foram menos suaves em razão da modelagem por partículas. Aumentar o nível de interpolação (3.15.2) deve reduzir esse efeito mas ter um impacto negativo no consumo de tempo. A tabela 4.5 confirma os comportamentos observados nos dados sintéticos: a propagação de linha possui alta eficiência; e o método global SAGA é capaz de realizar a reconstrução em aproximadamente metade do tempo que o método de polimerização. 


\section{Capítulo 6}

\section{Conclusões}

Atualmente, devido a uma maior disponibilidade de máquinas de ressonância magnética, as técnicas não invasivas para estudo da arquitetura de tecidos biológicos como a ressonância magnética ponderada por difusão se tornaram mais populares.

Por outro lado, essa modalidade de imagens impõe limites, como a troca entre alta resolução de aquisição e nível de ruído aceitável, que influenciam as diferentes técnicas de tractografia utilizadas nos estudos. Nesta dissertação, foi abordada inicialmente a base necessária para compreensão da tractografia (3) para então revisar diferentes métodos encontrados na literatura (3.1). Dentre os métodos revisados se destacaram os de tractografia por propagação de linha, devido ao alto impacto em publicações, e o método global por simulação de partículas (3.12) em razão de sua robustez à regiões de incerteza sobre as quais o primeiro produz reconstruções incorretas. Porém esses métodos globais introduziram sua própria complexidade e dificuldades, como tempo de processamento elevado e instabilidade entre sucessivas execuções, que motivam novos trabalho nessa área. Baseado nisso foi desenvolvido um método global por simulação de partículas que busca resolver, ou ao menos mitigar, parte dos problemas encontrados (3.15).

A tractografia por propagação de linha utilizando a integração numérica de Runge-Kutta se comportou nos testes como descrito na literatura: tempo de computação baixo, mesmo para dados densos; mas, reconstrução incorreta nas regiões de cruzamento de fibras.

Os métodos globais, apesar de tentarem lidar com essas regiões de incerteza, representam uma ferramenta complementar ao método de propagação de linha. Os métodos globais adicionam suposições que precisam estar claras para quem os aplica, pois não esgotam todas as possibilidades de arquitetura possíveis para regiões de incerteza e há poucos estudos sobre falso positivos. Assim seus impactos na literatura são muito menores se comparados a esse método anterior, tanto em razão de serem mais recentes quanto por seu elevado consumo de recursos computacionais que motivam os objetivos do trabalho (2.1). O método de polimerização chamou a atenção para os métodos de tractografia global com uma abordagem com tempo de execução reduzido, alta densidade do conjunto de fibras reconstruído e sua acurácia em representar regiões de incerteza. Isso proporcionou mais trabalhos relacionados expandindo suas capacidades de forma a levar em conta múltiplos tecidos $\left[\mathrm{CRD}^{+} 15\right]$, geração de atlas para comparação de estudos entre indivíduos [CRD $\left.{ }^{+} 14\right]$ e inclusive a obtenção de propriedades mesoestruturais $\left[\mathrm{RKD}^{+} 14\right]$. Ainda assim, o tempo de execução para reconstruir um cérebro humano persistia em 12 horas para um desktop convencional de 2014, conforme publicado.

Para avaliar tais métodos em perspectiva com o método SAGA um protótipo de software foi elaborado que implementa tanto o método de polimerização quanto as melhorias propostas por este. Esses possibilitaram testes (2.1) com dados sintéticos e reais, que são importantes para demonstrar que a acurácia dos métodos originais de simulação de partículas não foi afetada pelas modificações propostas. Na verdade a estabilidade aumentou, o consumo de tempo foi reduzido e o desempenho em dados cardíacos foi o que chegou mais próximo do método de propagação de linha. Esse protótipo, além de importante para executar os testes mencionados e confirmar as suposições, é importante por fornecer uma implementação livre tanto para o ambos os métodos globais por simulação de 
partículas. Isso possibilita maior facilidade para pesquisas futuras que tentem replicar os resultados.

Nos testes com dados sintéticos foi possível observar que o método de polimerização foi capaz de reconstruir as regiões de cruzamento e alta curvatura como esperado. Por outro lado, o método se mostrou instável ao criar diversas fibras com terminação prematura e um alto índice de partículas sem conexão. Para minimizar isso, durante os testes notou-se que aumentar a quantidade de partículas no sistema (por meio do parâmetro $\lambda$ da equação 3.18) é efetivo para produzir fibras mais longas e produzir a densidade desejada nas regiões de incerteza. Porém o aumento da quantidade de partículas eleva tanto o tempo de execução quanto quantidade de partículas que não formam nenhuma fibra.

Em comparação, o método SAGA também se mostrou capaz de reconstruir os cruzamentos e regiões de alta curvatura dos testes. Porém, alcançou resultados mais estáveis sem terminações prematuras de fibras e poucas partículas desconectadas. Da mesma forma, sua reconstrução do segmento dos dados cardíacos foi a mais próxima dos resultados obtidos pelo método de propagação de linhas. De acordo com os dados expostos nas tabelas de métricas em 4 é possível observar que essa maior estabilidade e organização se refletem em quantidades menores de partículas necessárias para a reconstrução. Essa redução se reflete no tempo de execução que foi reduzido, como era esperado de acordo com as análises de consumo de recursos (3.16) que demonstraram para ambos os métodos a dependência na quantidade de partículas, $|X|$.

Tais resultados para o método SAGA são possíveis devido a sua proposta de reduzir repetições desnecessárias do processo de otimização, por meio da divisão em passos especializados para cada parte da reconstrução. Essa separação permitiu redução da quantidade de partículas necessárias no sistema e introdução de maior organização ao sistema. Por sua vez, esses proporcionaram redução da instabilidade e possibilitaram o armazenamento de passos intermediários para produzir correções que melhoram o resultado final da reconstrução.

\subsection{Perspectivas}

A implementação fornecida juntamente com esse trabalho colocou à prova as modificações propostas, mas também outras tantas que falharam. Tais experimentos requiriram uma generalidade alta para as estruturas de código do protótipo que acabam adicionando complexidade desnecessária. Assim, uma implementação voltada ao estado final do método proposto traria resultados melhores.

Um segundo trabalho futuro seria o de estudar como cada uma das modificações propostas separadamente afetam a acurácia e o tempo de execução do método original. Dessa forma, algumas podem ser julgadas desnecessárias e removidas e outras mais importantes receberem atenção para que sejam melhoradas.

Com o protótipo refinado seria possível extrair mais dados dos testes relevantes para a comparação dos métodos globais como quantidade de partículas por fibra e quantidade de partículas desconectadas. Além desses dois dados é possível avaliar a estabilidade das reconstruções entre sucessivas repetições. Isto é, criar uma métrica de distância entre as fibras resultantes para compará-las e obter uma soma final das suas diferenças. Quando tomadas a média e variância dessas observações é possível obter a métrica de estabilidade mencionada.

Em seguida, outro ponto a ser explorado é o aproveitamento de processamento paralelo na placa gráfica. Os métodos originais de tractografia não o aproveitam pois são inerentemente sequenciais. Por outro lado, o método SAGA apresentado nesse trabalho pode ser paralelizado na etapa de inicialização da grade com partículas (3.15.3). Isso deve reduzir mais seu tempo de execução.

Finalmente com a implementação da tractografia global refinada e os estudos de validação expandidos, é possível empregar esses conceitos como base para estudos mais a fundo sobre as regiões de incerteza. O primeiro passo de tal estudo seria formular um método automatizado para catalogar regiões de incerteza em dMRI por meio do comportamento do método de tractografia. Aplicar tal método à um grande volume de diferentes aquisições de dMRI possibilita o mapeamento de regiões de incerteza comuns entre aquisições. Sobre essas regiões comuns podem ser obtidos perfis médios. Com essa informação, é possível investigar se as atuais suposições empregadas na 
tractografia global são suficientes para cobrir todos os casos e, caso não sejam, formular novas que satisfaçam os requisitos encontrados pelos estudos antecedentes. 


\section{Referências Bibliográficas}

[ABA02] D. C. Alexander, G. J. Barker e S. R. Arridge. Detection and modeling of nongaussian apparent diffusion coefficient profiles in human brain data. Magn Reson Med, 48(2):331-40, 2002. 16

$\left[\mathrm{AHL}^{+} 01\right]$ A. L. Alexander, K. M. Hasan, M. Lazar, J. S. Tsuruda e D. L. Parker. Analysis of partial volume effects in diffusion-tensor mri. Magn Reson Med, 45(5):770-80, 2001. 18

[ALS09] I. Aganj, C. Lenglet e G. Sapiro. Odf reconstruction in q-ball imaging with solid angle consideration. Proc IEEE Int Symp Biomed Imaging, 2009:1398-1401, 2009. 9

[AP08] Y. Assaf e O. Pasternak. Diffusion tensor imaging (dti)-based white matter mapping in brain research: a review. J Mol Neurosci, 34(1):51-61, 2008. 16

$\left[\right.$ BBJ $\left.^{+} 07\right]$ T. E. Behrens, H. J. Berg, S. Jbabdi, M. F. Rushworth e M. W. Woolrich. Probabilistic diffusion tractography with multiple fibre orientations: What can we gain? Neuroimage, 34(1):144-55, 2007. 7

$\left[\mathrm{BMA}^{+} 05\right]$ P. G. Batchelor, M. Moakher, D. Atkinson, F. Calamante e A. Connelly. A rigorous framework for diffusion tensor calculus. Magn Reson Med, 53(1):221-5, 2005. 16

[BML94] P. J. Basser, J. Mattiello e D. LeBihan. Estimation of the effective self-diffusion tensor from the nmr spin echo. J Magn Reson B, 103(3):247-54, 1994. 1, 3

[Bro28] Robert Brown. A Brief Account of Microscopical Observations Made... on the Particles Contained in the Pollen of Plants, and on the General Existence of Active Molecules in Organic and Inorganic Bodies. 1828. 14

[CJ93] F. Crick e E. Jones. Backwardness of human neuroanatomy. Nature, 361(6408):109-10, 1993. 1

$\left[\mathrm{CRD}^{+} 14\right]$ Daan Christiaens, Marco Reisert, Thijs Dhollander, Frederik Maes, Stefan Sunaert e Paul Suetens. Atlas-guided global tractography: imposing a prior on the local track orientation, páginas 115-123. Springer, 2014. 28, 57

$\left[\mathrm{CRD}^{+} 15\right]$ D. Christiaens, M. Reisert, T. Dhollander, S. Sunaert, P. Suetens e F. Maes. Global tractography of multi-shell diffusion-weighted imaging data using a multi-tissue model. Neuroimage, 123:89-101, 2015. 29, 57

[CSR ${ }^{+}$05] J. S. Campbell, K. Siddiqi, V. V. Rymar, A. F. Sadikot e G. B. Pike. Flow-based fiber tracking with diffusion tensor and q-ball data: validation and comparison to principal diffusion direction techniques. Neuroimage, 27(4):725-36, 2005. 7, 19

[DDPLT] Alessandro Daducci, Alessandro Dal Palu, Alia Lemkaddem e Jean-Philippe Thiran. A convex optimization framework for global tractography. Em 2013 IEEE 10th International Symposium on Biomedical Imaging, páginas 524-527. IEEE. 22 
[DDPLT15] A. Daducci, A. Dal Palù, A. Lemkaddem e J. P. Thiran. Commit: Convex optimization modeling for microstructure informed tractography. IEEE Trans Med Imaging, 34(1):246-57, 2015. 7, 22

[Ein05] Albert Einstein. Über die von der molekularkinetischen theorie der wärme geforderte bewegung von in ruhenden flüssigkeiten suspendierten teilchen. Annalen der physik, 4, 1905. 14, 16

$\left[\mathrm{FDG}^{+} 11\right]$ P. Fillard, M. Descoteaux, A. Goh, S. Gouttard, B. Jeurissen, J. Malcolm, A. RamirezManzanares, M. Reisert, K. Sakaie, F. Tensaouti, T. Yo, J. F. Mangin e C. Poupon. Quantitative evaluation of 10 tractography algorithms on a realistic diffusion mr phantom. Neuroimage, 56(1):220-34, 2011. 4, 7, 21

[FPM09] P. Fillard, C. Poupon e J. F. Mangin. A novel global tractography algorithm based on an adaptive spin glass model. Med Image Comput Comput Assist Interv, $12(\mathrm{Pt}$ 1):927-34, 2009. 7, 8, 25, 26

[FSS ${ }^{+}$97] Rosemary Fama, Edith V Sullivan, Paula K Shear, Laura Marsh, Jerome A Yesavage, Jared R Tinklenberg, Kelvin O Lim e Adolf Pfefferbaum. Selective cortical and hippocampal volume correlates of mattis dementia rating scale in alzheimer disease. Archives of Neurology, 54(6):719-728, 1997. 1

$\left[\mathrm{GBC}^{+} 12\right]$ Eleftherios Garyfallidis, Matthew Brett, Marta Morgado Correia, Guy B. Williams e Ian Nimmo-Smith. Quickbundles, a method for tractography simplification. Frontiers in Neuroscience, 6, 2012. 22

[GG84] S. Geman e D. Geman. Stochastic relaxation, gibbs distributions, and the bayesian restoration of images. IEEE Trans Pattern Anal Mach Intell, 6(6):721-41, 1984. 25

$\left[\mathrm{GMM}^{+} 01\right]$ K. M. Gauvain, R. C. McKinstry, P. Mukherjee, A. Perry, J. J. Neil, B. A. Kaufman e R. J. Hayashi. Evaluating pediatric brain tumor cellularity with diffusion-tensor imaging. AJR Am J Roentgenol, 177(2):449-54, 2001. 1

[Goh09] Alvina Goh. Deterministic tractography using orientation distribution functions estimated with probability density constraints and spatial regularity. Em MICCAI workshop on Diffusion Modelling and the Fiber Cup (DMFC'09), London, United Kingdom, 2009. 7

[Gre95] Peter J Green. Reversible jump markov chain monte carlo computation and bayesian model determination. Biometrika, 82(4):711-732, 1995. 24, 29

[GSG09] Sylvain Gouttard, Anuja Sharma e Guido Gerig. Fiber challenge-sci utah solution. Em MICCAI workshop on Diffusion Modelling and the Fiber Cup (DMFC'09), London, United Kingdom, 2009. 7

[Hal10] John E Hall. Guyton and Hall Textbook of Medical Physiology: Enhanced E-book. Elsevier Health Sciences, 2010. 14

[Has70] W Keith Hastings. Monte carlo sampling methods using markov chains and their applications. Biometrika, 57(1):97-109, 1970. 24

[JBB09] Heidi Johansen-Berg e Timothy EJ Behrens. Diffusion MRI: From quantitative measurement to in-vivo neuroanatomy. Academic Press, 2009. 8, 15, 16, 17, 19, 20

[JKQ $\left.{ }^{+} 05\right]$ M. Jackowski, C. Y. Kao, M. Qiu, R. T. Constable e L. H. Staib. White matter tractography by anisotropic wavefront evolution and diffusion tensor imaging. Med Image Anal, 9(5):427-40, 2005. 3, 7, 16, 22 
[JLTS09] Ben Jeurissen, Alexander Leemans, Jacques-Donald Tournier e Jan Sijbers. Fiber tracking on the 'fiber cup phantom' using constrained spherical deconvolution. Em Medical Image Computing and Computer-Assisted Intervention (MICCAI) Workshop on Diffusion Modelling and the Fiber Cup (DMFC'09), páginas 232-235, 2009. 7

$\left[\mathrm{KAB}^{+} 00\right]$ C. Köbbert, R. Apps, I. Bechmann, J. L. Lanciego, J. Mey e S. Thanos. Current concepts in neuroanatomical tracing. Prog Neurobiol, 62(4):327-51, 2000. 1

[KHI] B Kreher, J Hennig e KA Il'yasov. Dti \& fibertools: A complete toolbox for dti calculation, fiber tracking, and combined evaluation. Em Proceeding of ISMRM 14th International Scientific Meeting, volume 2006. 13

[Kir84] Scott Kirkpatrick. Optimization by simulated annealing: Quantitative studies. Journal of statistical physics, 34(5-6):975-986, 1984. 25

[KMK08] B. W. Kreher, I. Mader e V. G. Kiselev. Gibbs tracking: a novel approach for the reconstruction of neuronal pathways. Magn Reson Med, 60(4):953-63, 2008. 7, 26

[LBC ${ }^{+}$97] Mark F Lythgoe, Albert L Busza, Fernando Calamante, Christopher H Sotak, Martin D King, Anna C Bingham, Stephen R Williams e David G Gadian. Effects of diffusion anisotropy on lesion delineation in a rat model of cerebral ischemia. Magnetic resonance in medicine, 38(4):662-668, 1997. 16

$\left[\operatorname{LSDP}^{+}{ }^{14}\right]$ A. Lemkaddem, D. Skiöldebrand, A. Dal Palú, J. P. Thiran e A. Daducci. Global tractography with embedded anatomical priors for quantitative connectivity analysis. Front Neurol, 5:232, 2014. 22

$\left[\mathrm{MHC}^{+}{ }^{12}\right]$ C. Mekkaoui, S. Huang, H. H. Chen, G. Dai, T. G. Reese, W. J. Kostis, A. Thiagalingam, P. Maurovich-Horvat, J. N. Ruskin, U. Hoffmann, M. P. Jackowski e D. E. Sosnovik. Fiber architecture in remodeled myocardium revealed with a quantitative diffusion cmr tractography framework and histological validation. J Cardiovasc Magn Reson, 14:70, 2012. 4, 11, 16, 56

[MHD $\left.{ }^{+} 11\right]$ C Mekkaoui, S Huang, G Dai, TG Reese, MP Jackowski e D Sosnovik. In vivo characterization of myocardial microstructure in normal and infarcted hearts using the supertoroidal model. Em Proc. 19th ISMRM Conf.(Montreal,), página 281, 2011. 1, 16,17

[MJS $\left.{ }^{+} 15\right]$ Choukri Mekkaoui, MarcelP Jackowski, ChristianT Stoeck, WilliamJ Kostis, Fabricio Pereira, Sebastian Kozerke e DavidE Sosnovik. Infarct delineation in patients with acute myocardial infarction using the tractographic propagation angle and late gadolinium enhancement. Journal of Cardiovascular Magnetic Resonance, 17(1):1-2, 2015. $1,3,11,16$

$\left[\mathrm{MPC}^{+} 02\right]$ J. F. Mangin, C. Poupon, Y. Cointepas, D. Rivière, D. Papadopoulos-Orfanos, C. A. Clark, J. Régis e D. Le Bihan. A framework based on spin glass models for the inference of anatomical connectivity from diffusion-weighted $\mathrm{mr}$ data - a technical review. NMR Biomed, 15(7-8):481-92, 2002. 4, 25, 26

[MRR $\left.{ }^{+} 53\right]$ Nicholas Metropolis, Arianna W Rosenbluth, Marshall N Rosenbluth, Augusta H Teller e Edward Teller. Equation of state calculations by fast computing machines. The journal of chemical physics, 21(6):1087-1092, 1953. 24

[MSR09] James G Malcolm, Martha E Shenton e Yogesh Rathi. Filtered tractography: Validation on a physical phantom. Em MICCAI workshop on Diffusion Modelling and the Fiber Cup (DMFC'09), London, United Kingdom, 2009. 7 
[NSR $\left.{ }^{+} 12\right]$ Peter F Neher, Bram Stieltjes, Marco Reisert, Ignaz Reicht, Hans-Peter Meinzer e Klaus H Fritzsche. Mitk global tractography. Em SPIE medical imaging, páginas 83144D-83144D-6. International Society for Optics and Photonics, 2012. 32, 44

[OCAP06] Connexions Web site OpenStax College Anatomy \& Physiology. Heart musculature. http://cnx.org/content/col11496/1.6/, 2006. [Online; acessado em 19 de Junho de 2013; licença CC BY 3.0 via Wikimedia Commons]. 11

$\left[\mathrm{OYS}^{+}\right.$07] H. Oouchi, K. Yamada, K. Sakai, O. Kizu, T. Kubota, H. Ito e T. Nishimura. Diffusion anisotropy measurement of brain white matter is affected by voxel size: underestimation occurs in areas with crossing fibers. AJNR Am J Neuroradiol, 28(6):1102-6, 2007. 16

[PA03] G. J. Parker e D. C. Alexander. Probabilistic monte carlo based mapping of cerebral connections utilising whole-brain crossing fibre information. Inf Process Med Imaging, 18:684-95, 2003. 7

[PJR ${ }^{+}$05] Xenophon Papademetris, Marcel Jackowski, Nallakkandi Rajeevan, R Todd Constable e LH Staib. Bioimage suite: An integrated medical image analysis suite. The Insight Journal, 1:3, 2005. 13, 21

$\left[\mathrm{PPR}^{+} 05\right]$ M. Perrin, C. Poupon, B. Rieul, P. Leroux, A. Constantinesco, J. F. Mangin e D. Lebihan. Validation of q-ball imaging with a diffusion fibre-crossing phantom on a clinical scanner. Philos Trans R Soc Lond B Biol Sci, 360(1457):881-91, 2005. 19

[PR11] Julien Pontabry e François Rousseau. Probabilistic tractography using q-ball modeling and particle filtering. Em International Conference on Medical Image Computing and Computer-Assisted Intervention, páginas 209-216. Springer, 2011. 7

[PTVF96] William H Press, Saul A Teukolsky, William T Vetterling e Brian P Flannery. Numerical recipes in $C$, volume 2. Cambridge university press Cambridge, 1996. 23, 37, 40

$\left[\mathrm{RKD}^{+}{ }^{14}\right]$ M. Reisert, V. G. Kiselev, B. Dihtal, E. Kellner e D. S. Novikov. Mesoft: unifying diffusion modelling and fiber tracking. Med Image Comput Comput Assist Interv, 17(Pt 3):201-8, 2014. 30, 57

$\left[\mathrm{RMA}^{+} 11\right]$ M. Reisert, I. Mader, C. Anastasopoulos, M. Weigel, S. Schnell e V. Kiselev. Global fiber reconstruction becomes practical. Neuroimage, 54(2):955-62, 2011. 4, 8, 22, 24, $26,27,32$

[RMK09a] Marco Reisert, Irina Mader e Valerij Kiselev. Global reconstruction of neuronal fibres. Em MICCAI workshop on Diffusion Modelling and the Fiber Cup (DMFC'09), London, United Kingdom, 2009. 7, 8, 13, 26, 27, 41

[RMK09b] Marco Reisert, Irina Mader e Valerij Kiselev. Tracking a physical phantom by global fibre reconstruction. 2009. 21, 26, 27

[RMRG09] Alonso Ramirez-Manzanares, Mariano Rivera e James C Gee. Depicting axon fibers on a diffusion phantom by means of hybrid dbf-dt data. Em MICCAI workshop on Diffusion Modelling and the Fiber Cup (DMFC'09), London, United Kingdom, 2009. 7

[RZA13] MC Rowe, H Zhang e DC Alexander. Nd-track: Tractography utilising parametric models of white matter fibre orientation dispersion. 2013. 7 
[Sak09] K Sakaie. Fast persistent angular structure based streamline tractography. Em MICCAI workshop on Diffusion Modelling and the Fiber Cup (DMFC'09), London, United Kingdom, 2009. 7

[SCBP13] A. Stamm, O. Commowick, C. Barillot e P. Pérez. Adaptive multi-modal particle filtering for probabilistic white matter tractography. Inf Process Med Imaging, 23:594606, 2013. 7

$\left[\mathrm{SKF}^{+} 14\right]$ M. Schober, N. Kasenburg, A. Feragen, P. Hennig e S. Hauberg. Probabilistic shortest path tractography in dti using gaussian process ode solvers. Med Image Comput Comput Assist Interv, 17(Pt 3):265-72, 2014. 7

[SRA10] A. J. Sherbondy, M. C. Rowe e D. C. Alexander. Microtrack: an algorithm for concurrent projectome and microstructure estimation. Med Image Comput Comput Assist Interv, 13(Pt 1):183-90, 2010. 7, 28

[Sue09] Paul Suetens. Fundamentals of medical imaging. Cambridge University Press, 2009. 14

[TLB09] Fatima Tensaouti, Jean Albert Lotterie e Isabelle Berry. Fiber tracking on the phantom dataset by using sisyphe software. Em MICCAI workshop on Diffusion Modelling and the Fiber Cup (DMFC'09), London, United Kingdom, 2009. 7

[Tuc04] David S. Tuch. Q-ball imaging, 01 2004. Q-ball imaging. 7, 19

[WLW00] M. R. Wiegell, H. B. Larsson e V. J. Wedeen. Fiber crossing in human brain depicted with diffusion tensor mr imaging. Radiology, 217(3):897-903, 2000. 18

[YAK09] Ting-Shou Yo, Alfred Anwander e TR Knosche. Fiber cup 2009: Reconstructing fibers from the phantom data. Em MICCAI workshop on Diffusion Modelling and the Fiber Cup (DMFC'09), London, United Kingdom, 2009. 7

[ZSWKA12] Hui Zhang, Torben Schneider, Claudia A. Wheeler-Kingshott e Daniel C. Alexander. Noddi: Practical in vivo neurite orientation dispersion and density imaging of the human brain. NeuroImage, 61(4):1000-1016, 2012. 8 